\title{
A FINITE ELEMENT ANALYSIS OF TIBIAL STEM GEOMETRY FOR TOTAL KNEE REPLACEMENTS
}

\author{
A Thesis \\ presented to \\ the Faculty of California Polytechnic State University, \\ San Luis Obispo
}

\author{
In Partial Fulfillment \\ of the Requirements for the Degree \\ Master of Science in Mechanical Engineering
}

by

Aaron Isidro Bautista

June 2015 
(C) 2015

Aaron Isidro Bautista

ALL RIGHTS RESERVED 


\section{COMMITTEE MEMBERSHIP}

TITLE:

AUTHOR:

DATE SUBMITTED:

COMMITTEE CHAIR:

COMMITTEE MEMBER:

COMMITTEE MEMBER:
A Finite Element Analysis of Tibial Stem Geometry for Total Knee Replacements

Aaron Isidro Bautista

June, 2015

Mohammad Noori, Ph.D.

Professor of Mechanical Engineering

Peter Schuster, Ph.D.

Professor of Mechanical Engineering

Scott Hazelwood, Ph.D.

Professor of Biomedical Engineering 


\begin{abstract}
A Finite Element Analysis of Tibial Stem Geometry for Total Knee Replacements Aaron Isidro Bautista
\end{abstract}

The purpose of this study was to investigate the influence of tibial stem geometry on stress shielding of the tibia for patients with a total knee replacement. Finite element analysis was used to study different tibial stem geometry types, as well as a vast array of different geometric sizes. Both a peg and stem type geometry were analyzed and compared in order to determine what type geometry causes the least amount of stress shielding. A static loading condition with a dynamic loading factor of three was used for the system and the stress responses were analyzed at regions of interest at various depths. Regions of interest include the posterior and medial regions, at depths ranging from the resurfaced tibial surface to 100 $\mathrm{mm}$ below the surface. It was found that the smallest stem/peg sizes produced the least amount of stress shielding, indicating that the less amount of foreign material within the tibia, the more natural the bending and stress response of the tibia. It was also concluded that for the loading conditions used in this study, peg type geometry yields a decreased amount of stress shielding when compared to stem type geometry. This is due to the fact that the peg type geometry allowed for more natural bending and a distributed loading transfer between two pegs rather than one long central stem. Further studies should be completed on other geometry types in order to understand how to best replicate the natural bending of the tibia.

FEA, finite, element, analysis, tibia, bone, stress, shielding, biomedical, biomechanical, mechanical, Abaqus 


\section{ACKNOWLEDGMENTS}

I would like to thank Dr. Mohammad Noori for his guidance throughout this study. The scope of this study was quite significant initially, Dr. Noori was instrumental in helping define the critical aspects which required study. I would also like to thank Dr. Scott

Hazelwood, for the frequent help with the solution process, as well as overall assistance with FEA simulation using Abaqus. In addition, I would like to thank Dr. Peter Schuster for his advice regarding model simplification, helping outline simulation assumptions, as well as general advice regarding FEA simulation using Abaqus. 


\section{TABLE OF CONTENTS}

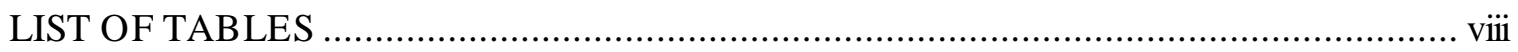

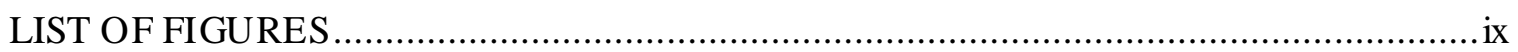

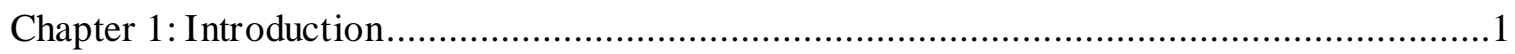

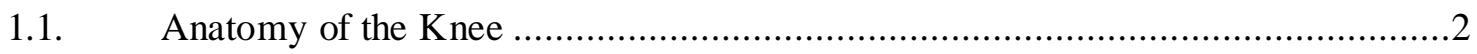

1.1.1. Knee Functionality - Range of Motion ..............................................

1.2. Causes for Total Knee Replace ment Surgery .................................................4

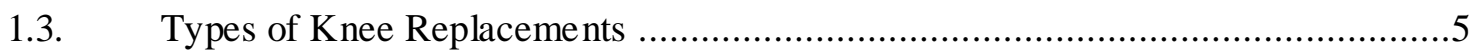

1.3.1. Fixed and Mobile Bearing Total Knee Replacements (TKR) ........................5

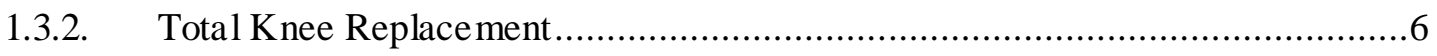

1.3.3. Partial Knee Replacement (Unic ompartmental) .....................................6

1.4. The Process of the Total Knee Replacement Surgery ......................................

1.5. Objective and the Employed Methodology .............................................

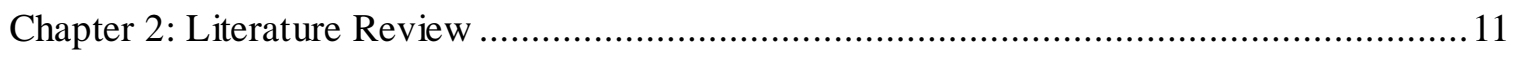

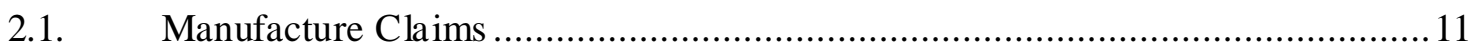

2.1.1. DePuy Synthes - Sigma Total Knee (Stem Type Geometry) ........................ 11

2.1.2. Zimmer - Trabecular Metal Persona Knee (Peg Type Ge ometry) ................... 12

2.2. Available Research Findings and Conclusions ............................................ 13

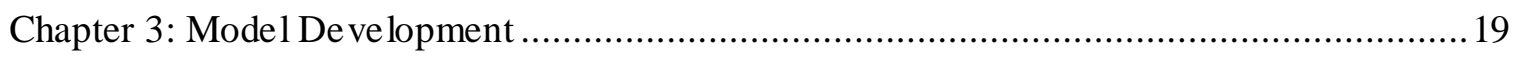

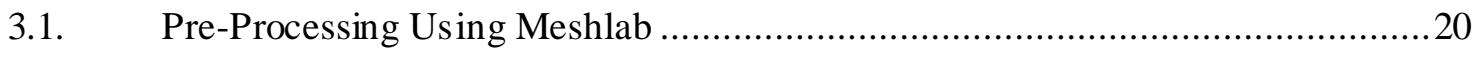

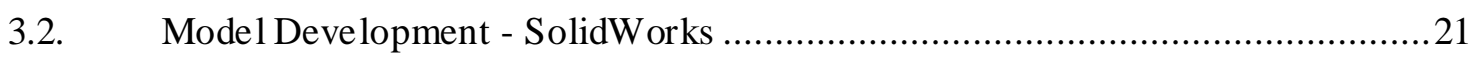

3.2.1. DePuy Synthes Sigma Total Knee (Stem Type Geometry) ..........................23

3.2.2. Zimmer - Persona Knee (Peg Type Geometry) .........................................24

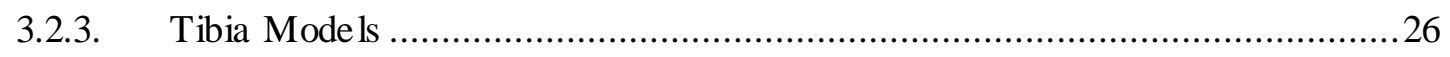

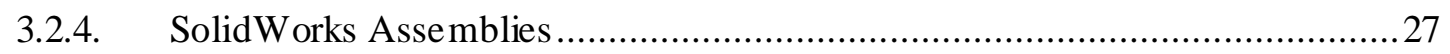

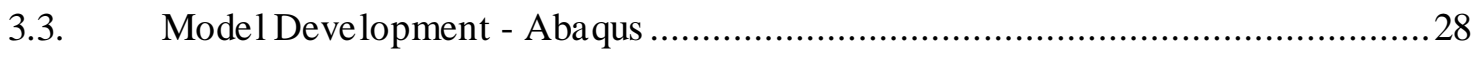




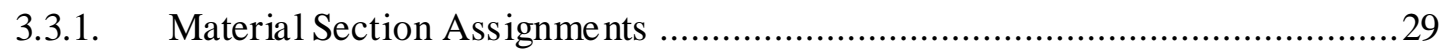

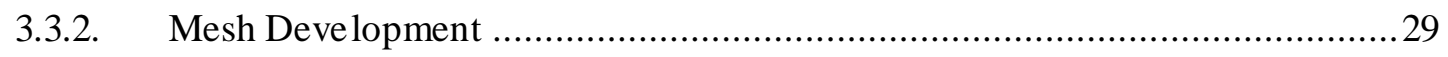

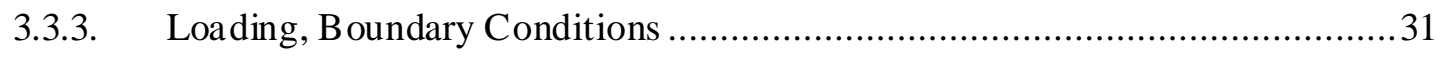

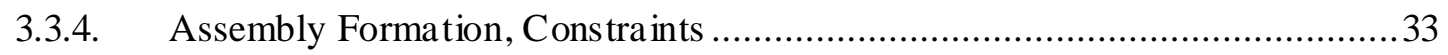

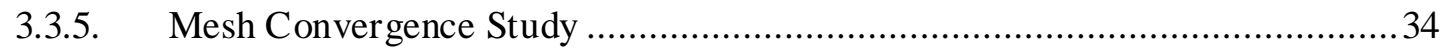

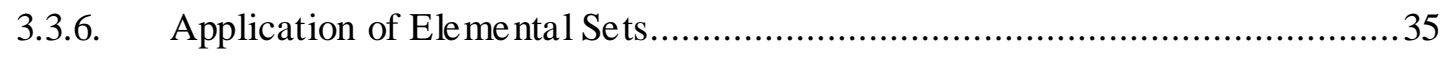

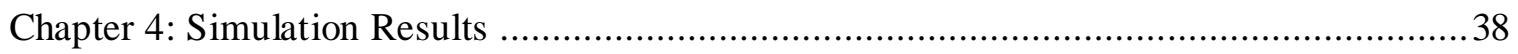

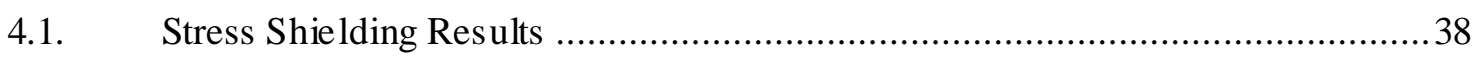

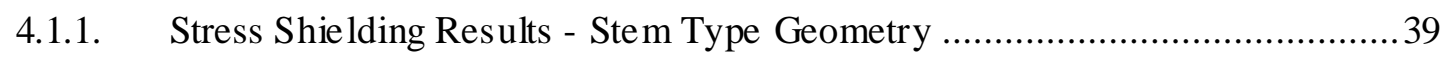

4.1.2. Stress Shielding Results - Peg Type Geometry ....................................... 45

4.2. Trends in Stress Shielding Experienced By the Tibia for All TKR Stem

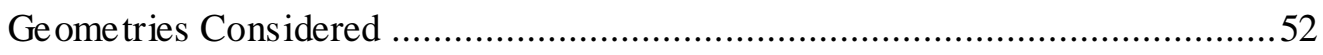

4.2.1. Additional Background Information for Data Interpretation .......................52

4.2.2. Important Trends observed in the Medial Region .....................................55

4.2.3. Noticed Trends for the Posterior Region ............................................... 57

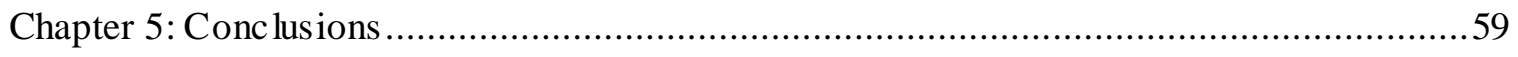

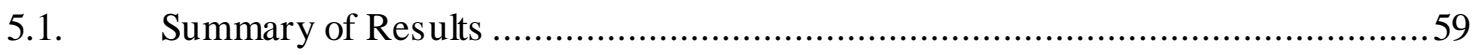

5.2. Future Work and Recommendations .....................................................61

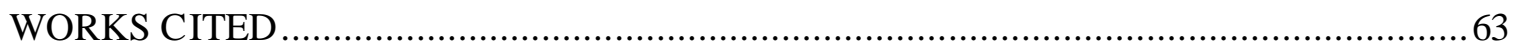

Appendix A: Additional Plots for Diameter/Width Comparis on ....................................67 


\section{LIST OF TABLES}

Table 1 - Summary of geometric types and sizes studied using finite ele ment analysis........22

Table 2 - Material properties applied to all components modeled within Abaqus.

Table 3 - Assembly figures for the total number of elements, nodes, and degrees of freedom of the system. In addition, the percent of the total number of elements which are distorted are shown below. Note that all percentages are less than $1 \%$ of the elements.

Table 4 - Stress shielding results for $12 \mathrm{~mm}$ stem type geometry for the medial and posterior region. Note that a negative stress shielding percentage indicates stress shielding.

Table 5 - Stress Shielding Results for $15 \mathrm{~mm}$ stem type geometry for the medial and posterior region. Note that a negative stress shielding percentage indicates stress shielding.

Table 6 - Stress shielding results for $12 \mathrm{~mm}$ peg type geometry for the medial and posterior region. Note that a negative stress shielding percentage indicates stress shie lding.

Table 7 - Stress Shielding Results for $16 \mathrm{~mm}$ peg type geometry for the medial and posterior region. Note that a negative stress shielding percentage indicates stress shielding. 


\section{LIST OF FIGURES}

Figure 1 - Definition of regions of the body and planes considered throughout this study [5]. .2

Figure 2 - Basic outline of the anatomy of the human knee [6]. 3

Figure 3 - Motion of the human knee joint during flexion/extension [5]. 4

Figure 4 - Fixed bearing a TKR model with outlined components [5].

Figure 5 - Comparison between total and partial knee replacement. Note that the partial knee replacement has much of the femoral condyle still intact, as well as portions of cartilage still intact [8].

Figure 6 - DePuy Synthes: Sigma Total Knee [11] ......................................................... 10

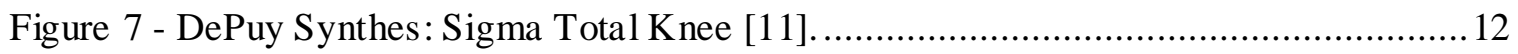

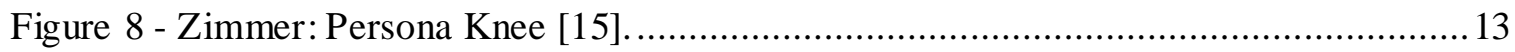

Figure 9 - Plot displaying stress as a percentage of which occurs in the intact tibia at measured depths from the resurfaced tibial surface. In this plot, a negative stress percentage is indicative of stress shielding [23].

Figure 10 - The significance of cementing technique and how cementing technique affects stress shielding of the tibia. Note that there is a significant decrease in compression for models A and B, which represent fully cemented models [25]....

Figure 11 - Tibia imported into Meshlab before complexity reduction. This model was unable to be imported into SolidWorks for modification.

Figure 12 - Tibia within Meshlab after complexity reduction. Complexity reduction allowed for SolidWorks importation.

Figure 13 - SolidWorks model of the stem type geometry model, smallest size under consideration.

Figure 14 - Cement model for the smallest stem type geometry model examined. The cement was modeled to be $1 \mathrm{~mm}$ thick. 24

Figure 15 - SolidWorks model of the peg type geometry model, smallest size under consideration in titanium. 
Figure 16 - Cement model used for the smallest peg type geometry model. All

dimensions were set for a $1 \mathrm{~mm}$ cement thickness.

Figure 17 - Intact tibia model derived from CT scanned of an adult.

Figure 18 - A TKR assembly model within Abaqus displaying the elemental disc sections utilized for stress shielding analys is.

Figure 19 - Medial regions used for stress shielding analysis include depths from 0

(top) to $100 \mathrm{~mm}$ (bottom).

Figure 20 - Posterior regions used for stress shielding analysis include depths from 0

(top) to $100 \mathrm{~mm}$ (bottom)

Figure 21 - Stress shielding percentage as a function of tibial depth in the posterior region for a $12 \mathrm{~mm}$ diameter stem type geometry model. Stress shielding is signified by a negative stress shielding percentage. Note the significant increase in stress shielding after the LTR region for the $12 \mathrm{X} 25$ model.

Figure 22 - Stress shielding percentage as a function of tibial depth in the medial region for a $12 \mathrm{~mm}$ diameter stem type geometry model. Stress shielding is signified by a negative stress shielding percentage.

Figure 23 - Stress shielding percentage as a function of tibial depth in the medial region for a $15 \mathrm{~mm}$ diameter stem type geometry model. Stress shielding is signified by a negative stress shielding percentage.

Figure 24 - Stress shielding percentage as a function of tibial depth in the posterior region for all stem type geometry models studied. Note that plots of individual length comparisons can be seen in Appendix A.

Figure 25 - Stress shielding percentage as a function of tibial depth in the medial region for all stem type geometry models studied. Note that plots of individual length comparis ons can be seen in Appendix A.

Figure 26 - Stress shielding percentage as a function of tibial depth in the posterior region for a $12 \mathrm{~mm}$ wide peg type geometry model. Stress shielding is signified by a negative stress shielding percentage.

Figure 27 - Stress shielding percentage as a function of tibial depth in the medial region for a $12 \mathrm{~mm}$ wide peg type geometry model. Stress shielding is signified by a negative stress shielding percentage. 
Figure 28 - Stress shielding percentage as a function of tibial depth in the posterior region for a $16 \mathrm{~mm}$ wide peg type geometry model. Stress shielding is signified by a

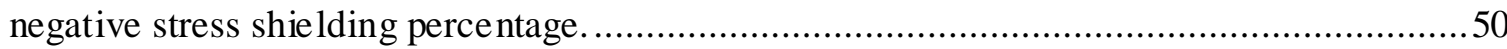

Figure 29 - Stress shielding percentage as a function of tibial depth in the medial region for a $16 \mathrm{~mm}$ wide peg type geometry model. Stress shielding is signified by a

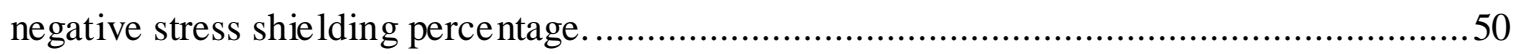




\section{Chapter 1: Introduction}

The need for a perfectly functioning knee replacement is at an all-time high, where $10 \%$ of Americans age 80 and older are currently living with at least one total knee replacement (TKR) [1]. Even more surprisingly, as of 2012, 4.5 million Americans are currently living with at least one total knee replacement; this in turn accounts for roughly $4.7 \%$ of the population age 50 years or older [2]. These staggering numbers indicate the necessity for this type of important procedure, as the knee is heavily influential in the dynamic mobility of the human body. Without a functioning knee, a patient is extremely confined, with hindered movement causing a devastating loss of mobility. In addition, with the average lifespan increasing, the need for treatment which preserves and restores normal body functionality is becoming much more in demand. Approximately $90 \%$ of the total number of total knee replacement surgeries performed has occurred within the last 10 years [3], a clear indication of how this surgical operation has increasingly become a seemingly routine orthopedic procedure to remedy the immobility associated with a malfunctioning knee. Subsequently, the demand for a successful method of restoration of the knee is at an all-time high, which is why total knee replacement surgery is currently so popular. Additionally, the popularity of this surgery is reflected in the statistics; for instance, $95 \%$ of patients report that they are satisfied with their procedure [3]. This procedure is sustainable as well, as the revision rate is fairly low. In another study, it was found that revision rates of $12 \%$ after 10 years are common in the United States [4]. The typical reason for revision after a long time period such as 10 years is due to loosening of the implant and general wear due to dynamic fatigue. This type of surgery also has a very low complication rate. Based on a study of 1.82 million patient records in all age groups, $7.5 \%$ of patients endure complications within 90 days of surgery [4]. These comprehensive statistics indicate the demand, as well as the effectiveness of total knee replacement surgery, which has truly become a growing industry within the medical community. 


\subsection{Anatomy of the Knee}

The knee can be modeled as synovial hinge joint, comprised of the proximal end of the tibia, the patella, and the distal end of the femur. It is important to define what each plane under consideration within this study is, relative to the human body. Planes considered within this study are shown below in Figure 1.

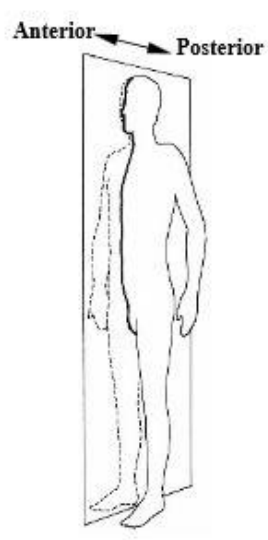

Sagittal plane

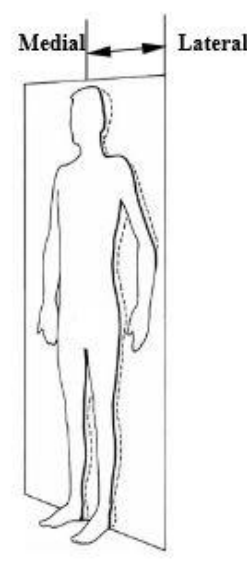

Coronal plane

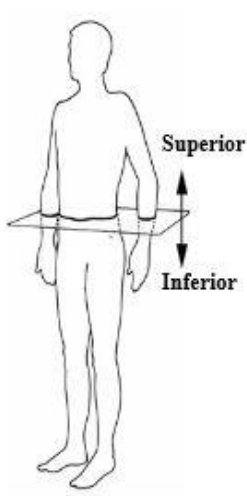

Transverse plane

Figure 1 - Definition of regions of the body and planes considered throughout this study [5].

The patella rests within a groove called the trochlea, which is located at the distal end of the femur. It is within this groove which the patella slides during knee flexion and extension. This articulation between the femur and patella is called femoropatellar articulation. In addition, articulation between the femur and tibia is called the femorotibial articulation. When examining motion with the femur, there are two articular bodies located on the distal end, called the lateral and medial condyles. The lateral condyle is slightly wider in the front than at the back, while the medial condyle has a constant cross sectional area. These dimensions enable a sliding and rolling motion during flexion between the condyles of the femur and the condyles of the tibia. A basic diagram outlining the knee anatomy is shown in Figure 2. 


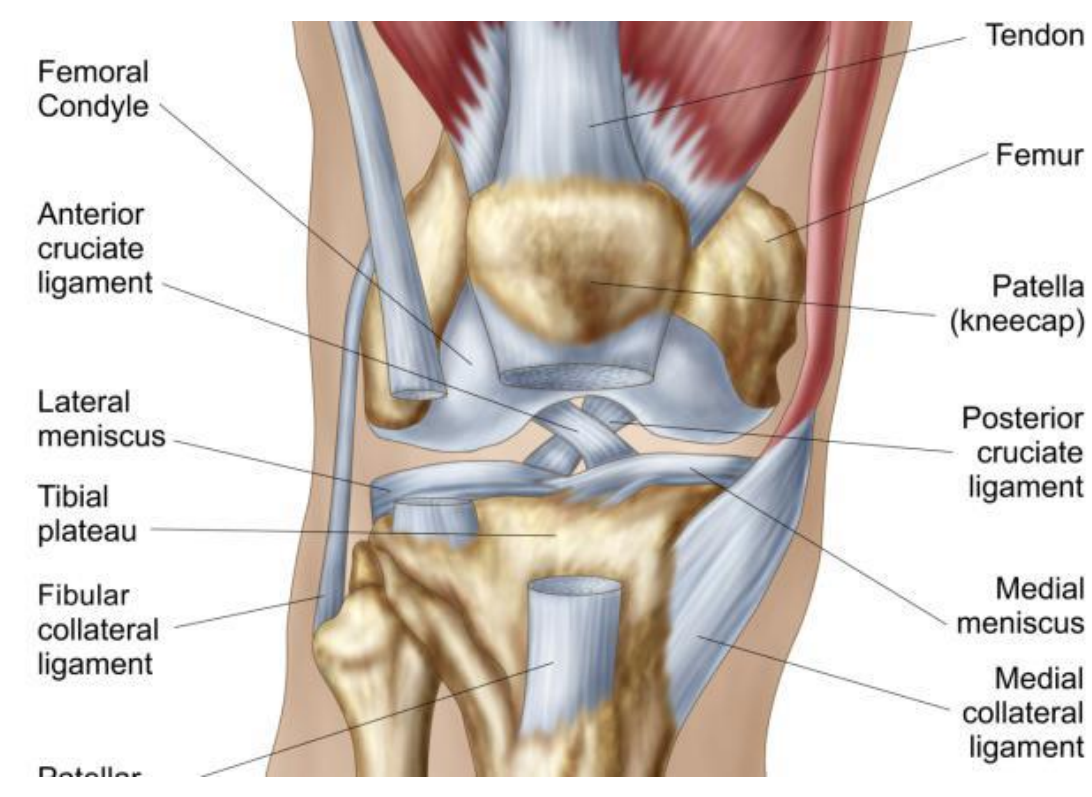

Figure 2 - Basic outline of the anatomy of the human knee [6].

Both fibrocartilage and cartilage can be found within the knee joint. Fibrocartilage refers to the medial and lateral menisci which have high tensile strength and act as shock absorbers for exerted loading. In addition, there is also hyaline cartilage, which is layered over the articulating surfaces, allowing for very low friction contact between the condyles. Hyaline cartilage is critical for joint movement, as this cartilage is what controls the smoothness of articulation during everyday activities. When the knee is in active flexion or extension, the knee does not simply bend. The knee itself will also have a small rotational component which contributes to the motion.

Lastly, there are two tendons, as well as four ligaments, which hold the knee together, ensuring that the knee follows the proper motion during flexion and extension. The two tendons which are directly overlaid over the patella are the quadriceps tendon and patellar tendon, which initiate flexion and extension during contraction. The quadriceps tendon is directly connected to the quadriceps, while the patellar tendon attaches to the proximal end of the tibia. The four ligaments include the posterior cruciate ligament, anterior cruciate ligament, medial collateral ligament, and the lateral collateral ligament; all play a crucial role in stability and limiting movement during flexion and extension. 


\subsubsection{Knee Functionality - Range of Motion}

As previously overviewed, the knee moves using a combination of rolling and sliding, between contact with the tibia and femoral condyle surfaces. As defined by Hoppenfeld in 1976 [7], the normal range of motion for the knee is 0 degrees at extension, to 135 degrees at flexion. In addition, a normal range of 5 to 10 degrees of internal and external rotation (in the superior/inferior plane) is expected for a healthy knee. The importance of this external rotation is to allow full extension, as the knee requires this rotation to be able to achieve a full 0 degrees of extension. This is due to the anatomical geometry of the joint, where the medial femoral condyle is slightly longer than the lateral femoral condyle. These are some of the main design constraints for knee replacements, as they need to be able to mimic this natural range of motion as closely as possible. An example of this range of motion for the natural human knee can be seen below in Figure 3.

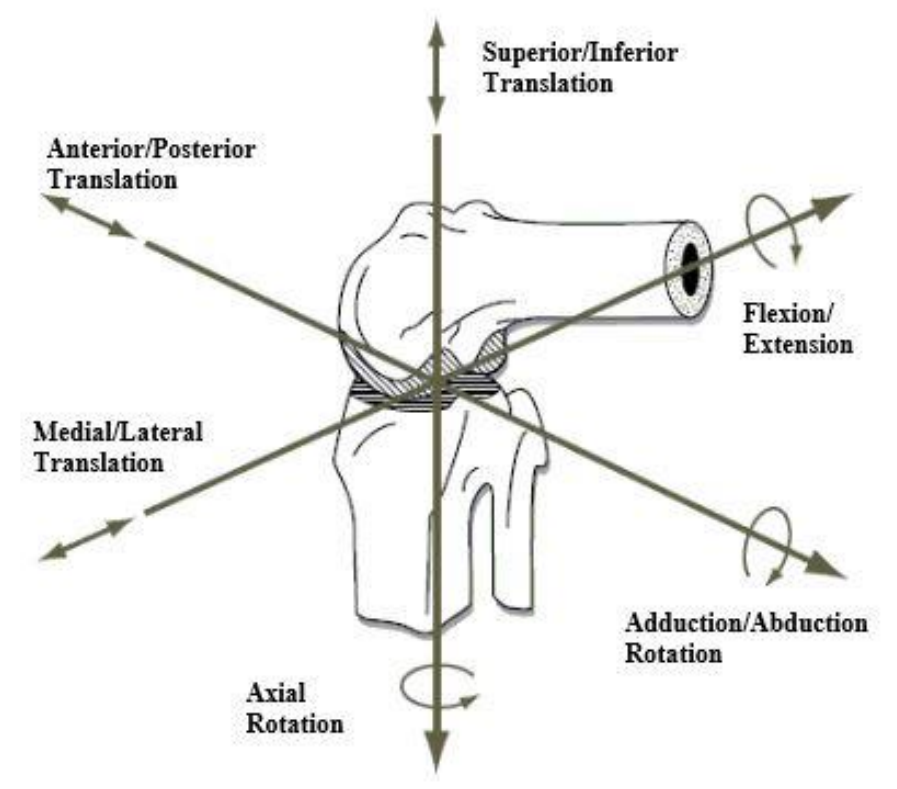

Figure 3 - Motion of the human knee joint during flexion/extension [5].

\subsection{Causes for Total Knee Replacement Surgery}

There are many reasons why a patient will require total knee replacement. The three most common types of arthritis which destroy the knee joint and surrounding bone includes 
osteoarthritis, rheumatoid arthritis, and post-traumatic arthritis. Arthritis is an extremely painful disease of the knee, causing the patient to have large amounts of pain due to normal everyday movement. Because of this loss of movement, an individual suffering from arthritis within the knee is confined to uncomfortable and sedentary living. This type of living is non ideal, painful, as well as unhealthy. Inactivity, especially among older adults, greatly affects health and life expectancy. Damage due to types of arthritis such as these may lead to deterioration of the surrounding bone. This in effect, leads to a loss of mechanical strength, causing the bone to see less stress due to decreased activity. Because the bone experiences less stress, this leads to further deterioration, producing a cycle of a loss of bone density surrounding the damaged area.

When medication and other forms of treatment no longer become viable options, a total knee replacement is often times the next step in treatment of a damaged knee. Doing so has the possibility of restoring the patient's ability to complete everyday activities without severe pain. In addition, severe arthritis can cause knee deformities, such as bowing in or out of the knee. A total knee replacement has the ability to restore the "natural" look of the knee if this type of damage is apparent. As previously outlined, follow up surgery is fairly uncommon for total knee replacement surgery, indicating that this type of surgery is a viable and effective option for those suffering from immobility due to arthritis.

\subsection{Types of Knee Replacements}

While this study examines total knee replacements, there are many different types of knee replacements which are commonly used in surgery. In particular, the characteristics of total knee replacements and partial knee replacements will be outlined. In addition, the advantage and disadvantage of each type of total knee replacement will be investigated.

\subsubsection{Fixed and Mobile Bearing Total Knee Replacements (TKR)}

Total knee replacements can be subdivided into two different functional types. These types are fixed bearing and mobile bearing total knee replacements. The crucial difference between the two is that the mobile bearing TKR allows for internal and external rotation (in the superior/inferior plane). In fixed bearing knee replacements, the polyethyle ne insert is static, 
in that it is press fitted or clipped into place on top of the titanium tibial tray. Essentially, mobile bearing TKRs function a bit more anatomically similar to a human knee, which allows for an added range of motion. An example of a fixed bearing model can be seen below in Figure 4.
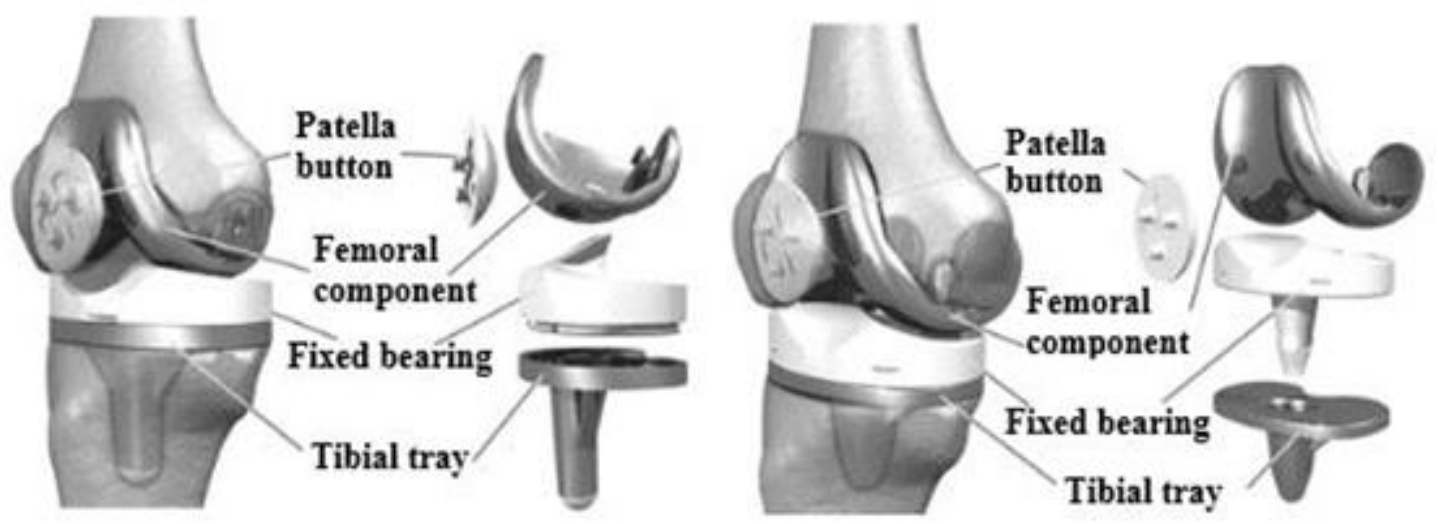

Figure 4 - Fixed bearing a TKR model with outlined components [5].

\subsubsection{Total Knee Replacement}

There are two particular types of total knee replacements currently used on the market. The first is the posterior-stabilized type, which involves the removal of the posterior cruciate ligament. This is needed when the posterior cruciate ligament can no longer support loading. The second type of total knee replacement is the cruciate-retaining model, which preserves the posterior cruciate ligament. These particular models have a groove which accommodates and protects the ligament, ensuring that the ligament provides more natural flexion and continues to provide stability to the knee. Typically, the anterior cruciate ligament is removed with a TKR, while it is usually left in place for a partial knee replacement.

\subsubsection{Partial Knee Replacement (Unicompartmental)}

In partial knee replacements, only sections of the knee are replaced rather than the entire knee, keeping much of the original biological tissue intact and functional. Typically, patients who proceed with a partial knee replacement are those who have osteoarthritis concentrated in a given region, rather than the entire knee. Regions where osteoarthritis can occur include 
the medial, lateral, and patella femoral compartment. In partial knee replacement surgeries, the compartment(s) which contained diseased tissue have both the bone and cartilage removed and replaced with artificial components made from metals such as titanium, as well as plastic components acting as a smooth articulation surface. Partial knee replacements are much more commonly performed on younger patients under 65, as well as on patients who lead a very active lifestyle. An example of a partial knee replacement compared to a total knee replacement can be seen below in Figure 5.
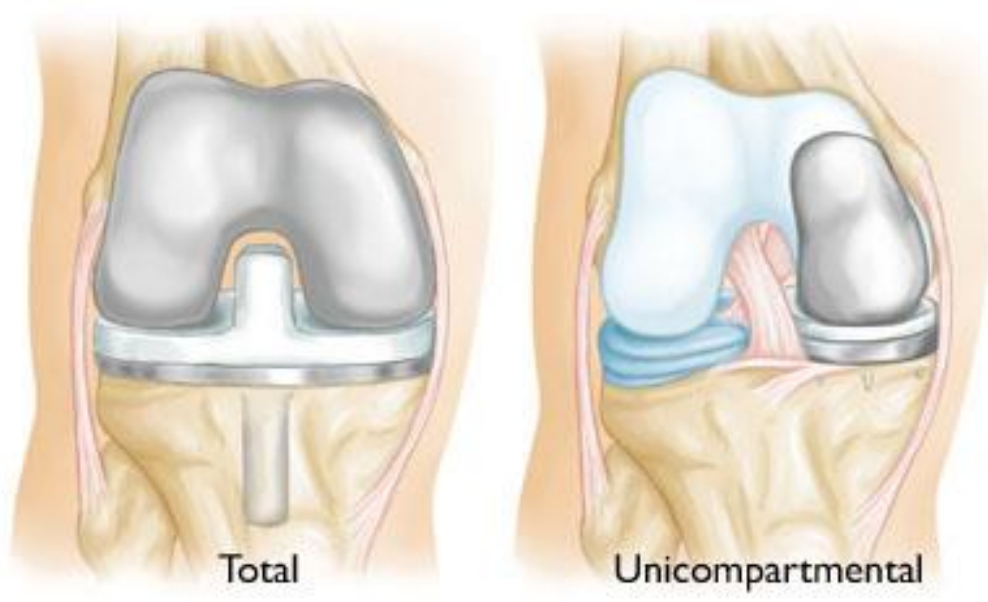

Figure 5 - Comparison between total and partial knee replacement. Note that the partial knee replacement has much of the femoral condyle still intact, as well as portions of cartilage still intact [8].

One major advantage of a partial knee replacement is that recovery time is cut down significantly, as well as the knee function feels much more natural than what patients experience with a total knee replacement. However, due to the fact that there is a chance that disease may spread to the other compartments which are still biologically intact, there is an increased chance that follow-up surgery may be required. Partial knee replacement implants are offered in both mobile and fixed bearing options. As outlined earlier, mobile bearing systems allow for rotation of the plastic insert within the tibial tray. Fixed bearing systems have the plastic insert secured to the tibial tray in a static position. 


\subsection{The Process of the Total Knee Replacement Surgery}

The general process of a total knee replacement surgery is fairly straight forward. First, damages to the bone and cartilage are removed and cut away. The distal end of the femur bone is then cut and reshaped precisely to match the geometry of the femoral component of the prosthesis. The femoral component of the prosthesis, typically made of metals such as chromium-cobalt and titanium, is then placed onto the cut surface of the distal end of the femur using bone cement such as polymethyl methacrylate (PMMA). The next step involves preparing the tibia. Damaged areas are cut away from the proximal end of the tibia. Next, the tibial surface is resurfaced by cutting a flat surface across the top. The geometry of the cut is sized to accept the tibial component, which consists of a metal tray (also usually Titanium) with a stem. Bone cement is then applied and the tray is then secured to the resurfaced proximal end of the tibia. A fixture is then used to implant the stem, through the tibial tray into the tibia bone itself. Next an insert, often times made of polyethylene, is secured to the top of the tibial tray. This insert functions as the cartilage, allowing for motion of the femoral component over the polyethylene insert. The rear of the patella is then resurfaced by cementing a polyethylene patellar component, allowing the patella to smoothly glide over the polyethylene insert. The procedure is then complete, where doctors then examine knee flexion and extension to ensure proper functionality [9].

\subsection{Objective and the Employed Methodology}

The objective of this study was to analyze the principal stresses of the tibia, both before and after a total knee replacement has been installed, under loads measured during normal gait for patients with heavy joint damage due to arthritis. Specifically, two different models representing the geometry of popular commercial tibial tray and tibial stems were examined for stress shielding. The specific length and width of each tibial stem type was examined as well, in order to encompass a range of dimensions for each given model knee replacement. From the data obtained using finite element analysis for static loading conditions given a dynamic load factor of three, a top performing stem geometry and type was determined for the tibia utilized, out of the dimensions/geometry studied. Stress shielding occurs when an implant within a bone experiences more of the load than the surrounding bone, decreasing the 
stress that would typically be experienced by the bone. According to Wolff's Law, bone will remodel in response to loading. With a decrease in the amount of loading seen by the bone due to an implant, the bone density will decrease, leading to the overall mechanical properties of the bone to deteriorate [10]. Optimally, a perfectly functioning knee replacement yields a stress shielding ratio of one, or stress shielding percentage of $0 \%$. This optimum ratio/percentage implies that the bone is seeing the same amount of stress that would be experienced without an installed prosthesis. Given the significance of stress shielding as a measure of an effective total knee replacement, hence the effectiveness of the prosthesis, calculation of stress shielding is chosen as the measure.

In this thesis, the assemblies studied to obtain a numerical estimation of stress shielding include a total knee replacement assembly, as well as an intact tibia assembly. The total knee replacement assembly consisted of a resurfaced CT scanned model of an adult tibia, PMMA cement, as well as the various total knee replacement CAD models under investigation. The total knee replacement model utilized for model validation contained the general geometry type of the DePuy Synthes Sigma Total Knee, which was designed using SolidWorks and then imported into Abaqus for analysis. The tibial stem within the Sigma Total Knee represents geometry which has been commonly studied in the literature, allowing for a method of model validation against published data. Upon model validation for the Sigma Total Knee, the same analysis process was used for analyzing all other knee replacement geometries. Specifically, it was concluded that only the stem, as well as the tibial tray would be modeled, as these components of the knee replacement are what influence stress shielding most significantly. In addition, considering these two components introduced much less variability into the results, improving the validity of results obtained. The Sigma Total Knee, which is the geometry which was used for model validation is shown in Figure 6. 


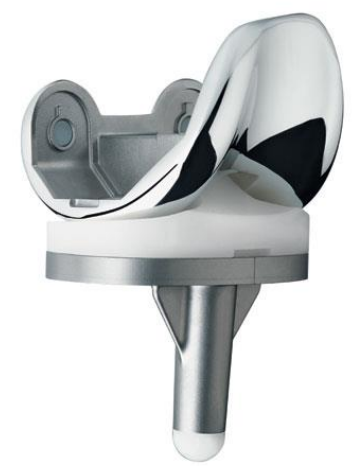

Figure 6 - DePuy Synthes: Sigma Total Knee [11].

It is envisioned that the results obtained in this study will then allow researchers and the general public to have a better understanding of how different geometries commonly used in commercial knee replacements will affect tibias of the same general size and dimension which has been studied within this report. From this data, the best performing type stem will be selected and proposed for the tibia under consideration, using static loading conditions within Abaqus, commercially and widely used finite element software. 


\section{Chapter 2: Literature Review}

In this chapter, the existing two commonly used total knee replacement models will be introduced and analyzed. All models being analyzed within this study are among the most well-known medical device designed and produced by the US biomedical device manufacturers. Existing research results will be analyzed within the field, all pertaining directly to the results within this study. Static modeling results will be reviewed for geometry which resembles the Sigma Total Knee, manufactured by DuPuy Synthes, a Johnson \& Johnson company. For each of the outlined models, the material properties utilized for the bone as well as the tibial components and cement will be outlined. All materials were modeled as linearly elastic, homogenous materials. These material properties are a crucial factor for the output results of this study, as the material properties and the arrangement of these materials within the model directly affect the calculated stress distribution of the system. The different geometries being examined will be compared and contrasted as well, where expected trends of stress distributions will be investigated.

\subsection{Manufacture Claims}

In this section we will present a general overview of each of the particular models under examination. In addition, the different patient options as well as materials utilized throughout the replacement will be highlighted. The particular geometric features of the entire system and manufacture claims will also be outlined, as well as general statistics relating to each product. This section is an unbiased overview of all models and their outlined characteristics.

\subsubsection{DePuy Synthes - Sigma Total Knee (Stem Type Geometry)}

Manufactured by DePuy Synthes, a Johnson \& Johnson company, this primary knee system is based on the P.F.C. Total Knee System which was originally introduced in 1984. The Sigma Total Knee is shown in Figure 7. 


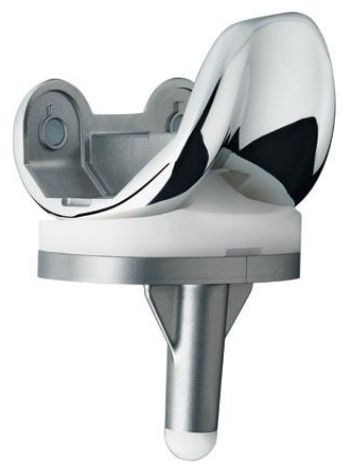

Figure 7 - DePuy Synthes: Sigma Total Knee [11].

The tibial stem of the Sigma Total Knee is a geometry more commonly found in other total knee replacement models from different manufacturers. This geometry consists of a cylindrical stem with flaring wedges on the side for added stability. The Sigma Total Knee is available in posterior cruciate retaining or posterior stabilized femoral component designs, as well as fixed and mobile bearing tibial component designs. The fixed bearing model has a polished cobalt chrome tibial tray, which is claimed to minimize polyethyle ne wear. In addition, the fixed bearing model contains an " $\mathrm{i} 2$ " mechanism used for locking, utilizing an interference fit for decreased system "micromotion" [12]. "XLK polyethylene" is utilized throughout the system as well, which is claimed to be a "oxidatively stable material." This model also offers a high angle of flexion of 150 degrees. It was also found in a study that 99.6\% of patients still had the Sigma Fixed-Bearing knee model which had stayed intact five years after surgery [13]. In another study targeting a duration of five to ten years after surgery, most patients reported that using the Fixed-Bearing model resulted in relief of pain, as well as an improved functionality of the knee [14].

\subsubsection{Zimmer - Trabecular Metal Persona Knee (Peg Type Geometry)}

Zimmer claims to have developed the most anatomically accurate knee implant, through utilizing analytics from men and women, as well as 1,500 different bone types, from 26 different ethnicities. Zimmer claims that the tibiofemoral kinematic implant design allows for more natural knee motion, as well as the patellofemoral groove allows for efficient knee 
flexion and proper patellar tracking. The tibial stem and tray is made of a "Trabecular Metal Material," which allows for biological fixation, allowing for bone growth into the tibial stem inserts [31]. Because of this, Zimmer utilizes a cement-less surgical technique, as cement would inhibit the bone growth functionality. This allows the tibial stem to function similar to the surrounding bone, without the requirement of direct cement application. The persona knee is able to accommodate ranges of motion up to 155 degrees, maintaining optimal contact area through flexion. The tibial insert utilizes "Vivacit-E Vitamin E HXPE," which according to Zimmer provides extremely low wear and enhanced strength, as well as oxidative stability according to Zimmer lab studies. Zimmer also boasts a large variation of sizing for the tibial insert and femoral component, allowing for an increased accuracy in fit for each patient. An image of the Zimmer Persona Knee can be seen below in Figure 8.

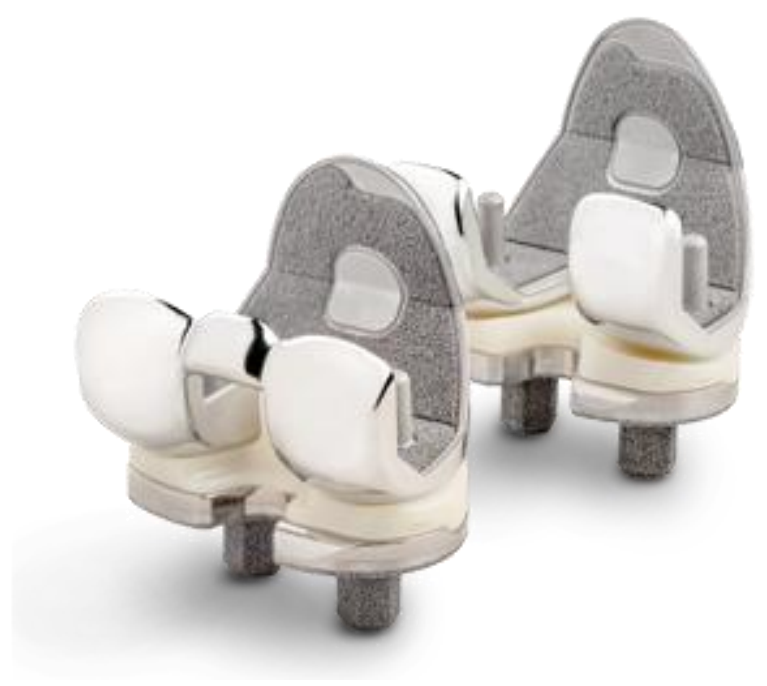

Figure 8 - Zimmer: Persona Knee [15].

Note that in the above figure, there are two tibial pegs rather than a central tibial stem. This geometry takes on quite a different shape than the tibial stem of the prior two total knee replacements. In addition, the tibial tray and stems are all made of a material with material properties close to the surrounding bone.

\subsection{Available Research Findings and Conclusions}

This section will outline published information from the article titled "The role of the design of tibial components and stems in knee replacement," by C.E.H. Scott and L.C. Biant. This 
article provides a general overview of published trends from many different sources and serves as an excellent resource for model validation. For the following published data/information, tibial stems representing the general geometry of the DePuy Synthes Sigma Total Knee (stem type geometry) is reflected. This geometry is characterized by a cylindrical stem with side fins protruding from just below the tibial tray. Micromotion of the cement to bone interface is decreased with the use of stems, reducing potential loosening of the tibial tray/resurfaced bone interface [16]. In addition, it has been concluded that a cemented tibial component resists shear micromotion better than an un-cemented tibial component [17]. It has also been found that stems help provide resistance to bending during normal daily activity [18]. Also, the length of the stem is directly proportional to stress shielding, meaning that the longer the stem, the more stress shielding should occur [19]. This particular finding will be reviewed when examining results, in order to establish the validity of this published trend. The amount of stress shielding is heavily influenced by the material type. In fact, the higher the difference of the modulus of elasticity compared to the surrounding the bone, the greater the amount of stress shielding, due to resulting in higher stiffness for the stem compared with that of tibia and hence [20].

Strain gauge studies which compared metal stems of $20 \mathrm{~mm}, 40 \mathrm{~mm}$, and $60 \mathrm{~mm}$ lengths found that proximal strain was reduced with a length of $60 \mathrm{~mm}$. This trend is not ideal, as a reduction in strain will promote a loss of bone mass density. This trend however was not found with shorter stems, or stems made of PE [21]. Furthermore, from additional studies it was found that depending on the modulus of elasticity of the surrounding bone, the use of stems can reduce proximal tibial strain anywhere between $20 \%$ and 60\% [22]. This means that it should be expected that an initial state of stress shielding should be more noticeable for longer length stems. The proximal stress reduction in un-cemented long stems of $110 \mathrm{~mm}$ have been shown to be reduced by $700 \%$, compared to no stress shielding with stems of $50 \mathrm{~mm}$ in length [23]. This reduction is maximized by not using bone cement for stem fixation. A plot outlining stress shielding for un-cemented stems can be seen below in Figure 9, as published by Completo A, Talaia P, Fonseca F, and Simões JA [23]. 


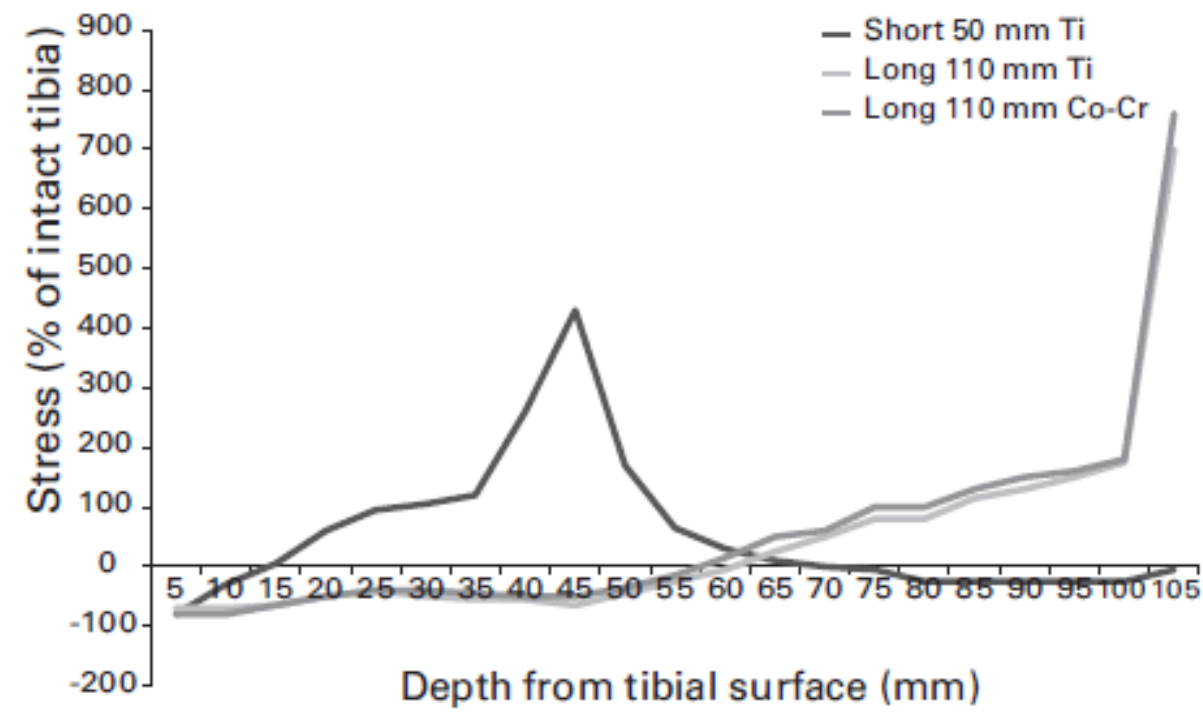

Figure 9 - Plot displaying stress as a percentage of which occurs in the intact tibia at measured depths from the resurfaced tibial surface. In this plot, a negative stress percentage is indicative of stress shielding [23].

Note that in the above plot, stress shielding occurred at depths up to roughly $15 \mathrm{~mm}$ below the resurfaced tibial surface for the short $50 \mathrm{~mm}$ Ti stem. Stress shielding then became a factor again at depths greater than roughly $70 \mathrm{~mm}$ for the short $50 \mathrm{~mm}$ Ti stem. With the 110 $\mathrm{mm}$ Ti stem however, stress shielding was observed roughly up to depths of $60 \mathrm{~mm}$ below the resurfaced tibial surface. It can also be seen that the titanium and cobalt chromium output roughly the same trend in stress shielding percentage. This previously published plot confirms the published trend established earlier which concluded that stem length was directly proportional to the amount of stress shielding of the tibia. It should be noted that the loading conditions for this particular study are quite different - as this particular published study used a pressure contact loading condition. In addition, the tibia was modeled with a cortical shell with internal trabecular bone. Among these differences, the most influential difference is the fact that the model studied within this published study was not cemented. Not cementing a stem will drastically change loading conditions at the load transfer point at the end of the stem, allowing for larger compressive stresses to exist, therefore minimizing the amount of stress shielding.

Upon comparison of the DePuy Synthes Sigma Total Knee type stem geometry to one of pegs such as the Zimmer Persona Knee, it was found that after seven years, a statistically 
significant number of patients showed a reduced bone density compared to a peg type geometry, characteristic of an increased amount of stress shielding for the DePuy Synthes Sigma Total Knee stem geometry [24]. It should be noted however that the model used within this study had four pegs rather than two.

Furthermore, the effect of cemented stems compared to un-cemented stems is significant on stress/strain shielding. According to a study which utilized strain gauges to physically measure strain shieling in synthetic tibiae in both cemented and un-cemented stems ranging from $35 \mathrm{~mm}$ to $150 \mathrm{~mm}$, it was found that strain shielding occurred within $33 \mathrm{~mm}$ of the tibial resurfaced surface/tibial tray interface, however cemented stems experienced a greater amount of strain shielding over a greater depth, up to four times that of the un-cemented stem [18]. In addition, it has been shown that the location of application of the cement plays a role in the expected minimum principal stress distribution. In a finite element study on the effect of length and cementing technique, it was found that the particular cementing technique influences the stress distribution in a significant way. As can be seen below in Figure 10, model A and C represent fully cemented stems of different lengths, while models B and D represent the same length stems, but only proximally cemented. As can be seen, with a fully cemented stem there is a significant positive shift in the minimum principal stress at the regions close to the end of the stem. This signifies that the bone sees a lower amount of compression at the end of the stem. Because of this, stress shielding should be much higher at this location for fully cemented models, as opposed to non-cemented or proximally cemented models. 

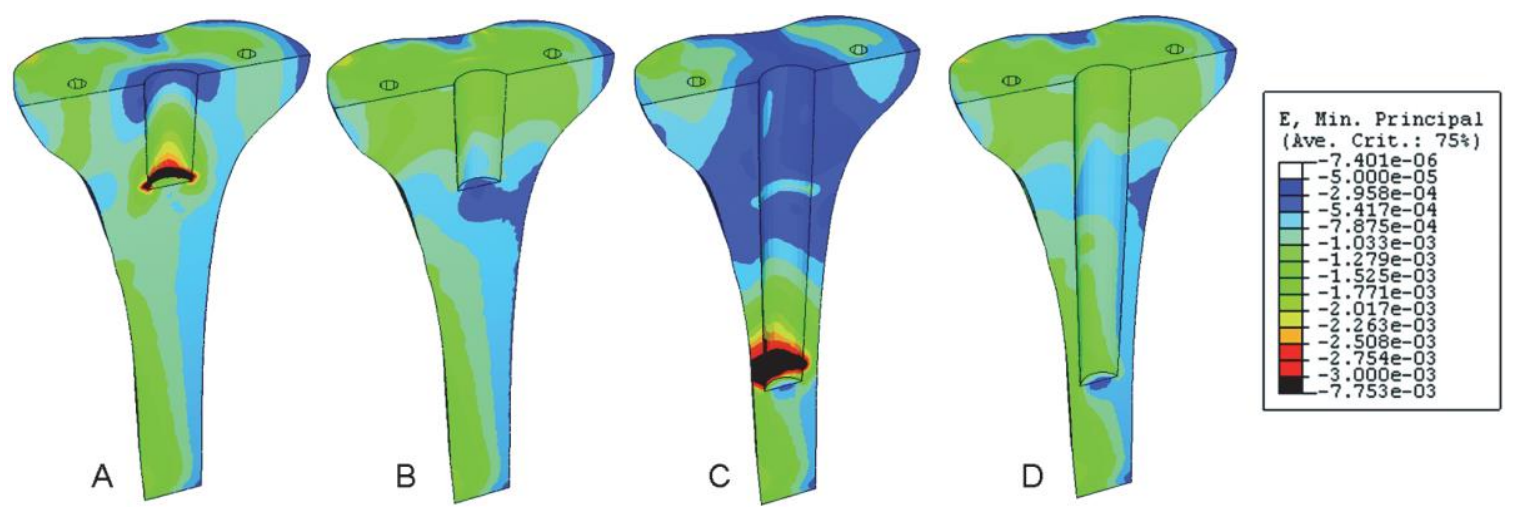

Figure 10 - The significance of cementing technique and how cementing technique affects stress shielding of the tibia. Note that there is a significant decrease in compression for models A and B, which represent fully cemented models [25].

In this section, a paper by Yash Agarwal from the University of Surrey titled "Investigating the effect of tibial augmentation on the stability of total knee replacements," will be reviewed for the comparison of results from this study [26]. In this study, DuPuy International supplied a CAD model of their implant for the study, allowing for a close comparison of results from this study to be compared to the study performed within this paper. A cement model was created within this study as well; however, cement was not modeled underneath the tibial tray. Another difference includes that the bone was modeled as two sections. This includes a cortical and trabecular section. All models were meshed using 4-noded linear tetrahedral 3D stress elements, which is what was utilized within this study. The loading simulated within the system is different for this particular study being considered; pressure contact patches were used for the TKR assembly and intact tibia assembly. Within the study performed in this paper, a joint contact force load is applied to the medial and lateral contact points for the TKR and intact tibia assembly. The lateral side of the bone carried more stresses than the medial side as well. Material properties for young's modulus for the cement, cortical bone, cancellous bone, and implant were $2150 \mathrm{MPa}, 17 \mathrm{GPa}, 700 \mathrm{MPa}$, and $117 \mathrm{GPa}$ respectively. As can be seen, the modulus of elasticity for the cement is much lower than that of the bone. This has its own adverse effects in stress shielding, affecting how 
Using the pressure distribution loading, Von Mises stresses of the system ranged from 6.797 E-3 and 1.485E1 $\mathrm{Pa}$. Some of the main conclusions drawn from the study being reviewed includes the following.

a) Most of the maximum principal compressive stress in cancellous regions (outer edges) remain less than $0.5 \mathrm{MPa}$.

b) Stress shielding more likely to occur in proximal, near implant fins, and distal end of the stem.

In another study, titled "Finite Element and In-Vitro Testing of Tibial Stem Length in Revision Total Knee Arthroplasty,” a study completed by Henderson, Schimdt, Ploeg, Deluzio, and Dunbar, in-vitro loading was compared to FE simulated loading of a Zimmer size 4 NegGen A/P Wedge tibial components [27]. This particular tibial stem design is extremely similar to the baseline, Dupuyes model being considered for model validation. In this study, four lengths were analyzed within Abaqus finite element software; these sizes included stem lengths of 125, 145, 175 and $200 \mathrm{~mm}$, all with a diameter of $12 \mathrm{~mm}$. In-vitro was simulated using composite tibias implanted with $12 \mathrm{~mm}$ diameter tibial components, five samples for both $145 \mathrm{~mm}$ length and $200 \mathrm{~mm}$ length stems. Finite element results revealed that with increasing stem length, average proximal cancellous Von Mises stress decrease, while overall peak stress are increased.

Based upon the research performed for this study, it was concluded that stress shielding for stem type geometry would be compared to stress shielding for peg type geometry tibial components. In addition, the effect of stem/peg length, as well as stem/peg diameter/width will be investigated. It was expected that a shorter, less thick stem/peg would yield results reflecting less stress shielding. In addition, a comparison of how stress is transmitted in a cement-less model compared to a fully cemented model will be performed. 


\section{Chapter 3: Model Development}

In this chapter the detail of the methodologies utilized in this research study for the development of the model and the corresponding analysis are presented. This includes using Meshlab for pre-processing of an obtained CT scanned tibia model, SolidWorks design of each model under examination, as well as FE simulation modeling techniques.

The following steps were performed to create each studied assembly, for each geometry type and size. This process was kept consistent in order to ensure results obtained from each assembly had minimal variability in model formation.

a) Obtain a CT scanned 3 dimensional model of an adult tibia-fibula as a.$d x f$ format (Drawing Exchange Format).

b) Import the tibia-fibula model into MeshLab for model simplification, export as an .$I G E S$ file type (Initial Graphics Exchange Specification). Import .IGES file into SolidWorks, then repair geometry.

c) Remove the fibula from the model, as only the tibia is being considered in this study.

d) Resurface tibia and create internal cuts matching the geometry of each TKR stem type, export as a.STEP file type (Standard for the Exchange of Product Data).

e) Create TKR models and cement models within SolidWorks, verify fit as a SolidWorks assembly, export components as a.STEP.

f) Import files into Abaqus, perform geometric tightening of tolerances.

g) Create material sections for each imported component of a given assembly.

h) Create $2.5 \mathrm{~mm}$ thick partitions, at depths of $0,20,40,60,80$, and $100 \mathrm{~mm}$ below the resurfaced tibial surface.

i) Apply a seed size mesh of $2.5 \mathrm{~mm} \mathrm{C3D10} \mathrm{elements} \mathrm{to} \mathrm{all} \mathrm{models.}$

j) Create elemental sets for each depth under consideration in post processing.

k) Create instances of each model and create an assembly.

1) Create boundary condition for mid diaphysis of the tibia.

m) Create joint contact forces for the medial and lateral condyle contact points.

n) Use tie constraints to tie nodes together - simulating cement, bone, and TKR interfaces. 


\subsection{Pre-Processing Using Meshlab}

Meshlab was used to simplify the tibia/fibula model complexity, allowing for model manipulation within SolidWorks. Meshlab is an open source program used for processing and editing 3D triangular meshes. This program is available online for free and is very effective at simplifying extremely complex models without losing model integrity. A CT scanned adult tibia/fibula which was uploaded onto the U.S. Department of Health and Human Services was used for all tibia models simulated [28]. Because of the model complexity, SolidWorks was unable to import the model. Meshlab was required for model simplification, where 47,818 faces were reduced to 30,355 faces using the quadratic edge collapse decimation function. In addition, the butterfly subdivision function was used to smooth the model after the reduction in the total number of faces. Using this method of preprocessing the tibia/fibula model, SolidWorks was successfully able to import the model for modification. An image of the tibia/fibula model before and after Meshlab pre-processing is shown in Figure 11 and Figure 12.

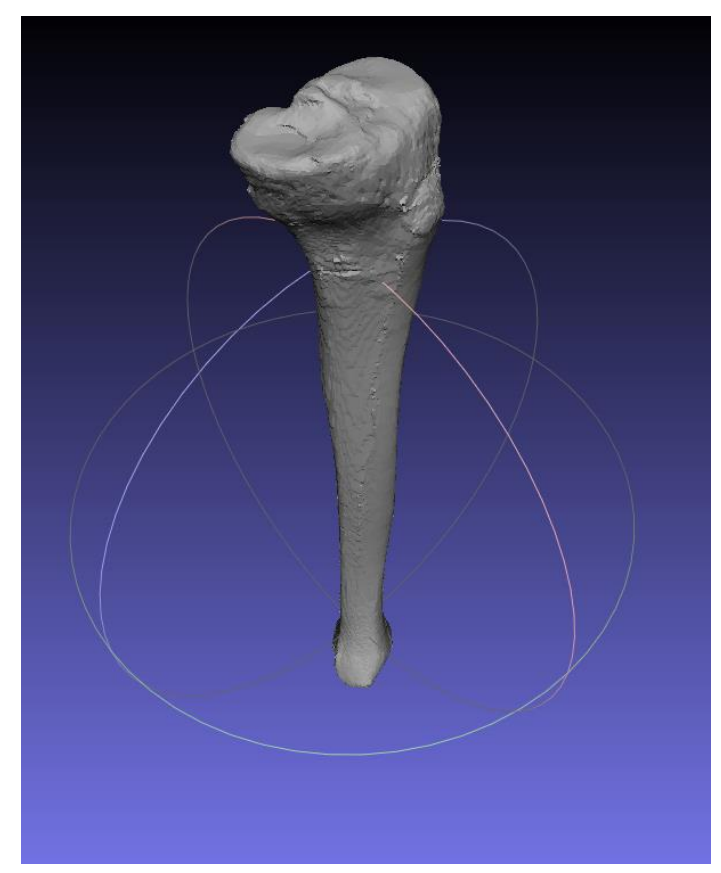

Figure 11 - Tibia imported into Meshlab before complexity reduction. This model was unable to be imported into SolidWorks for modification. 


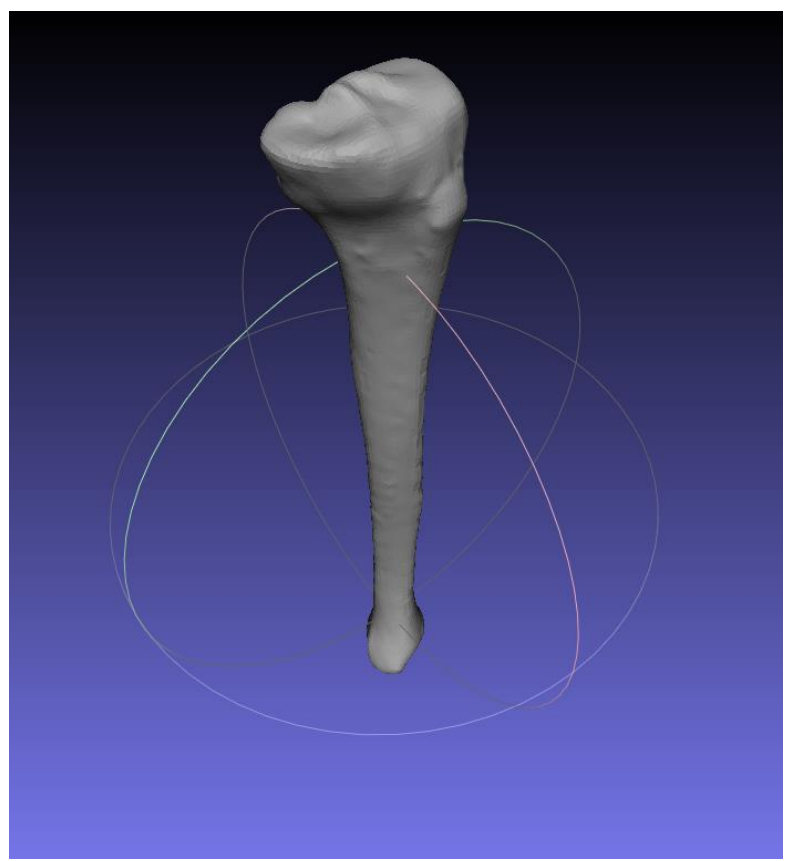

Figure 12 - Tibia within Meshlab after complexity reduction. Complexity reduction allowed for SolidWorks importation.

\subsection{Model De velopment - SolidWorks}

SolidWorks was used to design each model for each different TKR under analysis. This included a total of two types of models, over a wide range of sizes. A summary of stem diameters/lengths for each model created within SolidWorks are presented in Table 1. 
Table 1 - Summary of geometric types and sizes studied using finite element analysis.

\begin{tabular}{|c|c|c|}
\hline $\begin{array}{c}\text { Geometry } \\
\text { Type }\end{array}$ & $\begin{array}{c}\text { Diameter/Width } \\
\text { (mm) }\end{array}$ & $\begin{array}{c}\text { Length } \\
\text { (mm) }\end{array}$ \\
\hline \multirow{6}{*}{ Stem } & \multirow{3}{*}{12} & 25 \\
\hline & & 50 \\
\hline & & 75 \\
\hline & \multirow{3}{*}{15} & 25 \\
\hline & & 50 \\
\hline & & 75 \\
\hline \multirow{6}{*}{ Pegs } & \multirow{3}{*}{12} & 12 \\
\hline & & 18 \\
\hline & & 24 \\
\hline & \multirow{3}{*}{16} & 12 \\
\hline & & 18 \\
\hline & & 24 \\
\hline
\end{tabular}

In addition, the different tibia models created for each stem type will be introduced as well, as each tibia required a different internally cut geometry given different stem types/geometries. The outlined geometric stem/peg sizes were studied in order to understand the impact of geometry on stress shielding of the tibia. 


\subsubsection{DePuy Synthes Sigma Total Knee (Stem Type Geometry)}

Using SolidWorks, an array of models were constructed based upon typical stem dimensions found in the DePuy Synthes surgical technique guides, as well as published data used for model validation. The two different stem diameters studied include 12 and $15 \mathrm{~mm}$. In addition, lengths of $25 \mathrm{~mm}, 50 \mathrm{~mm}$, and $75 \mathrm{~mm}$ were constructed, for a total of 6 combinations of dimensions studied. The physical representation of the tibial plate was matched as close to the actual tibial plate as possible, as DePuy Synthes would not supply a physical model to dimension or a dimensioned CAD drawing. Because of this, all dimensions were approximated to fit the adult CT scanned tibia used in this study. The fins of the model were approximated as closely as possible as well, and kept consistent in size with increasing sizes. The smallest size TKR model constructed for the stem type geometry model is presented in Figure 13.

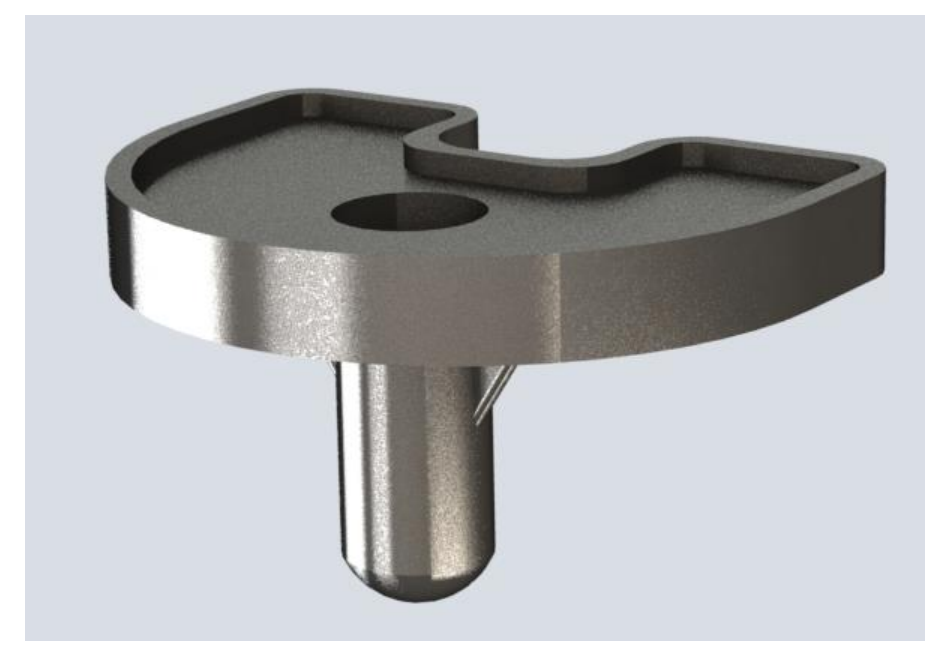

Figure 13 - SolidWorks model of the stem type geometry model, smallest size under consideration.

The cement was constructed to be $1 \mathrm{~mm}$ thick in all dimensions and was constructed to be a perfect fit to the bottom surfaces of the tibial tray and tibial stem. The cement was constructed based upon the surgical technique guidelines for cement application for the Sigma Total Knee. This includes accounting for the internally drilled hole for the tibial stem, as well as the top surface of the resurfaced tibia - tibial tray interface. All dimensions were made to match that of the constructed Sigma Total Knee for each size under consideration. 
The smallest size cement model constructed for the Sigma Total Knee is shown in Figure 14. Material properties utilized for the cement and all other models considered can be seen later in this section.

Figure 14 - Cement model for the smallest stem type geometry model examined. The cement was modeled to be $1 \mathrm{~mm}$ thick.

\subsubsection{Zimmer - Persona Knee (Peg Type Geometry)}

The Zimmer Persona Knee was constructed to match models displayed in surgical techniques, as well as models supplied on the Zimmer website. The dimensions for all components were unavailable, requiring an estimation of geometry to be applied. Estimation of the major dimensions of the tibial tray were kept consistent with other models, in order to avoid uncertainty produced with varying tibial tray geometries. As previously outlined, the tibial tray was dimensioned to fit the tibia model being used. As previously covered, Zimmer produces the Persona Knee tibial component as a composite. This composite is made up of trabecular metal lining the bottom surfaces, allowing for bone growth, as well as a titanium upper trabecular tray region. However, this study is only examining the effect of geometry and has used a fully titanium assembly which is fully cemented. Doing so allows for consistency across results, as well as takes away as many influential factors other than 
geometry. An image of the constructed SolidWorks fully titanium model is shown in Figure 15.

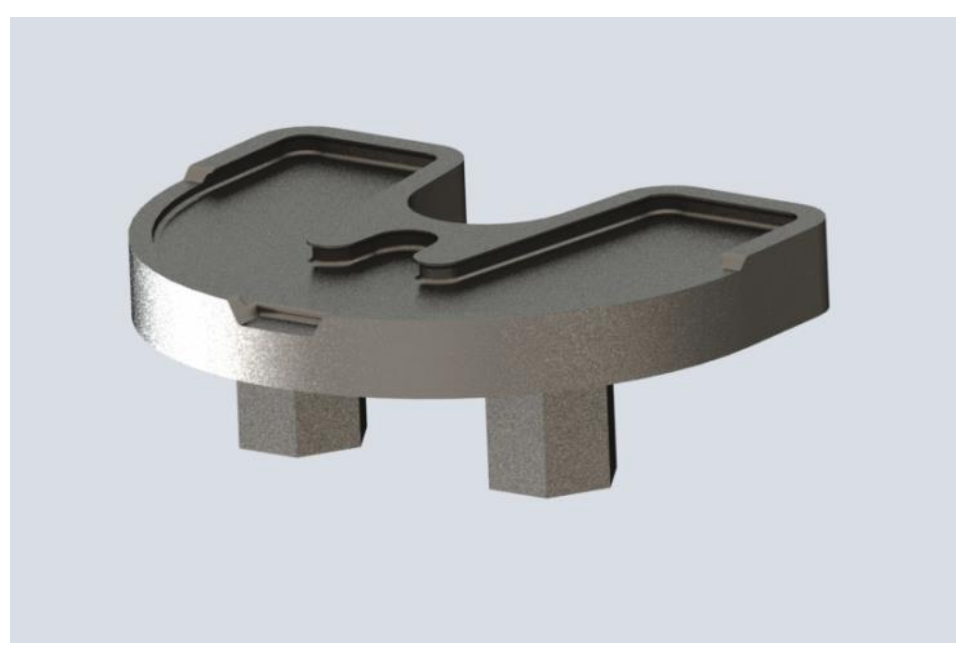

Figure 15 - SolidWorks model of the peg type geometry model, smallest size under consideration in titanium.

In addition, cement was constructed for titanium model, as titanium requires cement due to its inability to stimulate bone growth. The cement model created within SolidWorks is shown in Figure 16. The cement was dimensioned to be $1 \mathrm{~mm}$ thick in all dimensions, covering the entirety of the bottom surface of the titanium model.

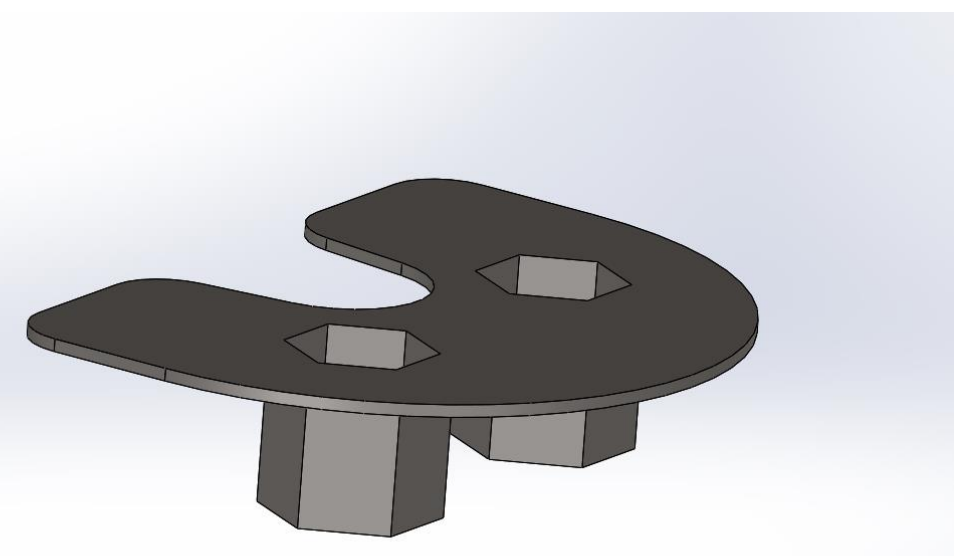

Figure 16 - Cement model used for the smallest peg type geometry model. All dimensions were set for a $1 \mathrm{~mm}$ cement thickness. 


\subsubsection{Tibia Models}

It was required to create different tibia models for each stem geometric shape/size studied. In order to study the stress shielding of the system, it was first necessary to import a standard, intact tibia model from Meshlab. This model had not been resurfaced, and was used in order to get baseline stressed in order to understand the stress shielding ratio. This model is presented in Figure 17.

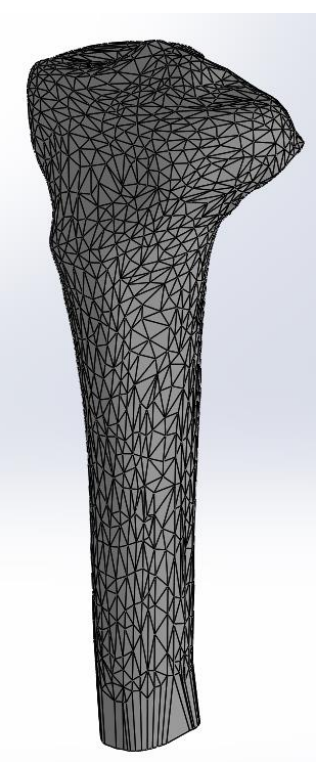

Figure 17 - Intact tibia model derived from CT scanned of an adult.

Resurfaced tibia models were needed for all stem types being studied. The resurfaced portion was estimated based upon various surgical techniques for each geometric stem type. In addition, all internal cuts were made to match the geometry of the required cement, depending on the model under consideration. The internal stem positioning cut was set based on the center of the tibial medullary canal. The SolidWorks models of the smallest stem size for each stem type are presented in Figure 18 and Figure 19. 


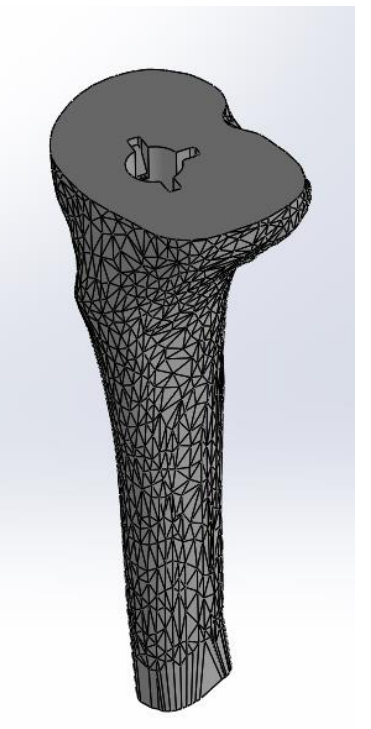

Figure 18 - Stem type geometry tibia model for the smallest TKR size (12 mm diameter, 25 mm length).

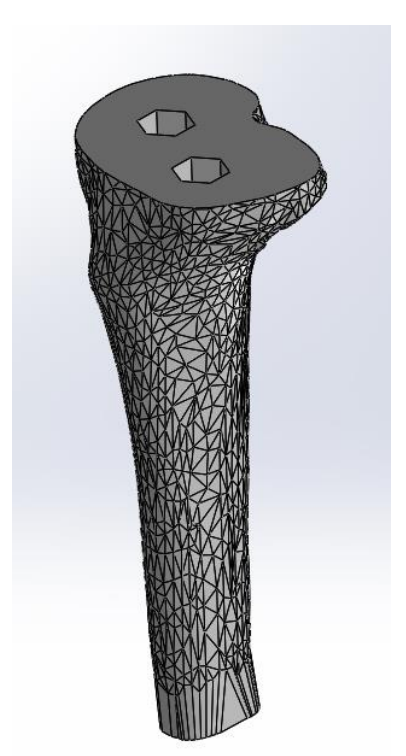

Figure 19 - Peg type geometry tibia model for the smallest TKR size (12 mm width, $12 \mathrm{~mm}$ length).

\subsubsection{SolidWorks Assemblies}

SolidWorks assemblies were created for every model under consideration in order to verify the geometric fit of the system. All fits were made as exact; in order to ensure that the tie 
functions which would be implemented within Abaqus were successful, with no nodes out of the given boundaries set. An example of the Zimmer model assembly is presented in Figure 20.

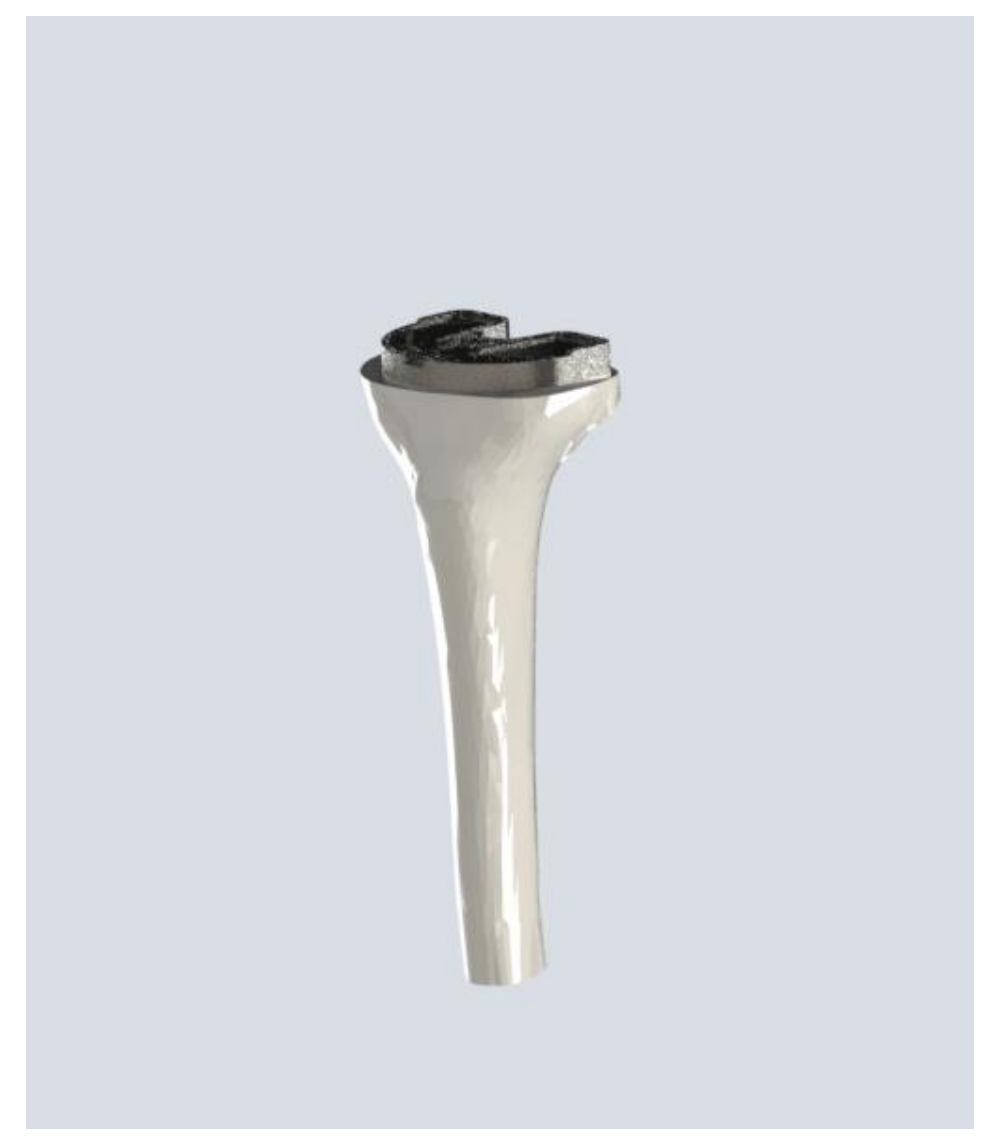

Figure 20 - SolidWorks Assembly for the Zimmer Persona Knee.

\subsection{Model Development - Abaqus}

Once all files were created and fits verified within SolidWorks, they were exported as .STEP (standardized graphic exchange file format) type files into Abaqus. Then using Abaqus' geometry editing functionality, all gaps within the model were tightened in order to allow for a solid model to be imported. An overview of the steps taken to obtain FE model results will be outlined below, while results obtained from the FE method using Abaqus will be examined in the next chapter. 


\subsubsection{Material Section Assignments}

Material sections were applied to each component within the imported parts of a given assembly. Material properties chosen were selected based upon preexisting studies in order to allow for model validation. A summary of implemented material properties are presented in Table 2. The cortical-trabecular bone matrix material properties were selected based upon pre-existing published data, which outlined the compressive modulus of elasticity within range of most accepted elastic modulus values. [29]. Cement and Ti material properties were found based upon preexisting material properties used in a published study on Dynamic FEA loading [26].

Table 2 - Material properties applied to all components modeled within Abaqus.

\begin{tabular}{|c|c|c|c|}
\hline \multirow{2}{*}{ Mate rial Property } & \multicolumn{3}{|c|}{ Mate rial } \\
\cline { 2 - 4 } & $\begin{array}{c}\text { Cortical/Trabecular } \\
\text { Bone Matrix }\end{array}$ & $\begin{array}{c}\text { Cement } \\
\text { (PMMA) }\end{array}$ & Ti \\
\hline $\begin{array}{c}\text { Modulus of } \\
\text { Elasticity (Pa) }\end{array}$ & $1.70 \mathrm{E}+10$ & $2.15 \mathrm{E}+09$ & $1.17 \mathrm{E}+11$ \\
\hline Poisson's Ratio & 0.3 & 0.48 & 0.3 \\
\hline Density (x10 $\mathbf{K g}^{\mathbf{3}} \mathbf{m}^{\mathbf{3}}$ ) & 1.8 & 1.1 & 4.5 \\
\hline
\end{tabular}

\subsubsection{Mesh Development}

Element types used were 10 node quadratic tetrahedral elements (C3D10), which were applied to all utilized models [32]. This element type is the same element type used in published studies similar to the study presented within this thesis. A mesh convergence study, which will be further defined later in this report, yielded an optimal global seed size of 2.5 mm. A fully meshed tibia is shown in Figure 21, as an example of visually what this kind of mesh entails. 


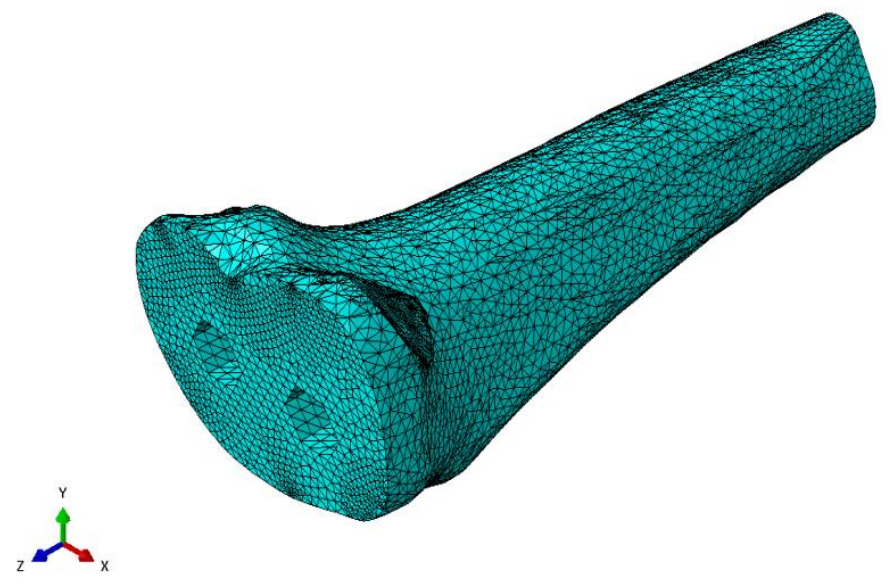

Figure 21 - Peg type geometry tibia model meshed with a seed size of $2.5 \mathrm{~mm}$ for quadratic tetrahedral elements.

The smallest assembly of each TKR model for each model produced an extremely high number of elements, nodes, and degrees of freedom. These figures, as well as the number of elements, nodes, and degrees of freedom for the intact tibia model are listed in Table 3. Note that only the smallest of all assemblies are plotted here, in order to serve a baseline scenario of how many elements and degrees of freedom are present within the system.

Table 3 - Assembly figures for the total number of elements, nodes, and degrees of freedom of the system. In addition, the percent of the total number of elements which are distorted are shown below. Note that all percentages are less than $1 \%$ of the elements.

\begin{tabular}{|c|c|c|c|c|}
\hline Model & $\begin{array}{c}\text { Number of } \\
\text { Elements }\end{array}$ & $\begin{array}{c}\text { Number of } \\
\text { Nodes }\end{array}$ & $\begin{array}{c}\text { Number of } \\
\text { Degrees of } \\
\text { Freedom }\end{array}$ & $\begin{array}{c}\text { Percent } \\
\text { Elements } \\
\text { Distorted }\end{array}$ \\
\hline $\begin{array}{c}\text { Intact } \\
\text { Tibia }\end{array}$ & 331658 & 456651 & 1369953 & $0.34 \%$ \\
\hline $\begin{array}{c}\text { 12X25 } \\
\text { Stem }\end{array}$ & 293837 & 415127 & 1245381 & $0.46 \%$ \\
\hline $\mathbf{1 2 X 1 2}$ & 288106 & 404133 & 1212399 & $0.66 \%$ \\
\hline Peg & & & & \\
\hline
\end{tabular}


Using these optimal mesh settings, the overall quality of the mesh was accurate enough to not affect results negatively. The percent of elements which are distorted can also be seen above in Table 3.

The limiting criterion was defined as $\min / \max$ angle criteria of $\alpha<135^{\circ}$ and $\beta>45^{\circ}$ (skew angle). The aspect ratio was also verified, where it was required that the aspect ratio be calculated using the equation $b / a<5$. Based upon these percentages, as well as the element locations, it can be concluded that these elements did not negatively affect output results.

\subsubsection{Loading, Boundary Conditions}

In order to capture the specified loading conditions, the joint contact force was distributed between the medial and lateral condyles evenly [30]. This static loading type simulates the heel strike-stance phase, where no ligament loading is applied to the system. A loading of $1029 \mathrm{~N}$ was applied to each condyle as a point load, which amounts to three times the weight of a $74 \mathrm{~kg}$ adult [26]. This loading condition utilizes a dynamic load magnification factor, somewhat simulating dynamic loading conditions. . Loading spacing was completed based upon published studies for anatomical measurements. The loading was applied roughly 38 $\mathrm{mm}$ apart; this measurement was found by finding the difference between the femoral condyle inner/outer width [30]. It was verified spatially that loading was applied in the same region in each simulation performed. An example of the load application location is shown below in Figure 22. 


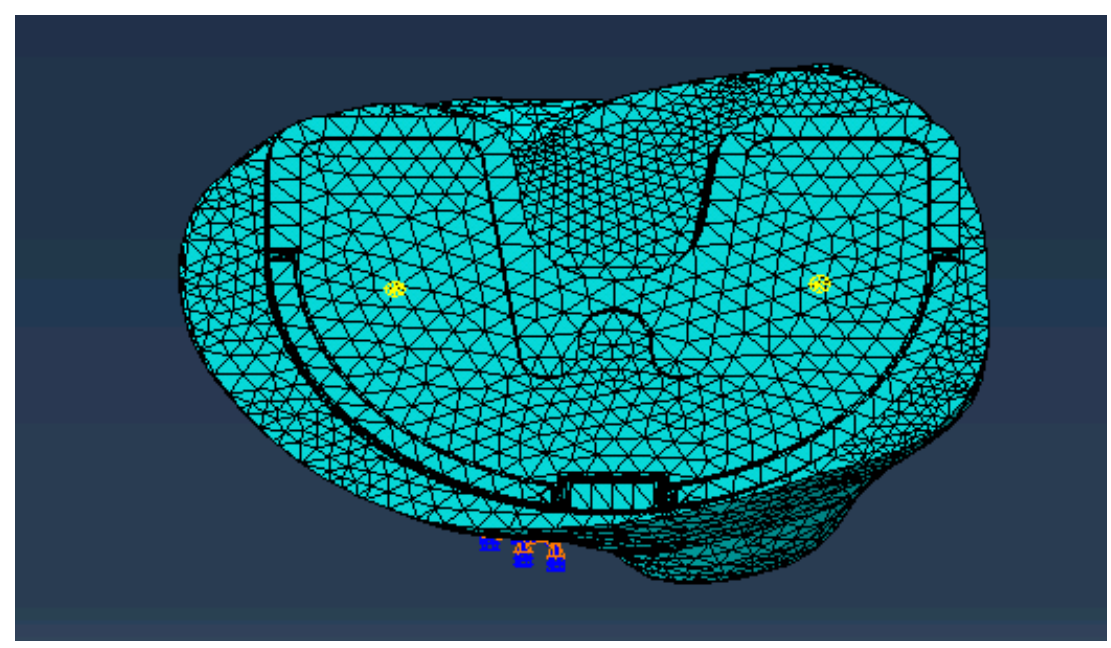

Figure 22 - Medial and lateral load application locations on the Zimmer TKR. Location is kept constant on all TKR model assemblies.

The boundary condition used was the encastre function, which constrained the bottom face and all connecting nodes of the bottom face. These static regions represent a rigid connection, located at the mid diaphysis. An example of where this boundary condition was applied, as well as the load application direction is shown below in Figure 23. This boundary condition simulates the rigidity of the distal tibia, where an assumed fully fixed condition exists. 


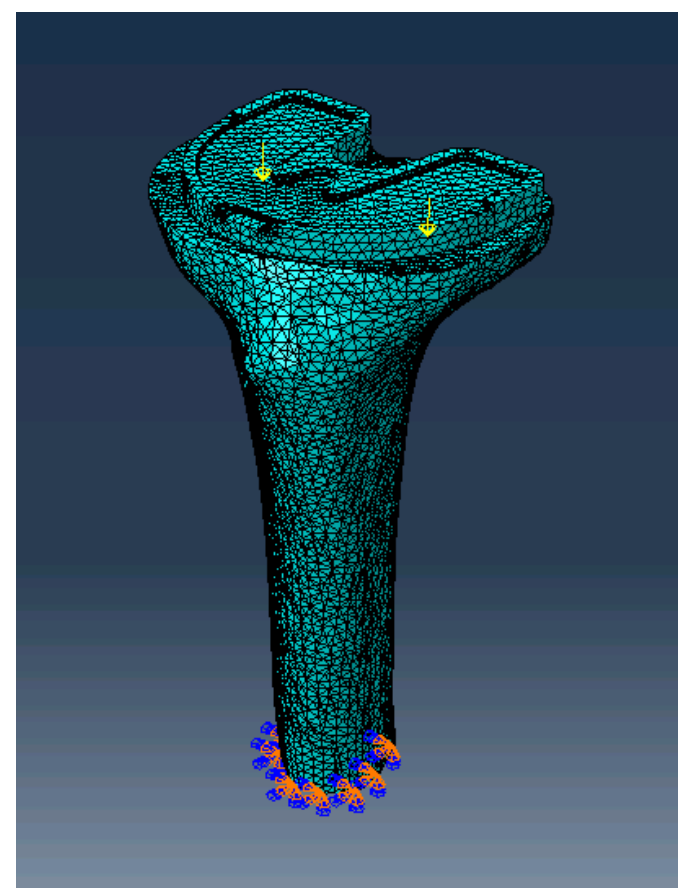

Figure 23 - Boundary condition application location and lateral/medial condyle loading directions, displayed in the Zimmer assembly.

\subsubsection{Assembly Formation, Constraints}

All models were assembled identically as they were within SolidWorks. Doing so ensured that all fits were consistent with resulting fits previously checked within SolidWorks. To assemble the models together in the correct order, a series of concentric contacts and face contacts were implemented, in the same methods of each model assembled. This allowed for the model to be formed as an assembly of all imported models for each TKR stem type under study. Doing so allowed for consistency in the assembly build, in order to avoid any differentials from assembly to assembly. An example of an assembly implemented within Abaqus is shown below in Figure 24. 


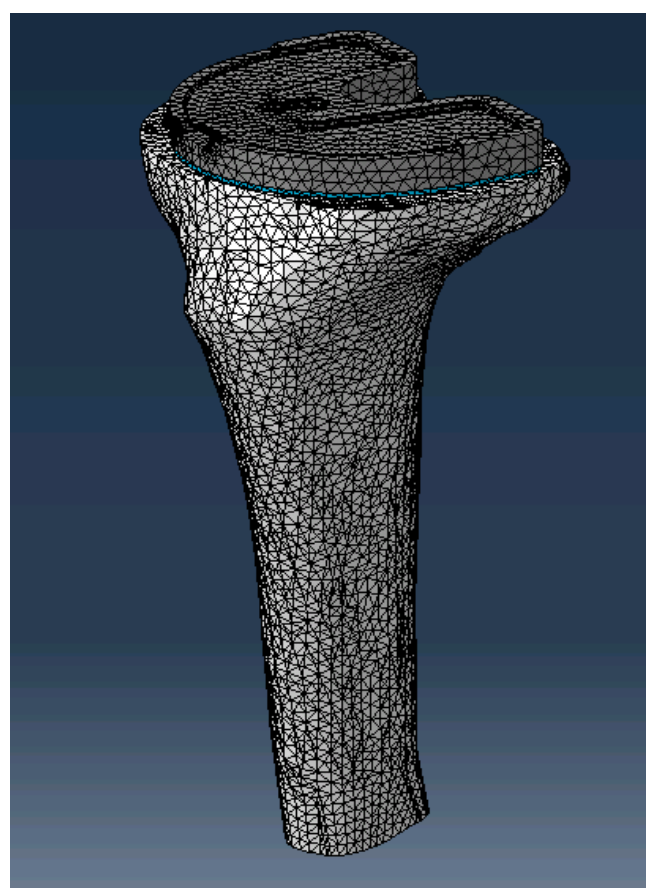

Figure 24 - TKR assembly within Abaqus for the Zimmer TKR model. This includes the tibia (white), cement (blue), and TKR (grey).

In addition, tie constraints were added within the assembly, simulating a statically and rigidly connected assembly with tied nodes. This constraint application simulates how the actual assembly would behave, as cement rigidly keeps the TKR in place. Similar to forming the assembly contacts, all tie constraints were consistent, with faces being tied to each other in order to ensure complete rigidity within the system. All models followed the same general procedure of forming the assembly and then applying the appropriate tie constraints.

\subsubsection{Mesh Convergence Study}

A mesh convergence study was performed in order to determine the optimal seed size. Using a uniformly distributed pressure of $0.5 \mathrm{MPa}$ on the tibial tray of the TKR assembly, an element which had the highest minimum principal stress was recorded for decreasing seed sizes. The data roughly began converging at a global seed size of $2.7 \mathrm{~mm}$, allowing for a global seed size of $2.5 \mathrm{~mm}$ to be used to reflect results as accurately as possible. A plot of the highest minimum principal stress as a function of the number of degrees of freedom is shown in Figure 25. 


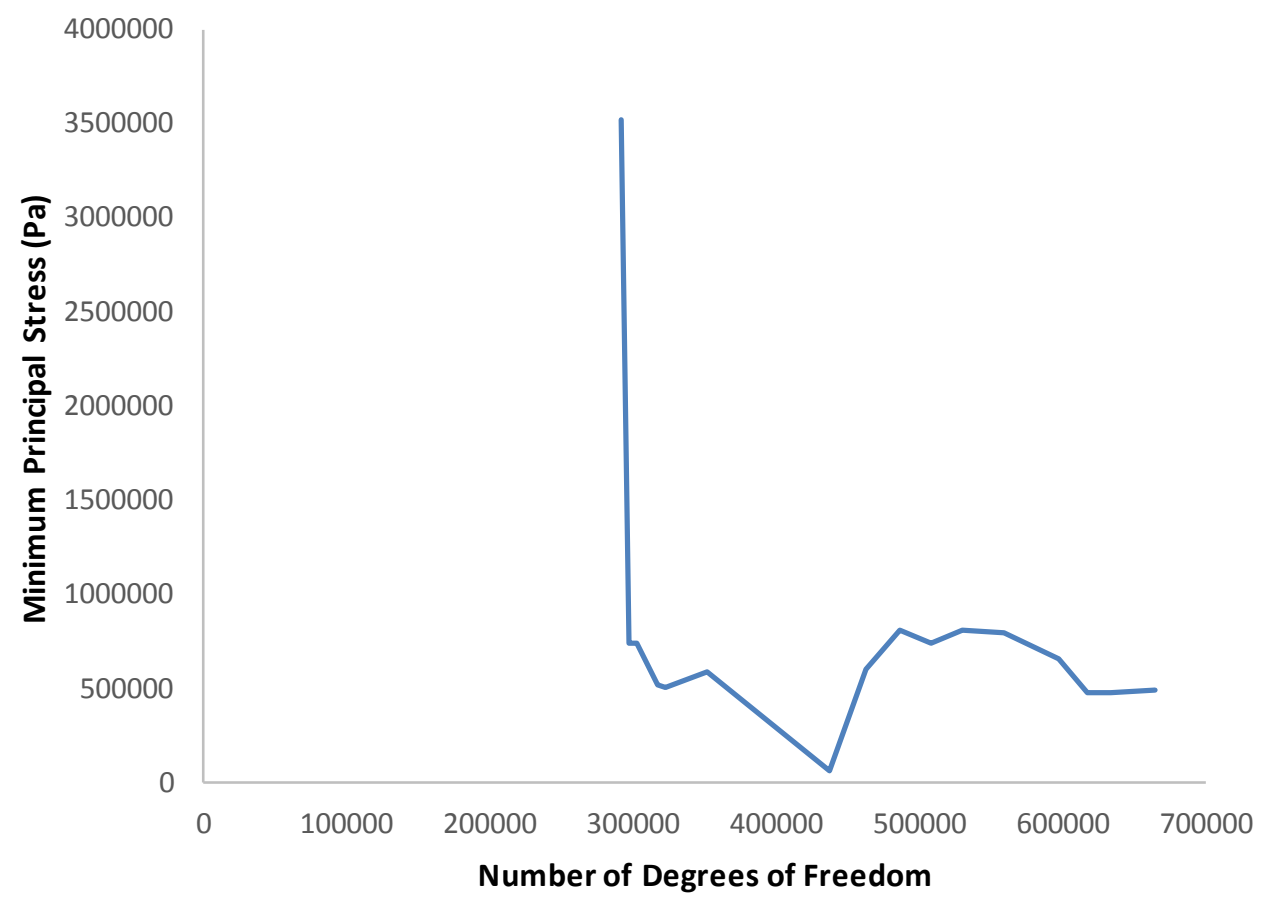

Figure 25 - Convergence study for determining the required global seed size for optimal results. It was found that a $2.5 \mathrm{~mm}$ seed size would yield results which accurately reflected the true model. As can be seen, results obtained under 300,000 degrees of freedom produced results with significant error.

\subsubsection{Application of Elemental Sets}

Elemental sets were formed using partitioning, where $2.5 \mathrm{~mm}$ thick disks were formed at depths of interest. All set depths were measured relative to the resurfaced tibial surface. Six elemental sets were established for each modeled assembly. These sets include depths of 0 , 20, 40, 60, 80 and $100 \mathrm{~mm}$ below the resurfaced tibial surface. An example of a TKR assembly with the highlighted depths can be seen below in Figure 26. 


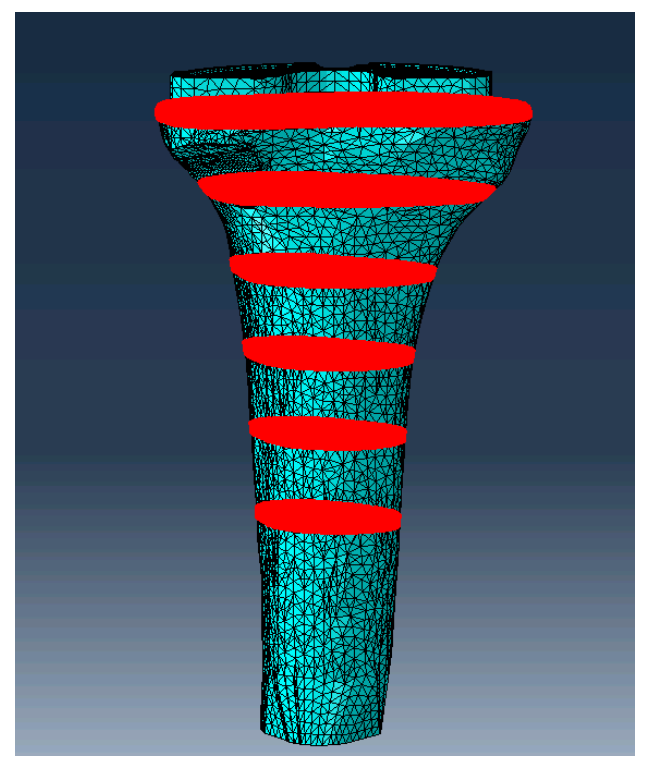

Figure 18 - A TKR assembly model within Abaqus displaying the elemental disc sections utilized for stress shielding analysis.

After forming sets for each depth, each set was divided into a posterior and medial region. To do so, a top view which allowed for elements to be selected throughout the entire depth was used. An example of both the medial region and posterior region are shown in Figure 27 and Figure 28 . 


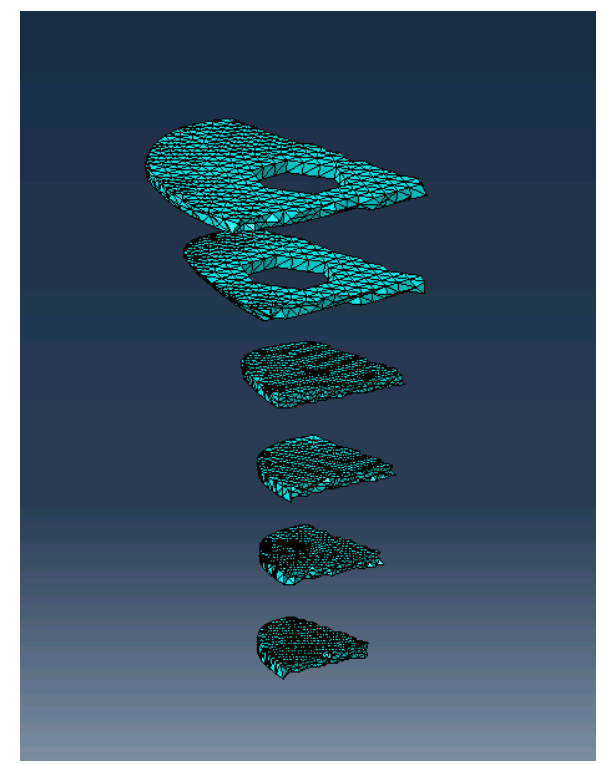

Figure 19 - Medial regions used for stress shielding analysis include depths from 0 (top) to $100 \mathrm{~mm}$ (bottom).

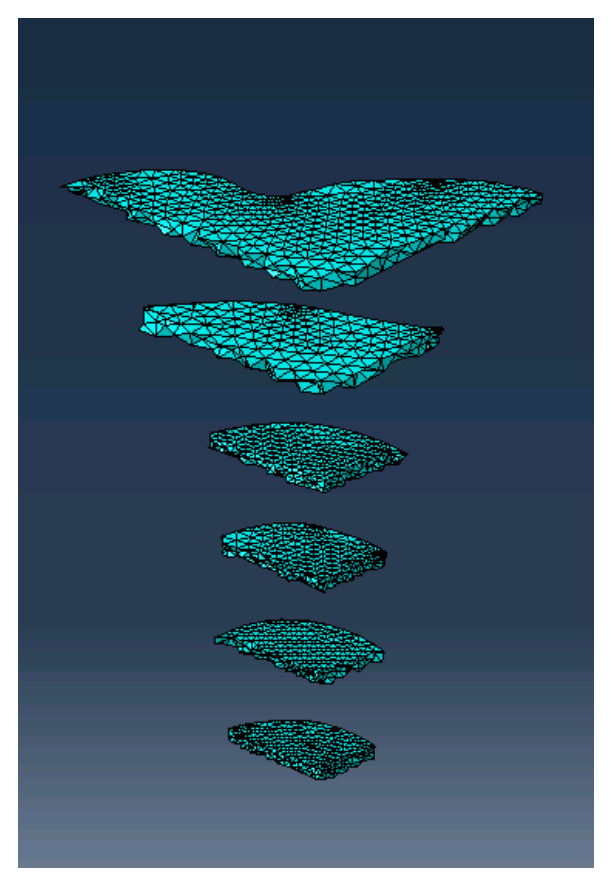

Figure 20 - Posterior regions used for stress shielding analysis include depths from 0 (top) to $100 \mathrm{~mm}$ (bottom) 


\section{Chapter 4: Simulation Results}

This chapter includes the results obtained using the finite element analysis through Abaqus. Before progressing through all simulations, the standard intact tibia was validated against an in vivo tibia strain gauge study. This particular validation will be examined later within this chapter. The overall process of how results were obtained will be examined, as several different outputs of importance were obtained through Abaqus. Static simulation results will be compared for all studied models and model sizes, in order to determine an overall trend of how geometry type and size affects the desired output results and relevant performance. A comparison of the results obtained in this study with published results from similar types of research will be examined in detail. The possible reasons for discrepancies will be investigated and it will be determined if these differences affect the models studied within this report. Conclusions regarding geometries and their sizes will be drawn in the Chapter 5, which will be based on results presented within this chapter.

\subsection{Stress Shielding Results}

In this section, stress shielding results are outlined. The minimum principal stress were examined in all regions of interest and used for stress shielding percentage calculation. The equation used to calculate stress shielding percentage is given by Equation 1. This equation is an equation which was used in a study previously outlined, published by Completo A, Talaia P, Fonseca F, and Simões JA [23]. Using this equation allows for negative values of stress shielding percentage represent stress shielding, while positive stress shielding percentage represents a tibia experiencing a higher amount of compressive stress than a typical in vivo tibia.

\section{(1) $\frac{\text { TKR tibia stress-intact tibia stress }}{\text { intact tibia stress }} X 100 \%=$ stress shielding percentage}

Minimum principal stress at the centroid of each element was the output of interest due to bone primarily seeing compression loading during analysis. The regions of interest included the medial and posterior regions, as these sections were in the highest state of stress. This was determined by observing the Von Mises stress at all regions. It was found that during bending, the medial region experienced the largest magnitude of tensile forces, however, was 
still on average in a state of compression. This will later be shown within this chapter to be true visually, as well as numerically. The posterior was in a net state of increasing compression during bending. The bend of the tibia can be imagined, as it is bending in a state of tension in the medial region, while in compression in the posterior region. As previously stated, this will be visually shown later in this chapter. Because of these reasons, only the posterior and medial regions were examined in this study. To determine the average centroidal minimum principal stress of each region, element centroidal minimum principal stress was averaged across all elements in each region of interest.

\subsubsection{Stress Shielding Results - Stem Type Geometry}

Stress shielding results for the stem type geometry are presented in this section. Tabulated results for the $12 \mathrm{~mm}$ diameter stem model are presented in Table 4. In addition, a plot of the tabulated data is shown in Figure $\mathbf{2 9}$ for the posterior region, and Figure $\mathbf{3 0}$ for the medial region. 
Table 4 - Stress shielding results for $12 \mathrm{~mm}$ stem type geometry for the medial and posterior region. Note that a negative stress shielding percentage indicates stress shielding.

\begin{tabular}{|c|c|c|c|c|c|c|c|}
\hline \multicolumn{8}{|c|}{12 mm Stem Type Geometry - Medial Region } \\
\hline \multirow[b]{2}{*}{$\begin{array}{l}\text { Depth } \\
(\mathrm{mm})\end{array}$} & Model: & \multicolumn{2}{|c|}{ Model: 12X25 } & \multicolumn{2}{|c|}{ Model: 12X50 } & \multicolumn{2}{|c|}{ Model: 12X75 } \\
\hline & $\begin{array}{c}\text { Avg. } \\
\text { Minimum } \\
\text { Principal } \\
\text { S tress (Pa) }\end{array}$ & $\begin{array}{c}\text { Avg. } \\
\text { Minimum } \\
\text { Principal } \\
\text { Stress (Pa) }\end{array}$ & $\begin{array}{c}\text { Stress } \\
\text { Shielding } \\
\text { Percentag } \\
\text { e }\end{array}$ & $\begin{array}{c}\text { Avg. } \\
\text { Minimum } \\
\text { Principal } \\
\text { Stress (Pa) }\end{array}$ & $\begin{array}{c}\text { Stress } \\
\text { Shielding } \\
\text { Percentage }\end{array}$ & $\begin{array}{c}\text { Avg. } \\
\text { Minimum } \\
\text { Principal } \\
\text { Stress (Pa) }\end{array}$ & $\begin{array}{c}\text { Stress } \\
\text { Shielding } \\
\text { Percentage }\end{array}$ \\
\hline $\mathbf{0}$ & $-1.8682 \mathrm{E}+06$ & $-1.1608 \mathrm{E}+06$ & $-37.86 \%$ & $-1.2900 \mathrm{E}+06$ & $-30.95 \%$ & $-1.25365 \mathrm{E}+06$ & $-32.89 \%$ \\
\hline 20 & $-1.6307 \mathrm{E}+06$ & $-1.7269 \mathrm{E}+06$ & $5.89 \%$ & $-1.3688 \mathrm{E}+06$ & $-16.06 \%$ & $-1.29541 \mathrm{E}+06$ & $-20.56 \%$ \\
\hline 40 & $-2.9992 \mathrm{E}+06$ & $-5.6425 \mathrm{E}+06$ & $88.13 \%$ & $-2.6627 \mathrm{E}+06$ & $-11.22 \%$ & $-2.26604 \mathrm{E}+06$ & $-24.45 \%$ \\
\hline 60 & $-3.9024 \mathrm{E}+06$ & $-5.6425 \mathrm{E}+06$ & $44.59 \%$ & $-3.5024 \mathrm{E}+06$ & $-10.25 \%$ & $-3.30366 \mathrm{E}+06$ & $-15.34 \%$ \\
\hline 80 & $-4.7893 \mathrm{E}+06$ & $-2.1432 \mathrm{E}+07$ & $347.50 \%$ & $-4.2603 \mathrm{E}+06$ & $-11.05 \%$ & $-4.06692 \mathrm{E}+06$ & $-15.08 \%$ \\
\hline 100 & $-5.2837 \mathrm{E}+06$ & $-3.2849 \mathrm{E}+07$ & $521.71 \%$ & $-4.5587 \mathrm{E}+06$ & $-13.72 \%$ & $-4.81473 \mathrm{E}+06$ & $-8.88 \%$ \\
\hline \multicolumn{8}{|c|}{12 mm Stem Type Geometry - Posterior Region } \\
\hline \multirow[b]{2}{*}{$\begin{array}{l}\text { Depth } \\
(\mathrm{mm})\end{array}$} & $\begin{array}{c}\text { Model: } \\
\text { Intact }\end{array}$ & \multicolumn{2}{|c|}{ Model: 12X25 } & \multicolumn{2}{|c|}{ Model: 12X50 } & \multicolumn{2}{|c|}{ Model: $12 X 75$} \\
\hline & $\begin{array}{c}\text { Avg. } \\
\text { Minimum } \\
\text { Principal } \\
\text { Stress (Pa) }\end{array}$ & $\begin{array}{c}\text { Avg. } \\
\text { Minimum } \\
\text { Principal } \\
\text { Stress (Pa) }\end{array}$ & $\begin{array}{c}\text { Stress } \\
\text { Shielding } \\
\text { Percentag } \\
\text { e }\end{array}$ & $\begin{array}{c}\text { Avg. } \\
\text { Minimum } \\
\text { Principal } \\
\text { Stress (Pa) }\end{array}$ & $\begin{array}{c}\text { Stress } \\
\text { Shielding } \\
\text { Percentage }\end{array}$ & $\begin{array}{c}\text { Avg. } \\
\text { Minimum } \\
\text { Principal } \\
\text { Stress (Pa) }\end{array}$ & $\begin{array}{c}\text { Stress } \\
\text { Shielding } \\
\text { Percentage }\end{array}$ \\
\hline $\mathbf{0}$ & $-3.4261 \mathrm{E}+05$ & $-5.2701 \mathrm{E}+05$ & $53.82 \%$ & $-2.7178 \mathrm{E}+05$ & $-20.67 \%$ & $-3.19198 \mathrm{E}+05$ & $-6.83 \%$ \\
\hline 20 & $-2.0721 \mathrm{E}+06$ & $-2.1487 \mathrm{E}+05$ & $-89.63 \%$ & $-1.8085 \mathrm{E}+06$ & $-12.72 \%$ & $-1.78292 \mathrm{E}+06$ & $-13.96 \%$ \\
\hline 40 & $-4.0364 \mathrm{E}+06$ & $-4.0668 \mathrm{E}+05$ & $-89.92 \%$ & $-4.2586 \mathrm{E}+06$ & $5.50 \%$ & $-3.85257 \mathrm{E}+06$ & $-4.56 \%$ \\
\hline 60 & $-4.9410 \mathrm{E}+06$ & $-7.2318 \mathrm{E}+05$ & $-85.36 \%$ & $-4.9202 \mathrm{E}+06$ & $-0.42 \%$ & $-4.92521 \mathrm{E}+06$ & $-0.32 \%$ \\
\hline 80 & $-5.5620 \mathrm{E}+06$ & $-1.1493 \mathrm{E}+06$ & $-79.34 \%$ & $-5.6961 \mathrm{E}+06$ & $2.41 \%$ & $-5.41351 \mathrm{E}+06$ & $-2.67 \%$ \\
\hline 100 & $-6.4044 \mathrm{E}+06$ & $-8.7027 \mathrm{E}+05$ & $-86.41 \%$ & $-6.7568 \mathrm{E}+06$ & $5.50 \%$ & $-6.07400 \mathrm{E}+06$ & $-5.16 \%$ \\
\hline
\end{tabular}




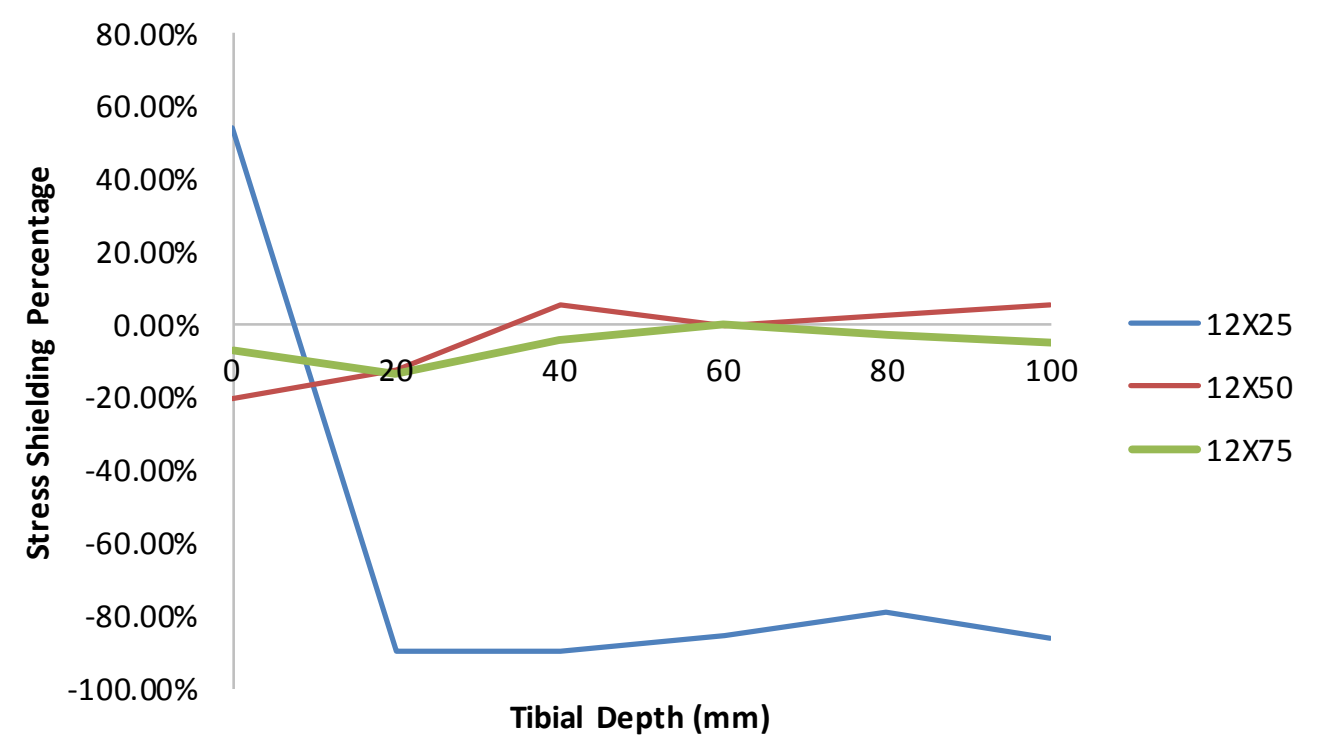

Figure 21 - Stress shielding percentage as a function of tibial depth in the posterior region for a $12 \mathrm{~mm}$ diameter stem type geometry model. Stress shielding is signified by a negative stress shielding percentage. Note the significant increase in stress shielding after the LTR region for the $12 \mathrm{X} 25$ model.

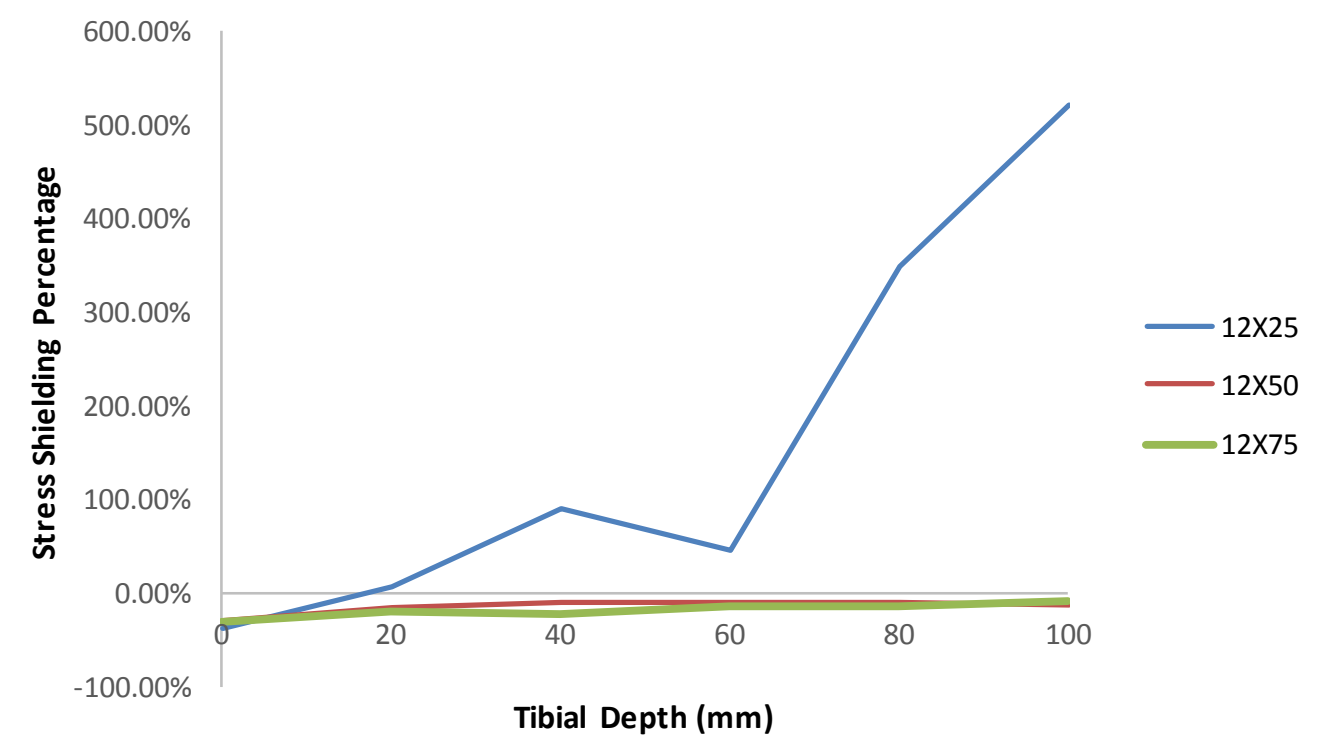

Figure 22 - Stress shielding percentage as a function of tibial depth in the medial region for a $12 \mathrm{~mm}$ diameter stem type geometry model. Stress shielding is signified by a negative stress shielding percentage. 
Tabulated results for the $15 \mathrm{~mm}$ diameter stem type model can be seen below in Table 5. In addition, plots of stress shielding as a function of depth can be seen below in Figure $\mathbf{3 1}$ for the posterior region and Figure $\mathbf{3 2}$ for the medial region.

Table 5 - Stress Shielding Results for $15 \mathrm{~mm}$ stem type geometry for the medial and posterior region. Note that a negative stress shielding percentage indicates stress shielding.

\begin{tabular}{|c|c|c|c|c|c|c|c|}
\hline \multicolumn{8}{|c|}{ Large Stem Type Geometry - Medial Region } \\
\hline \multirow[b]{2}{*}{$\begin{array}{l}\text { Depth } \\
(\mathrm{mm})\end{array}$} & Model: Intact & \multicolumn{2}{|c|}{ Model: $15 X 25$} & \multicolumn{2}{|c|}{ Model: $15 X 50$} & \multicolumn{2}{|c|}{ Model: $15 \times 75$} \\
\hline & $\begin{array}{c}\text { Avg. } \\
\text { Minimum } \\
\text { Principal } \\
\text { Stress }(\mathrm{Pa})\end{array}$ & $\begin{array}{c}\text { Avg. } \\
\text { Minimum } \\
\text { Principal } \\
\text { Stress }(\mathrm{Pa})\end{array}$ & $\begin{array}{c}\text { Stress } \\
\text { Shielding } \\
\text { Percentage }\end{array}$ & $\begin{array}{c}\text { Avg. } \\
\text { Minimum } \\
\text { Principal } \\
\text { Stress }(\mathrm{Pa})\end{array}$ & $\begin{array}{c}\text { Stress } \\
\text { Shielding } \\
\text { Percentage }\end{array}$ & $\begin{array}{c}\text { Avg. } \\
\text { Minimum } \\
\text { Principal } \\
\text { Stress }(\mathrm{Pa})\end{array}$ & $\begin{array}{c}\text { Stress } \\
\text { Shielding } \\
\text { Percentage }\end{array}$ \\
\hline 0 & $-1.8682 \mathrm{E}+06$ & $-1.2103 \mathrm{E}+06$ & $-35.21 \%$ & $-1.1552 \mathrm{E}+06$ & $-38.16 \%$ & $-1.20640 \mathrm{E}+06$ & $-35.42 \%$ \\
\hline 20 & $-1.6307 \mathrm{E}+06$ & $-1.5094 \mathrm{E}+06$ & $-7.44 \%$ & $-1.3907 \mathrm{E}+06$ & $-14.72 \%$ & $-1.26069 \mathrm{E}+06$ & $-22.69 \%$ \\
\hline 40 & $-2.9992 \mathrm{E}+06$ & $-2.9049 \mathrm{E}+06$ & $-3.14 \%$ & $-2.8268 \mathrm{E}+06$ & $-5.75 \%$ & $-2.23810 \mathrm{E}+06$ & $-25.38 \%$ \\
\hline 60 & $-3.9024 \mathrm{E}+06$ & $-4.0688 \mathrm{E}+06$ & $4.26 \%$ & $-3.5807 \mathrm{E}+06$ & $-8.24 \%$ & $-3.36793 \mathrm{E}+06$ & $-13.70 \%$ \\
\hline 80 & $-4.7893 \mathrm{E}+06$ & $-4.9168 \mathrm{E}+06$ & $2.66 \%$ & $-4.1924 \mathrm{E}+06$ & $-12.46 \%$ & $-3.96818 \mathrm{E}+06$ & $-17.15 \%$ \\
\hline 100 & $-5.2837 \mathrm{E}+06$ & $-5.3706 \mathrm{E}+06$ & $1.65 \%$ & $-4.9010 \mathrm{E}+06$ & $-7.24 \%$ & $-4.65490 \mathrm{E}+06$ & $-11.90 \%$ \\
\hline \multicolumn{8}{|c|}{ Large Stem Type Geometry - Posterior } \\
\hline \multirow[b]{2}{*}{$\begin{array}{l}\text { Depth } \\
(\mathrm{mm})\end{array}$} & Model: Intact & \multicolumn{2}{|c|}{ Model: $15 \times 25$} & \multicolumn{2}{|c|}{ Model: $15 X 50$} & \multicolumn{2}{|c|}{ Model: $15 X 75$} \\
\hline & $\begin{array}{c}\text { Avg. } \\
\text { Minimum } \\
\text { Principal } \\
\text { Stress }(\mathrm{Pa})\end{array}$ & $\begin{array}{c}\text { Avg. } \\
\text { Minimum } \\
\text { Principal } \\
\text { Stress }(\mathrm{Pa})\end{array}$ & $\begin{array}{c}\text { Stress } \\
\text { Shielding } \\
\text { Percentage }\end{array}$ & $\begin{array}{c}\text { Avg. } \\
\text { Minimum } \\
\text { Principal } \\
\text { Stress }(\mathrm{Pa})\end{array}$ & $\begin{array}{c}\text { Stress } \\
\text { Shielding } \\
\text { Percentage }\end{array}$ & $\begin{array}{c}\text { Avg. } \\
\text { Minimum } \\
\text { Principal } \\
\text { Stress }(\mathrm{Pa})\end{array}$ & $\begin{array}{c}\text { Stress } \\
\text { Shielding } \\
\text { Percentage }\end{array}$ \\
\hline 0 & $-3.4261 \mathrm{E}+05$ & $-3.1920 \mathrm{E}+05$ & $-6.83 \%$ & $-3.5512 \mathrm{E}+05$ & $3.65 \%$ & $-3.21232 \mathrm{E}+05$ & $-6.24 \%$ \\
\hline 20 & $-2.0721 \mathrm{E}+06$ & $-2.0757 \mathrm{E}+06$ & $0.17 \%$ & $-1.9170 \mathrm{E}+06$ & $-7.49 \%$ & $-1.80065 \mathrm{E}+06$ & $-13.10 \%$ \\
\hline 40 & $-4.0364 \mathrm{E}+06$ & $-3.8684 \mathrm{E}+06$ & $-4.16 \%$ & $-4.3413 \mathrm{E}+06$ & $7.55 \%$ & $-3.92517 \mathrm{E}+06$ & $-2.76 \%$ \\
\hline 60 & $-4.9410 \mathrm{E}+06$ & $-4.7530 \mathrm{E}+06$ & $-3.80 \%$ & $-4.7964 \mathrm{E}+06$ & $-2.93 \%$ & $-5.07514 \mathrm{E}+06$ & $2.72 \%$ \\
\hline 80 & $-5.5620 \mathrm{E}+06$ & $-5.4018 \mathrm{E}+06$ & $-2.88 \%$ & $-5.6518 \mathrm{E}+06$ & $1.62 \%$ & $-5.43701 \mathrm{E}+06$ & $-2.25 \%$ \\
\hline 100 & $-6.4044 \mathrm{E}+06$ & $-6.1048 \mathrm{E}+06$ & $-4.68 \%$ & $-6.3819 \mathrm{E}+06$ & $-0.35 \%$ & $-6.19548 \mathrm{E}+06$ & $-3.26 \%$ \\
\hline
\end{tabular}




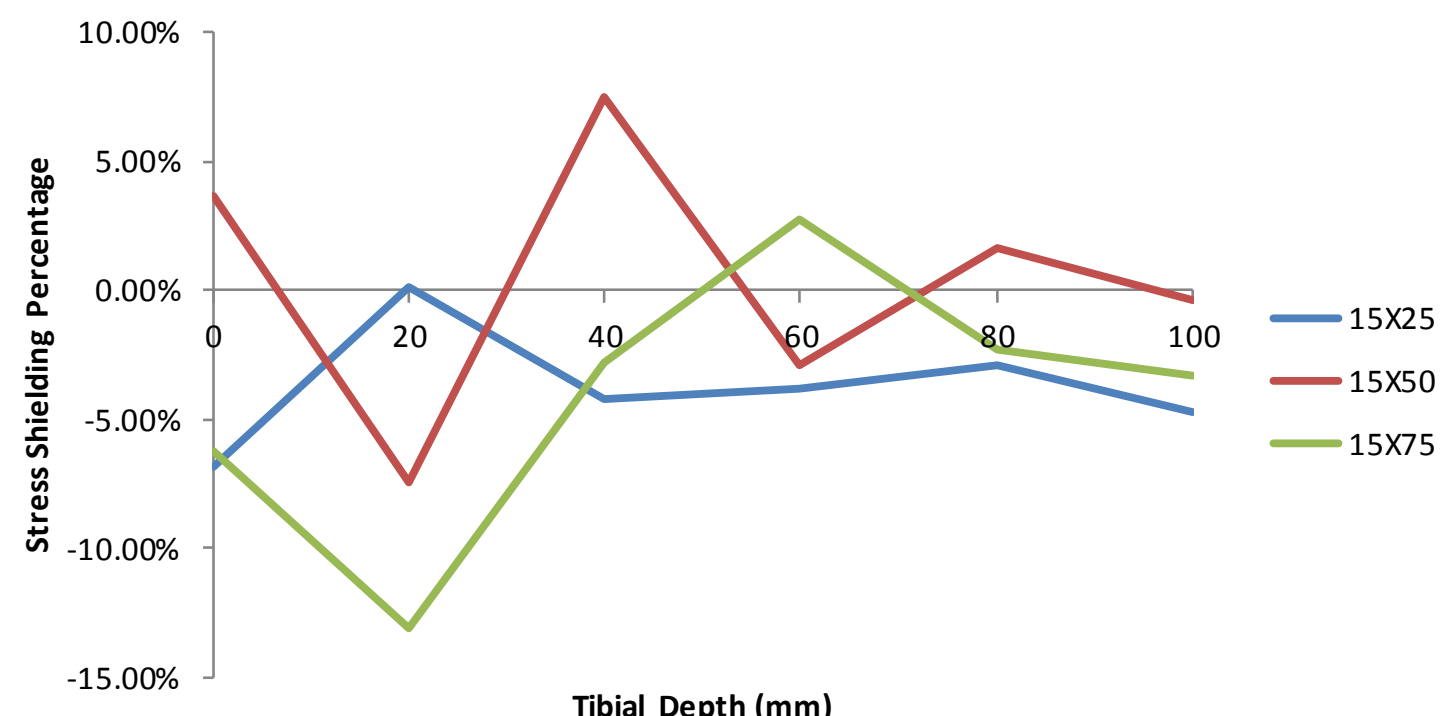

Figure 31 - Stress shielding percentage as a function of tibial depth in the posterior region for a $15 \mathrm{~mm}$ diameter stem type geometry model. Stress shielding is signified by a negative stress shielding percentage.

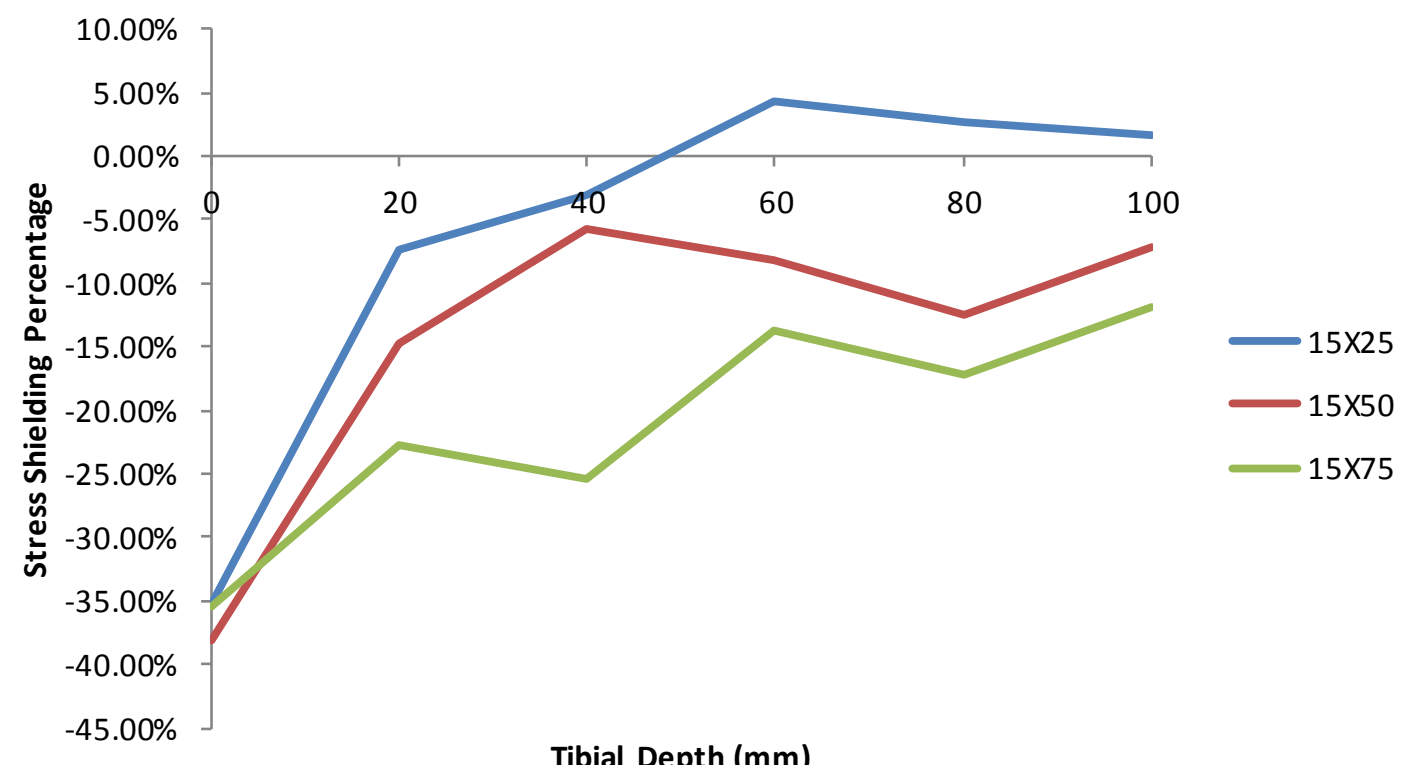

Figure 23 - Stress shielding percentage as a function of tibial depth in the medial region for a $15 \mathrm{~mm}$ diameter stem type geometry model. Stress shielding is signified by a negative stress shielding percentage. 
In order to compare the effects of diameter, all models were plotted against each other for a given length at each diameter. All of these plots can be seen in Appendix A. In addition, all models were plotted on the same graph, in order to see trends in how length and diameter affect stress shielding overall. This can be seen below in Figure $\mathbf{3 3}$ for the posterior region and Figure 34 for the medial region.

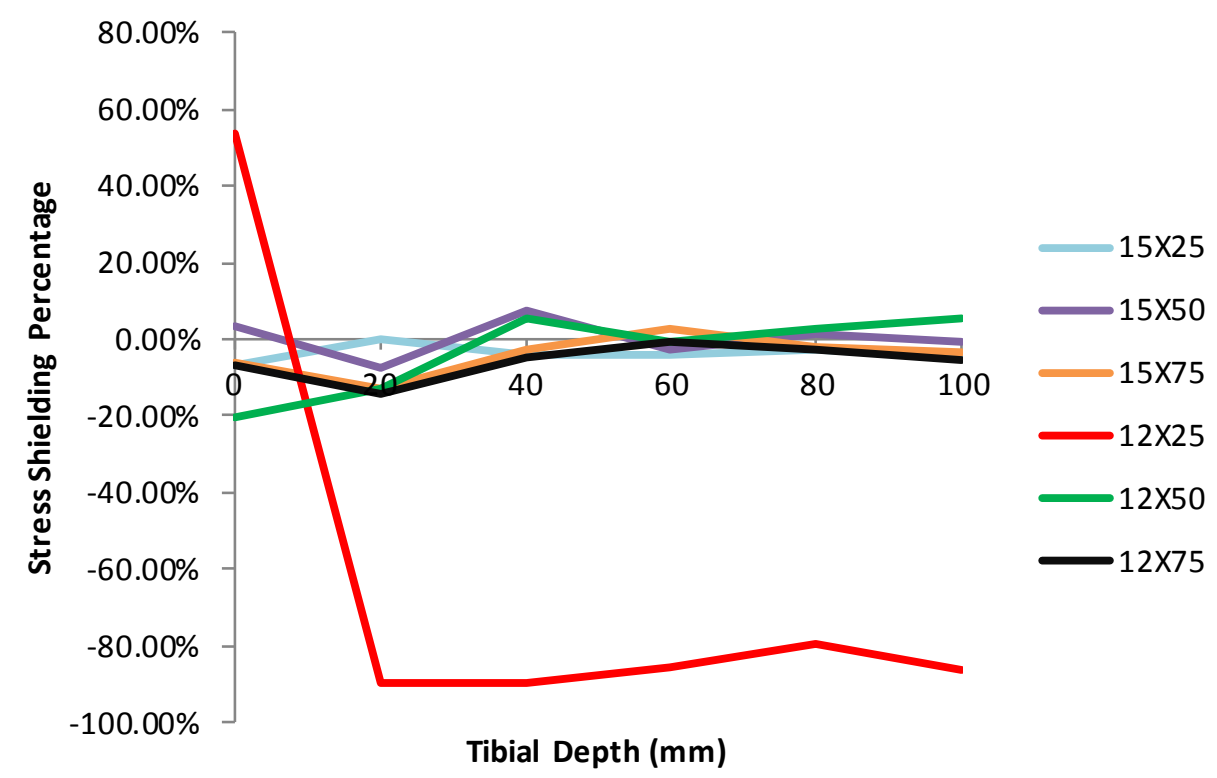

Figure 24 - Stress shielding percentage as a function of tibial depth in the posterior region for all stem type geometry models studied. Note that plots of individual length comparisons can be seen in Appendix A. 


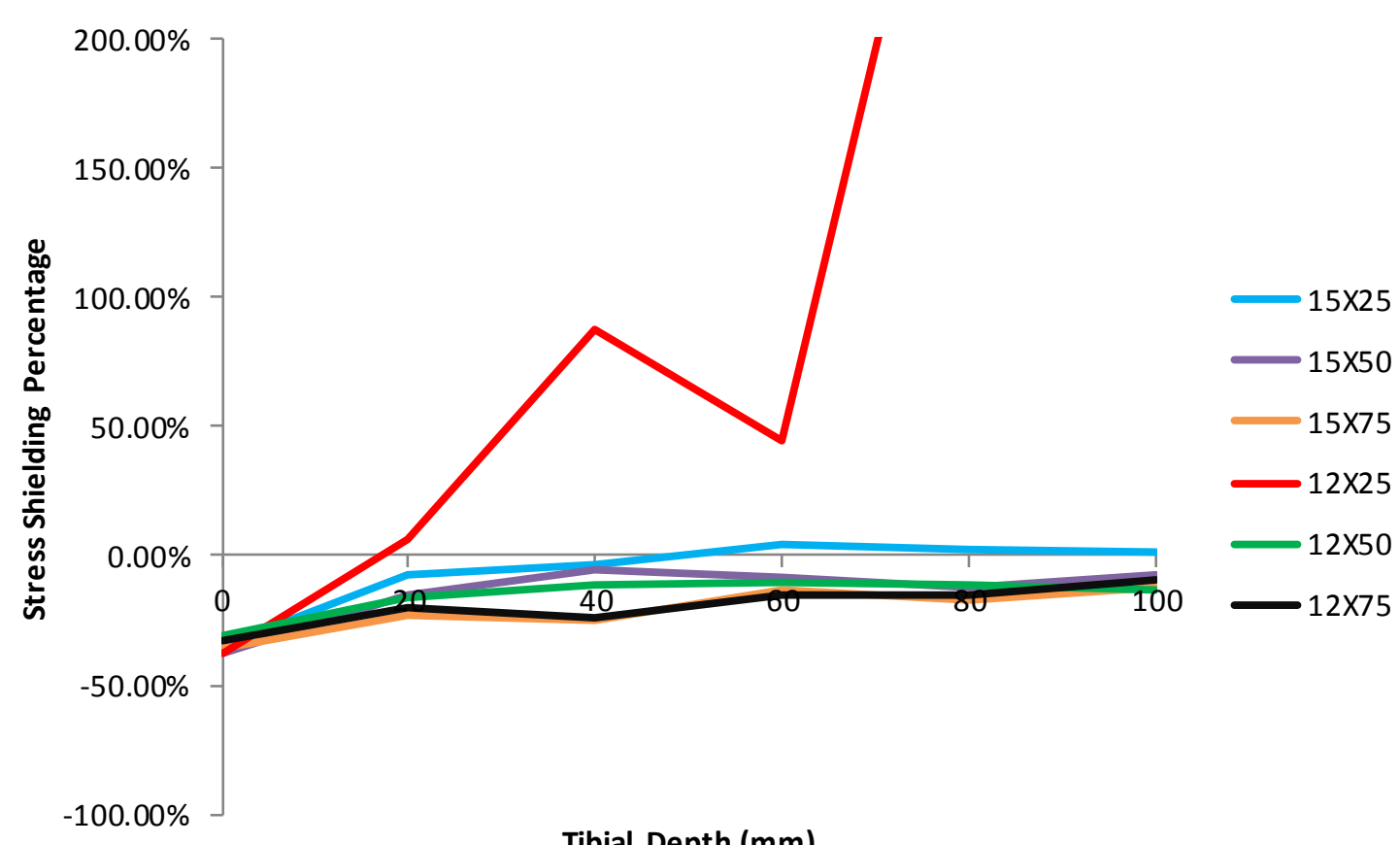

Tibial Depth $(\mathrm{mm})$

Figure 25 - Stress shielding percentage as a function of tibial depth in the medial region for all stem type geometry models studied. Note that plots of individual length comparisons can be seen in Appendix A.

\subsubsection{Stress Shielding Results - Peg Type Geometry}

In this section, all simulation results regarding the peg type geometry models are presented. Stress shielding as a function of tibial depth for the posterior and medial are shown in Figure 35 and Figure 36. In addition, tabulated data for all peg type geometry model data are illustrated in Table 6. 
Table 6 - Stress shielding results for $12 \mathrm{~mm}$ peg type geometry for the medial and posterior region. Note that a negative stress shielding percentage indicates stress shielding.

\begin{tabular}{|c|c|c|c|c|c|c|c|}
\hline \multicolumn{8}{|c|}{ Small Peg Type Geometry - Medial Region } \\
\hline \multirow[b]{2}{*}{$\begin{array}{l}\text { Depth } \\
(\mathrm{mm})\end{array}$} & Model: & \multicolumn{2}{|c|}{ Model: $12 X 12$} & \multicolumn{2}{|c|}{ Model: 12X18 } & \multicolumn{2}{|c|}{ Model: $12 X 24$} \\
\hline & $\begin{array}{c}\text { Avg. } \\
\text { Minimum } \\
\text { Principal } \\
\text { Stress }(\mathrm{Pa})\end{array}$ & $\begin{array}{c}\text { Avg. } \\
\text { Minimum } \\
\text { Principal } \\
\text { Stress }(\mathrm{Pa})\end{array}$ & $\begin{array}{c}\text { Stress } \\
\text { Shielding } \\
\text { Percentage }\end{array}$ & $\begin{array}{c}\text { Avg. } \\
\text { Minimum } \\
\text { Principal } \\
\text { Stress }(\mathrm{Pa})\end{array}$ & $\begin{array}{c}\text { Stress } \\
\text { Shielding } \\
\text { Percentage }\end{array}$ & $\begin{array}{c}\text { Avg. } \\
\text { Minimum } \\
\text { Principal } \\
\text { Stress }(\mathrm{Pa})\end{array}$ & $\begin{array}{c}\text { Stress } \\
\text { Shielding } \\
\text { Percentage }\end{array}$ \\
\hline 0 & $-1.8682 \mathrm{E}+06$ & $-1.1267 \mathrm{E}+06$ & $-39.69 \%$ & $-1.0538 \mathrm{E}+06$ & $-43.59 \%$ & $-1.1227 \mathrm{E}+06$ & $-39.90 \%$ \\
\hline 20 & $-1.6307 \mathrm{E}+06$ & $-1.5188 \mathrm{E}+06$ & $-6.87 \%$ & $-1.5902 \mathrm{E}+06$ & $-2.49 \%$ & $-1.8001 \mathrm{E}+06$ & $10.39 \%$ \\
\hline 40 & $-2.9992 \mathrm{E}+06$ & $-2.9723 \mathrm{E}+06$ & $-0.90 \%$ & $-3.2948 \mathrm{E}+06$ & $9.86 \%$ & $-2.8807 \mathrm{E}+06$ & $-3.95 \%$ \\
\hline 60 & $-3.9024 \mathrm{E}+06$ & $-4.0793 \mathrm{E}+06$ & $4.53 \%$ & $-4.1785 \mathrm{E}+06$ & $7.08 \%$ & $-3.9285 \mathrm{E}+06$ & $0.67 \%$ \\
\hline 80 & $-4.7893 \mathrm{E}+06$ & $-4.9499 \mathrm{E}+06$ & $3.35 \%$ & $-5.0540 \mathrm{E}+06$ & $5.53 \%$ & $-4.7418 \mathrm{E}+06$ & $-0.99 \%$ \\
\hline 100 & $-5.2837 \mathrm{E}+06$ & $-5.9171 \mathrm{E}+06$ & $11.99 \%$ & $-5.7914 \mathrm{E}+06$ & $9.61 \%$ & $-5.6930 \mathrm{E}+06$ & $7.75 \%$ \\
\hline \multicolumn{8}{|c|}{ Small Peg Type Geometry - Posterior Region } \\
\hline \multirow[b]{2}{*}{$\begin{array}{l}\text { Depth } \\
(\mathrm{mm})\end{array}$} & $\begin{array}{c}\text { Model: } \\
\text { Intact }\end{array}$ & \multicolumn{2}{|c|}{ Model: $12 X 12$} & \multicolumn{2}{|c|}{ Model: $12 X 18$} & \multicolumn{2}{|c|}{ Model: $12 X 24$} \\
\hline & $\begin{array}{c}\text { Avg. } \\
\text { Minimum } \\
\text { Principal } \\
\text { Stress }(\mathrm{Pa})\end{array}$ & $\begin{array}{c}\text { Avg. } \\
\text { Minimum } \\
\text { Principal } \\
\text { Stress }(\mathrm{Pa})\end{array}$ & $\begin{array}{c}\text { Stress } \\
\text { Shielding } \\
\text { Percentage }\end{array}$ & $\begin{array}{c}\text { Avg. } \\
\text { Minimum } \\
\text { Principal } \\
\text { Stress }(\mathrm{Pa})\end{array}$ & $\begin{array}{c}\text { Stress } \\
\text { Shielding } \\
\text { Percentage }\end{array}$ & $\begin{array}{c}\text { Avg. } \\
\text { Minimum } \\
\text { Principal } \\
\text { Stress }(\mathrm{Pa})\end{array}$ & $\begin{array}{c}\text { Stress } \\
\text { Shielding } \\
\text { Percentage }\end{array}$ \\
\hline 0 & $-3.4261 \mathrm{E}+05$ & $-2.7845 \mathrm{E}+05$ & $-18.73 \%$ & $-2.9369 \mathrm{E}+05$ & $-14.28 \%$ & $-2.66951 \mathrm{E}+05$ & $-22.08 \%$ \\
\hline 20 & $-2.0721 \mathrm{E}+06$ & $-2.0339 \mathrm{E}+06$ & $-1.84 \%$ & $-2.1300 \mathrm{E}+06$ & $2.80 \%$ & $-2.02276 \mathrm{E}+06$ & $-2.38 \%$ \\
\hline 40 & $-4.0364 \mathrm{E}+06$ & $-4.1364 \mathrm{E}+06$ & $2.48 \%$ & $-4.1515 \mathrm{E}+06$ & $2.85 \%$ & $-4.02156 \mathrm{E}+06$ & $-0.37 \%$ \\
\hline 60 & $-4.9410 \mathrm{E}+06$ & $-5.0549 \mathrm{E}+06$ & $2.30 \%$ & $-5.0079 \mathrm{E}+06$ & $1.35 \%$ & $-5.05968 \mathrm{E}+06$ & $2.40 \%$ \\
\hline 80 & $-5.5620 \mathrm{E}+06$ & $-6.1146 \mathrm{E}+06$ & $9.94 \%$ & $-5.9102 \mathrm{E}+06$ & $6.26 \%$ & $-5.93091 \mathrm{E}+06$ & $6.63 \%$ \\
\hline 100 & $-6.4044 \mathrm{E}+06$ & $-7.0996 \mathrm{E}+06$ & $10.85 \%$ & $-6.8298 \mathrm{E}+06$ & $6.64 \%$ & $-6.78070 \mathrm{E}+06$ & $5.87 \%$ \\
\hline
\end{tabular}




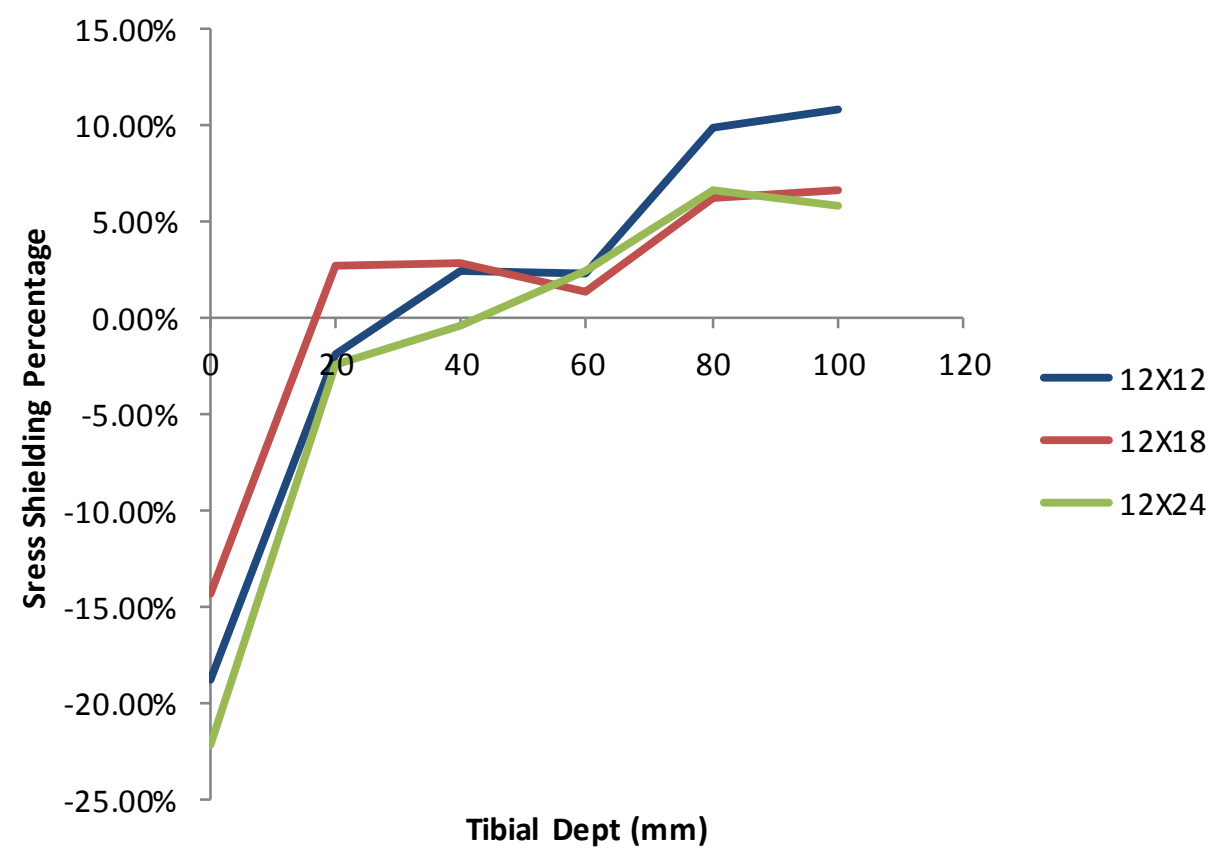

Figure 26 - Stress shielding percentage as a function of tibial depth in the posterior region for a $12 \mathrm{~mm}$ wide peg type geometry model. Stress shielding is signified by a negative stress shielding percentage. 


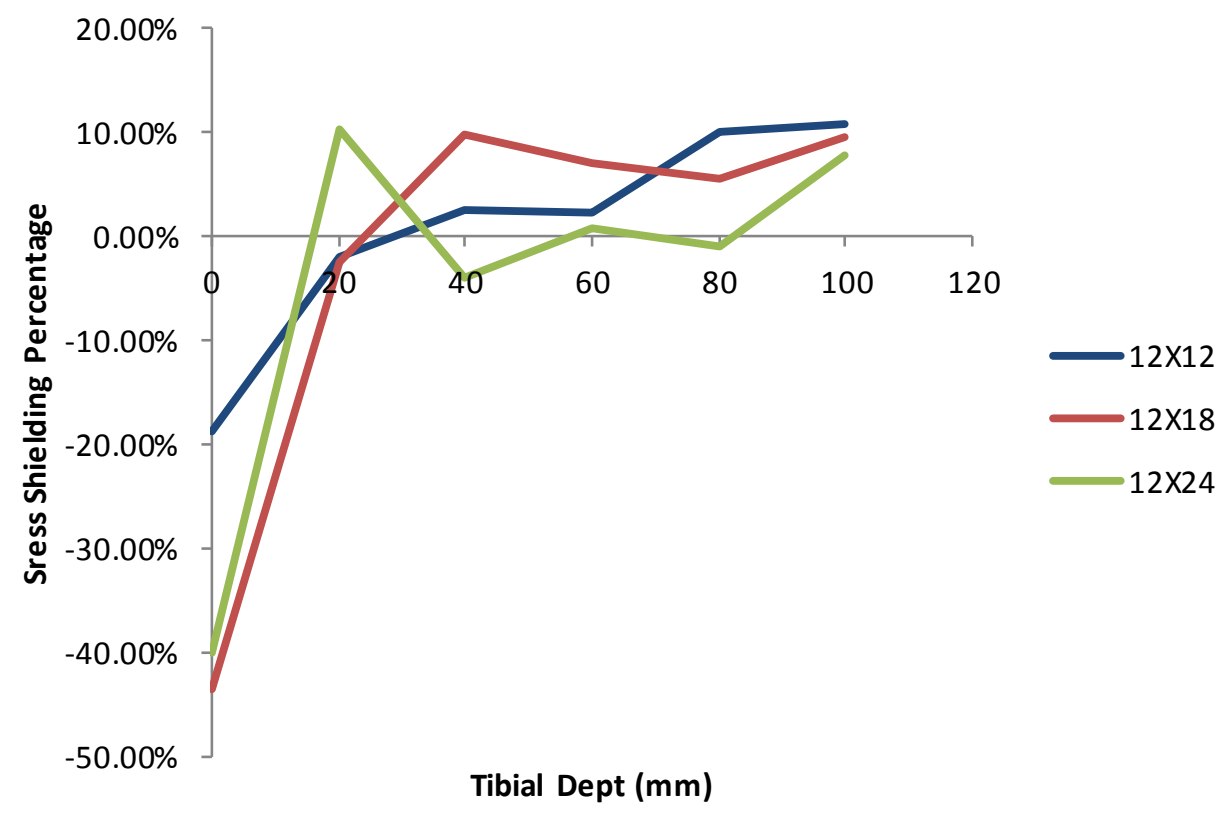

Figure 27 - Stress shielding percentage as a function of tibial depth in the medial region for a $12 \mathrm{~mm}$ wide peg type geometry model. Stress shielding is signified by a negative stress shielding percentage.

In addition, tabulated results for the $16 \mathrm{~mm}$ width peg type model can be seen below in Table 7. 
Table 7 - Stress Shielding Results for $16 \mathrm{~mm}$ peg type geometry for the medial and posterior region. Note that a negative stress shielding percentage indicates stress shielding.

\begin{tabular}{|c|c|c|c|c|c|c|c|}
\hline \multicolumn{8}{|c|}{ Large Peg Type Geometry - Medial Region } \\
\hline \multirow[b]{2}{*}{$\begin{array}{l}\text { Depth } \\
(\mathrm{mm})\end{array}$} & Model: Intact & \multicolumn{2}{|c|}{ Model: 16X12 } & \multicolumn{2}{|c|}{ Model: $16 X 18$} & \multicolumn{2}{|c|}{ Model: 16X24 } \\
\hline & $\begin{array}{c}\text { Avg. } \\
\text { Minimum } \\
\text { Principal } \\
\text { Stress }(\mathrm{Pa})\end{array}$ & $\begin{array}{c}\text { Avg. } \\
\text { Minimum } \\
\text { Principal } \\
\text { Stress }(\mathrm{Pa})\end{array}$ & $\begin{array}{c}\text { Stress } \\
\text { Shielding } \\
\text { Percentage }\end{array}$ & $\begin{array}{c}\text { Avg. } \\
\text { Minimum } \\
\text { Principal } \\
\text { Stress }(\mathrm{Pa})\end{array}$ & $\begin{array}{c}\text { Stress } \\
\text { Shielding } \\
\text { Percentage }\end{array}$ & $\begin{array}{c}\text { Avg. } \\
\text { Minimum } \\
\text { Principal } \\
\text { Stress }(\mathrm{Pa})\end{array}$ & $\begin{array}{c}\text { Stress } \\
\text { Shielding } \\
\text { Percentage }\end{array}$ \\
\hline 0 & $-1.8682 \mathrm{E}+06$ & $-7.2288 \mathrm{E}+05$ & $-61.31 \%$ & $-1.2084 \mathrm{E}+06$ & $-35.32 \%$ & $-1.22030 \mathrm{E}+06$ & $-34.68 \%$ \\
\hline 20 & $-1.6307 \mathrm{E}+06$ & $-1.5207 \mathrm{E}+06$ & $-6.75 \%$ & $-1.4764 \mathrm{E}+06$ & $-9.46 \%$ & $-1.98483 \mathrm{E}+06$ & $21.71 \%$ \\
\hline 40 & $-2.9992 \mathrm{E}+06$ & $-2.8725 \mathrm{E}+06$ & $-4.22 \%$ & $-2.7557 \mathrm{E}+06$ & $-8.12 \%$ & $-2.70397 \mathrm{E}+06$ & $-9.84 \%$ \\
\hline 60 & $-3.9024 \mathrm{E}+06$ & $-3.9059 \mathrm{E}+06$ & $0.09 \%$ & $-3.8403 \mathrm{E}+06$ & $-1.59 \%$ & $-3.82349 \mathrm{E}+06$ & $-2.02 \%$ \\
\hline 80 & $-4.7893 \mathrm{E}+06$ & $-4.5706 \mathrm{E}+06$ & $-4.57 \%$ & $-4.6091 \mathrm{E}+06$ & $-3.76 \%$ & $-4.55226 \mathrm{E}+06$ & $-4.95 \%$ \\
\hline 100 & $-5.2837 \mathrm{E}+06$ & $-5.4563 \mathrm{E}+06$ & $3.27 \%$ & $-5.4577 \mathrm{E}+06$ & $3.29 \%$ & $-5.43621 \mathrm{E}+06$ & $2.89 \%$ \\
\hline \multicolumn{8}{|c|}{ Large Peg Type Geometry - Posterior } \\
\hline \multirow[b]{2}{*}{$\begin{array}{l}\text { Depth } \\
(\mathrm{mm})\end{array}$} & Model: Intact & \multicolumn{2}{|c|}{ Model: $16 X 12$} & \multicolumn{2}{|c|}{ Model: $16 \mathrm{X} 18$} & \multicolumn{2}{|c|}{ Model: $16 X 24$} \\
\hline & $\begin{array}{c}\text { Avg. } \\
\text { Minimum } \\
\text { Principal } \\
\text { Stress }(\mathrm{Pa})\end{array}$ & $\begin{array}{c}\text { Avg. } \\
\text { Minimum } \\
\text { Principal } \\
\text { Stress }(\mathrm{Pa})\end{array}$ & $\begin{array}{c}\text { Stress } \\
\text { Shielding } \\
\text { Percentage }\end{array}$ & $\begin{array}{c}\text { Avg. } \\
\text { Minimum } \\
\text { Principal } \\
\text { Stress }(\mathrm{Pa})\end{array}$ & $\begin{array}{c}\text { Stress } \\
\text { Shielding } \\
\text { Percentage }\end{array}$ & $\begin{array}{c}\text { Avg. } \\
\text { Minimum } \\
\text { Principal } \\
\text { Stress }(\mathrm{Pa})\end{array}$ & $\begin{array}{c}\text { Stress } \\
\text { Shielding } \\
\text { Percentage }\end{array}$ \\
\hline 0 & $-3.4261 \mathrm{E}+05$ & -318505.8708 & $-7.04 \%$ & $-3.8701 \mathrm{E}+05$ & $12.96 \%$ & $-3.90128 \mathrm{E}+05$ & $13.87 \%$ \\
\hline 20 & $-2.0721 \mathrm{E}+06$ & -1961997.567 & $-5.31 \%$ & $-2.1575 \mathrm{E}+06$ & $4.12 \%$ & $-2.29487 \mathrm{E}+06$ & $10.75 \%$ \\
\hline 40 & $-4.0364 \mathrm{E}+06$ & -4078846.949 & $1.05 \%$ & $-3.9972 \mathrm{E}+06$ & $-0.97 \%$ & $-4.10302 \mathrm{E}+06$ & $1.65 \%$ \\
\hline 60 & $-4.9410 \mathrm{E}+06$ & -4886477.097 & $-1.10 \%$ & $-4.9154 \mathrm{E}+06$ & $-0.52 \%$ & $-4.82399 \mathrm{E}+06$ & $-2.37 \%$ \\
\hline 80 & $-5.5620 \mathrm{E}+06$ & -5900706.849 & $6.09 \%$ & $-5.5882 \mathrm{E}+06$ & $0.47 \%$ & $-5.58543 \mathrm{E}+06$ & $0.42 \%$ \\
\hline 100 & $-6.4044 \mathrm{E}+06$ & -6640574.232 & $3.69 \%$ & $-6.3804 \mathrm{E}+06$ & $-0.38 \%$ & $-6.30339 \mathrm{E}+06$ & $-1.58 \%$ \\
\hline
\end{tabular}

The data was then plotted for stress shielding percentage as a function of tibial depth for the $16 \mathrm{~mm}$ wide models. The posterior region and medial region results are presented in Figure 37 and Figure 38 respectively. Lastly, all data found for peg type geometry models are plotted in Figure 39 for the posterior region and Figure $\mathbf{4 0}$ for the medial region. 


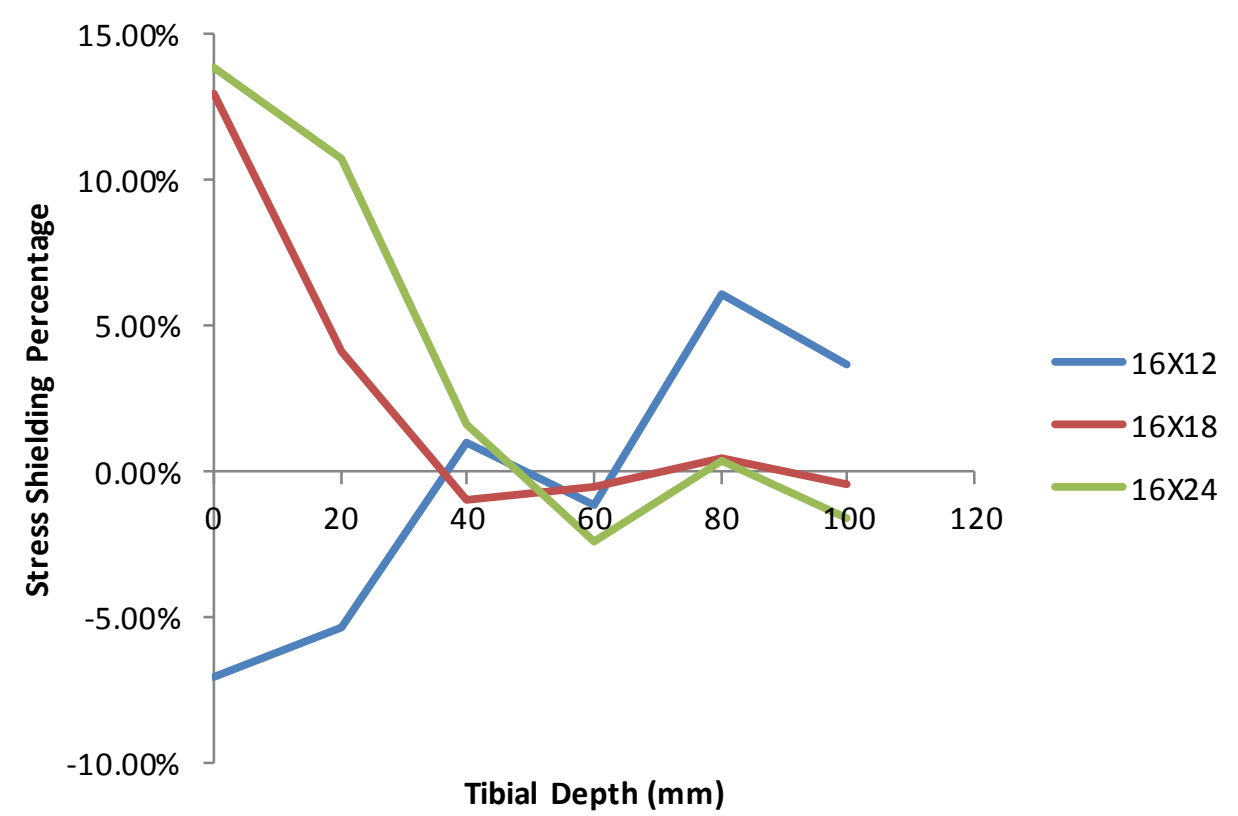

Figure 28 - Stress shielding percentage as a function of tibial depth in the posterior region for a $16 \mathrm{~mm}$ wide peg type geometry model. Stress shielding is signified by a negative stress shielding percentage.

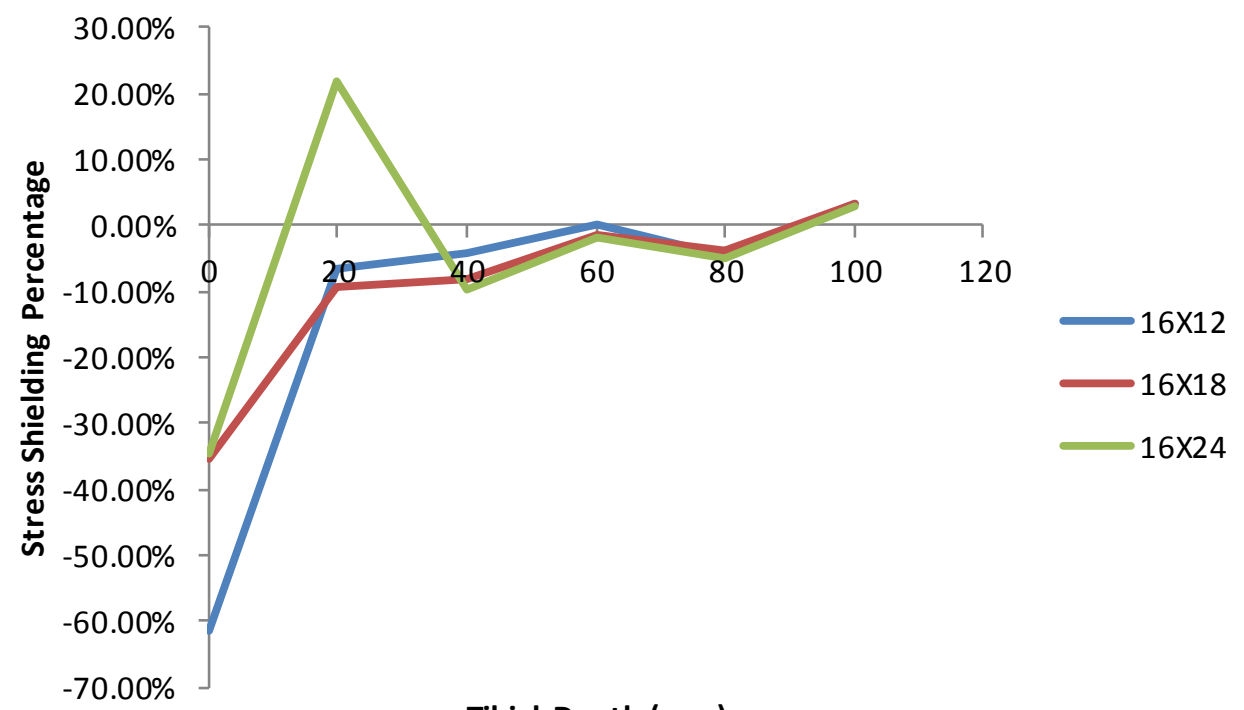

Tibial Depth $(\mathrm{mm})$

Figure 29 - Stress shielding percentage as a function of tibial depth in the medial region for a $16 \mathrm{~mm}$ wide peg type geometry model. Stress shielding is signified by a negative stress shielding percentage. 


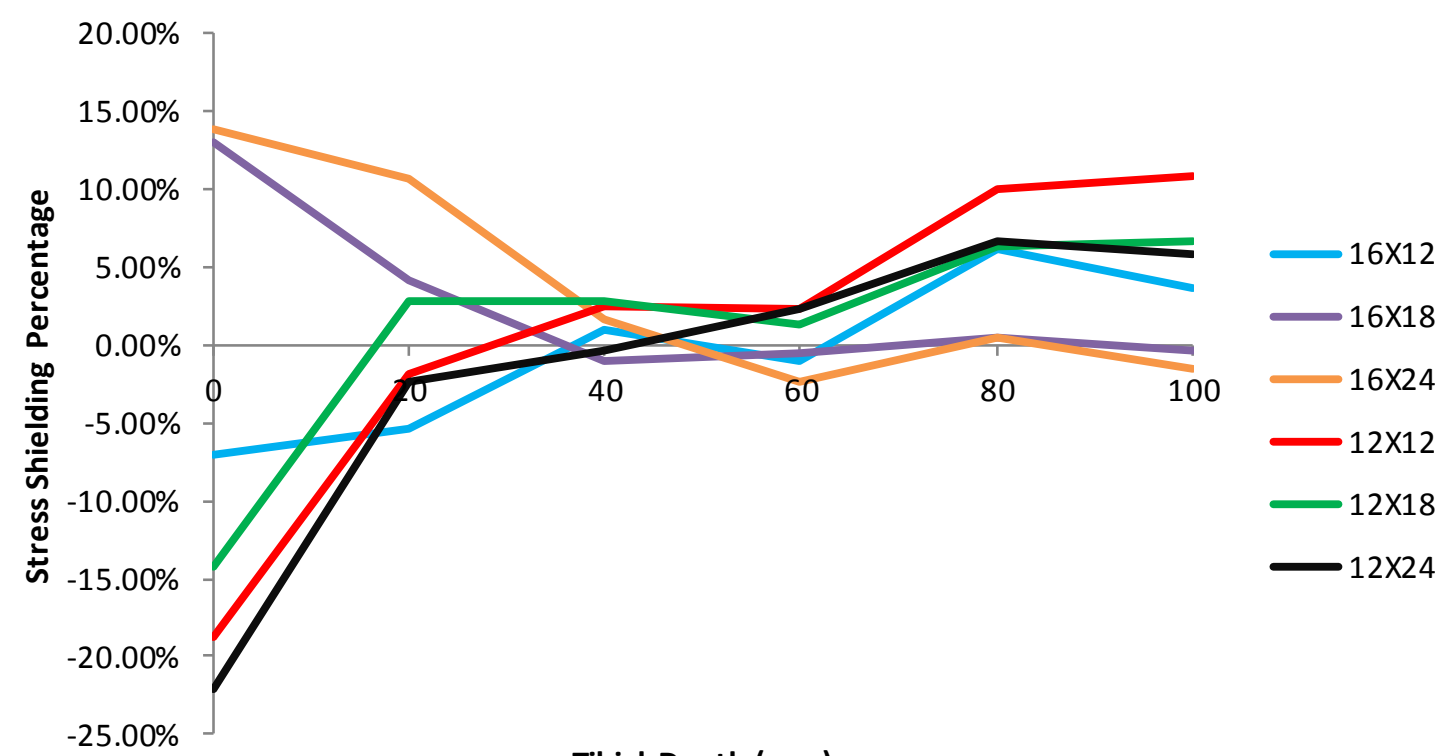

Tibial Depth (mm)

Figure 39 - Stress shielding percentage as a function of tibial depth in the posterior region for all peg type geometry models studied. Note that plots of individual length comparisons can be seen in Appendix A. 


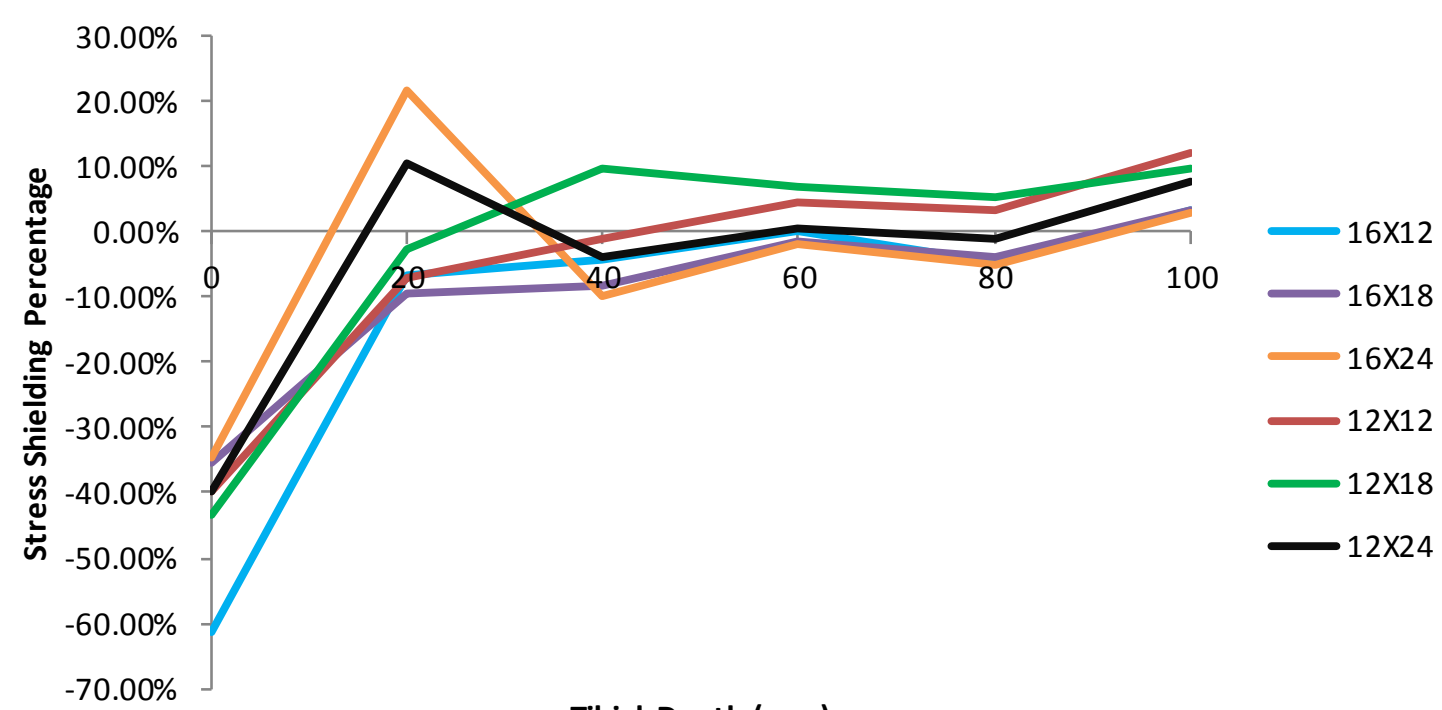

Tibial Depth (mm)

Figure 40 - Stress shielding percentage as a function of tibial depth in the medial region for all peg type geometry models studied. Note that plots of individual length comparisons can be seen in Appendix A.

\subsection{Trends in Stress Shielding Experienced By the Tibia for All TKR Stem Geometries Considered}

Primarily, the first objective was to validate the tibia model within Abaqus for expected strain in the medial region of the mid-diaphysis. Using the material properties and loading conditions outlined, strain was within the targeted range, indicating that the tibia model was approximately behaving as an in vivo tibia should react under loading. From this result, it was concluded that all material properties and loading conditions should remain constant throughout all tests, as the intact tibia validation was successful. Within this section, results will be interpreted and explained.

\subsubsection{Additional Background Information for Data Interpretation}

It should be noted that for the stem type geometry, $12 \mathrm{X} 25$ refers to a $12 \mathrm{~mm}$ diameter stem, with a $25 \mathrm{~mm}$ length; a $12 \mathrm{X} 12$ peg type model refers to $12 \mathrm{~mm}$ wide and $12 \mathrm{~mm}$ long pegs. Also, as previously explained, stress shielding is expressed as a negative stress shielding 
percentage. An increase in the amount of stress shielding refers to a more negative stress shielding percentage, while a decrease in stress shielding percentage refers to a more positive stress shielding percentage. By this definition, a loss in the amount of compression experienced by a given region would be an increase in stress shielding percentage, which is a result of more tension and the elements experiencing a more positive minimum principal stress. Another important characteristic which is a measure of the effectiveness of a stem type is the effect on bending. As stated, during bending the medial region is in a state of tension, while the posterior region is in a state of compression. This means that for an increase in bending, one region will see an increase in stress shielding, while the other region experiences a decrease in stress shielding. Lastly, throughout this section, the load transfer region (LTR) will be frequently cited. This region is the approximate region where the stem/peg length ends and the load carried through the TKR component is transferred directly onto the surrounding bone.

It was verified visually what direction the tibia deflects during bending. An un-loaded TKR assembly is shown in Figure 41. Take note that in its unloaded state, there is no deflection. However, as can be seen in Figure 42, the tibia bends towards the posterior-medial region, leaving the posterior region with a tendency of being more in a state of compression, while the medial region is more in a state of tension. 


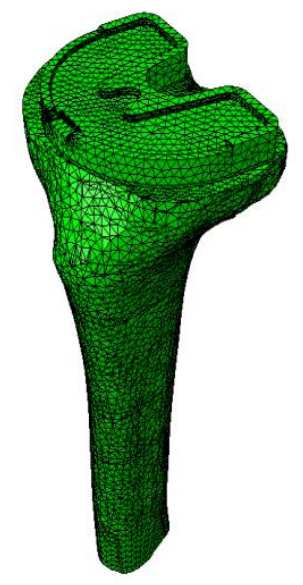

Figure 41- TKR assembly under no load. Note that there is no residual deflection; therefore this figure can be used for comparison to the loaded model to understand bending.
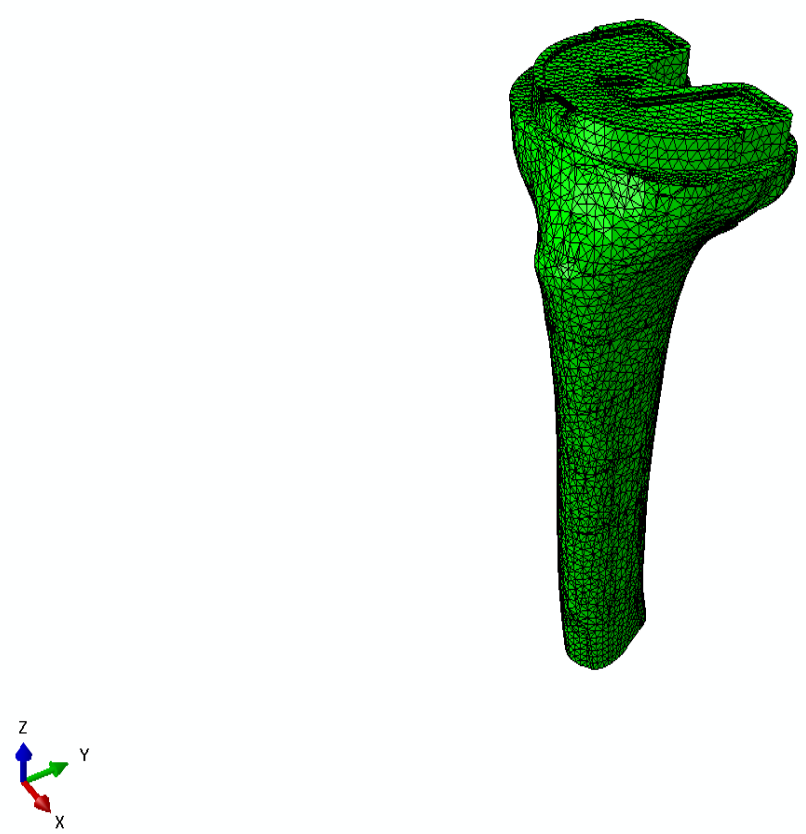

Figure 42 - TKR assembly under load. Note that the tibia bends towards the posterior-medial side. Because of this, the posterior side sees a higher amount of 
compression during bending, while the medial side experiences a higher amount of tension.

In addition, a contour plot of both the medial and posterior regions is shown in Figure 43. As can be concluded from the plot, the medial region would have a growing amount of elements in tension with an increased bending (hotter colored elements, i.e. red). In addition, it can be seen that with increased bending, the posterior side will begin experiencing a greater amount of compression, as can be clearly seen in the last four regions modeled (cooler colored elements, i.e. blue).
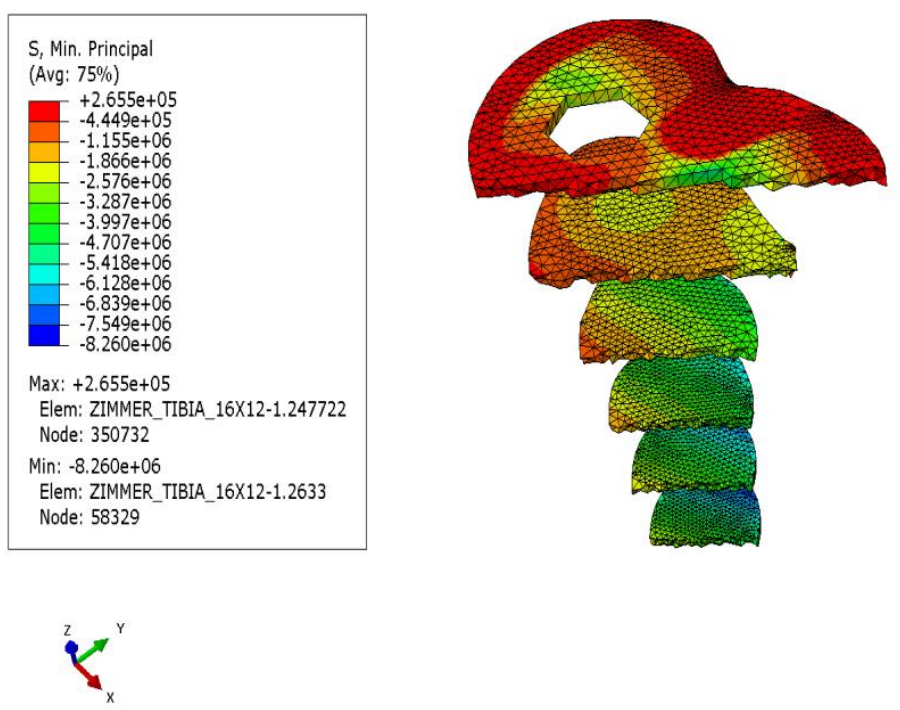

Figure 43 - Medial and posterior sections progressing down the length of the tibia. Note that the posterior side begins to become compression dominated at a depth of $40 \mathrm{~mm}$, while tension will grow in the medial region at this same point. With increased bending, compression forces will increase in the posterior region, while tension forces will grow faster in the medial region.

\subsubsection{Important Trends observed in the Medial Region}

In this section, important conclusions related to the medial region, based on the numerical results that were presented earlier are discussed. Subsequently, the posterior region will be examined and then further conclusions will be drawn in the next chapter. 
One trend which was extremely consistent across all models studied was a net decrease in the amount of stress shielding from a depth of $0 \mathrm{~mm}$ to the LTR. The length of the area being considered changes with longer stem models; for example, the $12 \mathrm{X} 12$ model has a $12 \mathrm{~mm}$ length of a net decrease in stress shielding, while the $12 X 24$ has a $24 \mathrm{~mm}$ length of a net decrease in stress shielding. This could potentially decrease for a number of reasons. A lower amount of bending relative to the intact model could be occurring within this region, driving a lower amount of tension. In addition, compressive forces may be increasing due to the nature of the stress gradient and the peak at the LTR. This increase in compressive forces may be more influential in the system response than the increased amount of bending as you approach the LTR. This trend was evident for all stem type geometry models, as well as peg type geometry models.

Another evident characteristic trend was a net decrease in stress shielding percentage beyond the LTR region within the medial region. It was expected that the stress shielding percentage should decrease after the LTR to the last region of interest $(100 \mathrm{~mm})$. This is due to the fact that relative to the intact tibia, a lower amount of bending should occur, driving the amount of tension experienced within this region downwards. This trend was clearly evident for all stem models, but was not quite as noticeable for $50 \mathrm{~mm}$ length stems. This trend was also obvious for the peg type geometry models, however was not as noticeable for the 16X24 model.

Another trend which was expected was that the longest length stem/peg model would experience the highest amount of stress shielding relative to all other models, over a greater duration of depth of the tibia. In preexisting studies, it has been found that stem length is directly proportional to the amount of stress shielding. It was found that this trend held true for all stem type geometry models and roughly held true for all peg type geometry models. This was an essential trend to confirm, as multiple studies have concluded that stem length is directly proportional to stress shielding. Verification of this conclusion, which has been reported before in the literature, was essential, allowing for a confirmation and the validity of data collected within this study.

The last major trend which needed to be confirmed was that stress shielding is more prominent throughout the length of the tibia in wider/larger diameter stem/peg type models. This finding has not been reported in the literature before - however, it is what could be 
expected considering that stress shielding is so heavily influenced by the amount of material in the stem/peg. Because a greater amount of stem/peg material within the tibia leads to greater stress shielding, it should be expected that larger diameter and thicker models should experience stress shielding throughout the length of the tibia. This expected trend was found to be true for all stem type geometry models, except the $15 \mathrm{X} 50$ when compared to the $12 \mathrm{X} 50$ model. This trend was also found to be true for all peg type geometry models.

\subsubsection{Noticed Trends for the Posterior Region}

Trends in the posterior region were found to be roughly the same as those in the medial region. The first major trend which was also experienced in the medial region was a net decrease in stress shielding percentage as the loading progresses towards the LTR. This conclusion is slightly more challenging to understand, as in the medial region for this trend to hold true, a decreased amount of bending should be experienced in this region relative to the intact tibia. Because of this decrease in bending, both less tension, as well as less compression will be experienced within this region. However, normal stresses may be increasing as progress towards the LTR, perhaps more so than the decrease in compression due to the decrease in bending. Increased amount of normal stresses should drive compression up faster than the amount of decreased compression due to less bending. This trend was observed in all stem type geometry models, except the 12X25 model. In addition, this trend was also observed for all models, except the 16X18 and 16X24 models.

Another trend which was observed in the posterior region was a net increase in stress shielding percentage beyond the LTR region. This trend was found to be the opposite, where a decrease in stress shielding percentage after the LTR was found in the medial region. This inverse type relationship in this trend is as expected however - with a decrease in bending, the posterior region will experience a lower amount of compression. Therefore, driving the stress shielding percentage more negative. Conversely, with a decreased amount of bending, the medial region will experience less tension, thus, driving the stress shielding percentage more positive. This trend was found to be true for all stem type geometry models. This trend was also found to be true for all models except the 16X12 model and all $12 \mathrm{~mm}$ width models. This may be an indication that in the posterior region, there are other factors such as bone geometry which may influence results for the smaller peg type geometry models. 
Another observable trend was that stem length is directly proportional to stress shielding. This trend was found to be true in the medial region and was also roughly found to be true for the posterior region. For the stem type geometry models, this trend was true except for the $15 \mathrm{X} 25$ and $12 \mathrm{X} 25$ model. This trend was found to be observable in all peg type geometry models.

The last observable trend for the posterior region was that the stress shielding is more prominent throughout the length of the tibia for larger/wider models. This trend was also observable for the medial region, which is as expected. Interestingly, this trend was not observable for all posterior regions of the stem type geometry model. The reason for this could be for a number of factors. These factors include the geometry of the posterior region of the tibia and higher compressive forces and lower bending forces throughout certain regions of the bone due to thicker/wider stems. Additional research would be beneficial for understanding what this trend does not hold true for posterior models. In addition, this trend held true for all peg type geometry models considered. 


\section{Chapter 5: Conclusions}

The objective of this study was to reach an understanding of how tibial stem geometry affects stress shielding of the tibia. Within this study, two different types of geometric shaped tibial stems were compared for stress shielding, spanning a wide range of stem/peg sizes. Testing a wide variety of sizes allowed for clear trends to appear in stress shielding as a function of stem size/geometry. The results obtained within this study are significant, as many of the expected trends based on published studies have been confirmed. Furthermore, results within this study allow for further conclusions to be understood, as will be presented throughout this chapter.

\subsection{Summary of Results}

It was found that the peg type geometry model yielded the results which experienced the least amount of stress shielding. Considering the loading conditions of this study, as well as the size/behavior of the tibia utilized in this study, it can be concluded that peg type geometry allows for bending more characteristic of the intact healthy tibia within a knee joint. In addition, it could be due to the load transfer distribution from two pegs rather than one central stem, which may model how the load is distributed more similarly to that of a healthy tibia.

It was also concluded that stress shielding is directly proportional to the amount of material used for the tibial components, which has stronger material properties than the surrounding bone. This refers to stem or peg length, as well as stem or peg diameter/width. It was found that length also has more profound effect on stress shielding, which could be due to the fact that bending is changed significantly within a tibia using a longer stem/peg stem component. It was also noticed that in general, all models had a trend of decreasing stress shielding leading to the LTR. From the LTR to the end of the depth of the tibia, the stress shielding percentage either increased or decreased, depending if one considers the medial or posterior region. It was found that at this point, stress shielding would increase in the posterior region, and decrease in the medial region. This shows the significance of bending, where bending has the ability to induce stress shielding on one region more than the other based upon the 
deflection of the tibia itself. This clearly demonstrates the importance of bending, and how certain regions of the bone at different depths will begin to lose density, due to the fact that loading conditions are not what they need to be for the tibia. Bending can influence which points of the tibia begin to lose density, while other sections may feel painful due to an increase in compression due to bending in that particular region. All positive values of stress shielding infer that the tibia is experiencing more compression in the TKR tibia rather than the intact tibia model. This increase in compression could potentially cause pain for a patient, as a greater amount of stress is being experienced by the knee joint than typically.

From all results outlined, it can be concluded that bending may be the most influential aspect of stress shielding in a tibia with a tibial stem prosthesis. Bending influences compression/tension dominance, a loading condition which is extremely unique to each tibia. Bending was the major influence when observing the numerical results from this study; models which were able to bend more closely to that of the natural healthy tibia responded in a fashion much more characteristic of a natural tibia and displayed the least amount of stress shielding. The peg type geometry models allowed for bending more characteristic of a natural tibia, which is the primary reason why this type of model performed so well under the static loading conditions studied.

It was also found that cement plays a very significant role in stress shielding. When comparing obtained data for the stem type geometry 12X50 model to published data, the general trend was found to be the same. However, the addition of a fully cemented stem caused a dramatic decrease in the load transfer at the LTR. This substantial decrease in compression at the LTR causes the stress shielding at this location to be not as low as it could be without cement. Because of this, another characteristic can be concluded of the knee replacement process. The least amount of cement used during surgery, the better. There is a balance however, as significant decreases in stress shielding may not be beneficial up to a certain point. Having a tibia which experiences an extremely high amount of compressive stress at the LTR may cause significant pain or discomfort for the patient. A material which is similar to bone, along with a decreased amount of cement used would be most optimal. The material with material properties similar to bone would transfer the load in a less dramatic fashion. In addition, with material properties closer to the surrounding bone, flexure will be as close to a natural tibia as possible. In addition, not having cement would ensure 
that this load transfer would be fully experienced by the tibia, allowing for a decrease in stress shielding that is beneficial but not too high.

Overall, under the loading conditions and the conditions established within this study, it can be concluded that an un-cemented, small stem which has material properties closest to the tibia is the ideal type of stem. Perhaps a model stem which was able to mimic bending of a healthy tibia would be the most optimal design for the stem component.

\subsection{Future Work and Recommendations}

While this study yielded conclusive results for static loading conditions, future work should be focused on dynamic loading of the system and how external moments affect stress shielding results for smaller models. While a dynamic load factor of three was used in this study, loading which accounts for twice the static load, it would be interesting to understand how direct moments affect the system. For the conditions of this study, it was found that having the smallest stem/peg model yielded optimal stress shielding results. For dynamic type conditions however, too small of a stem may lead to fatigue and loosening under applied moments. Because of this, it can be understood that stem length is a delicate balance which needs to be further understood. Having an optimal length which allows for adequate protection from bending fatigue, but also a short enough length to allow for more natural bending, could potentially be the most optimal design. Dynamic studies should be performed on the same models in order to understand how stress shielding results change with different loading conditions. In addition, a wider variety of geometries should be tested. It should be stated that there are other types of designs, besides those studied in this thesis, which are quite different geometrically, such as the Zimmer Persona Knee, which incorporates peg type geometry. A wider variety of geometries would allow for a better understanding of how bending is affected. Ideally, the most effective method of forming a stem for a patient would be to measure the displacements within the patient's tibia. With an understanding of how the patient's tibia displaces under various loading conditions, a stem could potentially be 3D printed to allow for natural flexion, specifically designed for the patient.

Another interesting aspect recommended to be further investigated is the effect of material and how influential material properties can be in stress shielding. This could be carried out 
using the peg type geometry model, as this study used titanium properties for the peg models. As previously outlined however, Zimmer produces this model as a cement-less model with material properties much closer to bone by using "trabecular metal." Testing a trabecular metal model and titanium model together would allow for a direct comparison of both how the choice of material affects the results, as well as how the method of cementation affects the performance.

Lastly, a greater number of data points could be taken by examining a higher number of depths. By observing more data, aliasing is minimized, allowing for a more accurate representation of the true trend of stress shielding as a function of depth. Overall however, this study was successful in drawing conclusions which may help lead to further development of optimal tibial components for a TKR. Further development should focus on mimicking the natural bending of the tibia, without sacrificing structural integrity and resistance to bending fatigue. 


\section{WORKS CITED}

1. "Knee Replacement Statistics Infographic." Knee Replacement Statistics. N.p., n.d. Web. 28 Oct. 2014.<http://www.healthline.com/health/total-kneereplacement-surgery/s tatistics-infographic>

2. "2012 AAOS Annual Meeting." 2012 AAOS Annual Meeting. American Academy of Orthopaedic Surgeons, 10 Feb. 2012. Web. 30 Jan. 2015.

3. HCUP FACTS AND FIGURES statistics on Hospital-Based Care in the United States, 2009.

http://www.hcupus.ahrq.gov/reports/factsandfigures/2009/pdfs/FF_report_2009.p df

4. Labek, G., M. Thaler, W. Janda, M. Agreiter, and B. Stockl. "Revision Rates after Total Joint Replacement." The Bone and Joint Journal 93.3 (2011): n. pag. Web.

5. Shi, Junfen. "Finite Element Analysis of Total Knee Replacement considering Gait Cycle Load and Malalignment." Thesis. University of Wolverhampton, n.d. (n.d.): n. pag. Finite Element Analysis of Total Knee Replacement considering Gait Cycle Load and Malalignment. Research Gate. Web.

6. Anterior View of the Knee. Digital image. N.p., n.d. Web. <http:/f.tqn.com/y/arthritis/1/S/U/M/188058334-crop.jpg>.

7. Hoppenfeld, Stanley. "Physical Examination of the Spine and Extremities Hardcover - June 5, 1976." Physical Examination of the Spine and Extremities: 9780838578537: Medicine \& Health Science Books @ Amazon.com. Prentice Hall, n.d. Web. <http://www.amazon.com/Physical-Examination-ExtremitiesStanley-Hoppenfeld/dp/0838578535>.

8. Unicompartmental Knee Replacement-OrthoInfo - AAOS. Digital image. Unicompartmental Knee Replacement-OrthoInfo - AAOS. N.p., n.d. Web. http://orthoinfo.aaos.org/topic.cfm?topic=A00585

9. Greengard, Samuel. "Step-by-Step Explanation of Knee Replacement Surgery." Step-by-Step Explanation of Knee Replacement Surgery. Heatlthline.com, 30 Apr. 2012. Web. <http//www.healthline.com/health-slideshow/total-kneereplacement-surgery-step-by-step>. 
10. Frost, M. H. "Wolff's Law and Bone's Structural Adaptations to Mechanical Usage: An Overview for Clinicians." National Center for Biotechnology Information. U.S. National Library of Medicine, 1994. Web. 04 Dec.

2014.<http://www.ncbi.nlm.nih.gov/pubmed/8060014>

11. Digital image. Kneereplacement.com. N.p., n.d. Web.

$<$ https://www.kneereplacement.com/binary/org/DEPUY/images/joint/knee/prod u ct/Sigma_LargeImage.jpg>.

12. Leisinger, S., S. Hazebrouck and D. Deffenbaugh. "A New Approach to Micromotion Characterization of Modular Tibia Implants." 54th Annual Meeting of the Orthopaedic Research Society, Poster No. 1952, March 2-5, 2008, San Francisco, CA

13. Dalury D, et al. "Midterm Results from the P.F.C. Sigma Total Knee Arthroplasty System." The Journal of Arthroplasty. Feb 2008:175-181.

14. Robertson, O., Knutson, K., Lewold, S., Lidgren, L. The Swedish Knee Arthroplasty Register, Outcome with Special Emphasis on1988-1997.Department of Orthopedics, University Hospital

15. Zimmer Persona Knee. Digital image. Zimmer.com. N.p., n.d. Web. <http://www.zimmer.com/medical-profess ionals/products/knee/persona-knee.html>.

16. Rawlinson JL, Peters LE, Campbell DA, et al. Cancellous bone strains indicate efficacy of stem augments in constrained condylar knees. Clin Orthop Relat Res 2005;440:107-116.

17. Stern SH, Wills RD, Gilbert JL. The effect of tibial stem design on component micromotion in knee arthroplasty. Clin Orthop Relat Res 1997;345:44-52

18. Completo A, Fonseca F, Simões JA. Strain shielding in proximal tibia of stemmed knee prosthesis: experimental study. J Biomech 2008;41:560-566.

19. Abraham R, Malkani AL, Lewis J, Beck D. An anatomical study of tibial metaphyseal/diaphyseal mismatch during revision total knee arthroplasty. J Arthroplasty 2007;22:241-244.

20. Au AG, James Raso V, Liggins AB, Amirfazli A. Contribution of loading conditions and material properties to stress shielding near the tibial component of total knee replacements. J Biomech 2007;40:1410-1416.

21. Murase K, Crowninshield RD, Pederson DR, Chang TS. An analysis of tibial component design in total knee arthroplasty. J Biomech 1982;16:13-22. 
22. Reilly D, Walker PS, Ben-Dov M, Ewald FC. Effects of tibial components on load transfer in the upper tibia. Clin Orthop Relat Res 1982;165:273-282.

23. Completo A, Talaia P, Fonseca F, Simões JA. Relationship of design features of stemmed tibial knee prosthesis with stress shielding and end-of-stem pain. Materials \& Design 2009;30:1391-1397.

24. McLean AJ, Howie CR. The effect of modular stems and cement fixation techniques on the initial stability of the tibial prosthesis and the strain distribution within the proximal tibia in primary and revision total knee arthroplasty. $\mathrm{PhD}$ Thesis: University of Edinburgh, Edinburgh: 2007.

25. Lonner JH, Klotz M, Levitz C, Lotke PA. Changes in bone density after cemented total knee arthroplasty: influence of stem design. J Arthroplasty 2001;16:107-111.

26. Agarwal, Yash. "Investigating the Effect of Tibial Augmentation on the Stability of Total Knee Replacements - Interim Report." Thesis. University of Surrey, 2009. Investigating the Effect of Tibial Augmentation on the Stability of Total Knee Replacements. Web.

<http://www.academia.edu/1605308/Investigating_the_effect_of_tibial_augmentatio n_on_the_stability_of_total_knee_replacements_-_Interim_Report>.

27. Au AG, Liggins AB, Raso VJ, Amirfazli A. A parametric analysis of fixation post shape in tibial knee prostheses. Med Eng Phys 2005;27:123-134.

28. "Human Tibia and Fibula." U.S. Department of Health and Human Services. Human Tibia and Fibula, 29 May 2014. Web. <http://3dprint.nih.gov/disc over/3dpx$000169>.1$

29. Kemper, Andrew, Craig McNally, Eric Kennedy, Sarah Manoogian, and Stefan DUMa. THE MATERIAL PROPERTIES OF HUMAN TIBIA CORTICAL BONE IN TENSION AND COMPRESSION: IM PLACATIONS FOR THE TIBIA INDEX. N.p., n.d. Web. <http://www-nrd.nhtsa.dot.gov/pdf/ESV/es v20/07-0470-O.pdf>.

30. Ioannis Terzidis, Trifon Totlis, Efthymia Papathanasiou, Aristotelis Sideridis, Konstantinos Vlasis, and Konstantinos Natsis, "Gender and Side-to-Side Differences of Femoral Condyles Morphology: Osteometric Data from 360 Caucasian Dried Femori,” Anatomy Research International, vol. 2012, Article ID 679658, 6 pages, 2012. doi:10.1155/2012/679658

31. Zimmer. Trabecular Metal Technology. N.p.: Zimmer, 2012. Zimmer Dental. Web. 
32. Nyman, Jeffry S., Scott J. Hazelwood, Juan J. Rodrigo, R. B. Martin, and Oscar C. Yeh. "Long Stemmed Total Knee Arthroplasty with Interlocking Screws: A Computational Bone Adaptation Study." National Center for Biotechnology Information. U.S. National Library of Medicine, 22 Jan. 2004. Web. 04 Dec. 2014.http://www.ncbi.nlm.nih.gov/pubmed/14656659 
Appendix A: Additional Plots for Diameter/Width Comparis on

Stress Shielding as a Function of Tibial Depth in the Posterior Region for Stem Type Geometry with a Length of $75 \mathrm{~mm}$

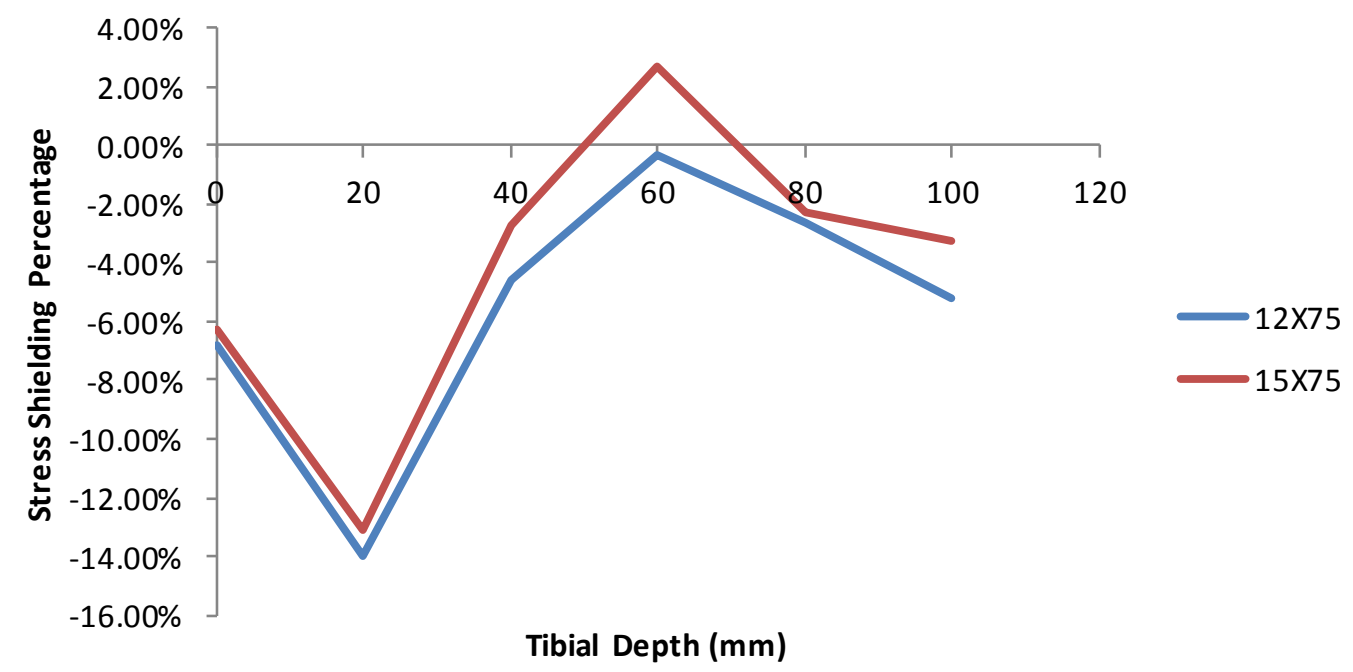

Stress Shielding as a Function of Tibial Depth in the Medial Region for Stem Type Geometry with a Length of 75 mm

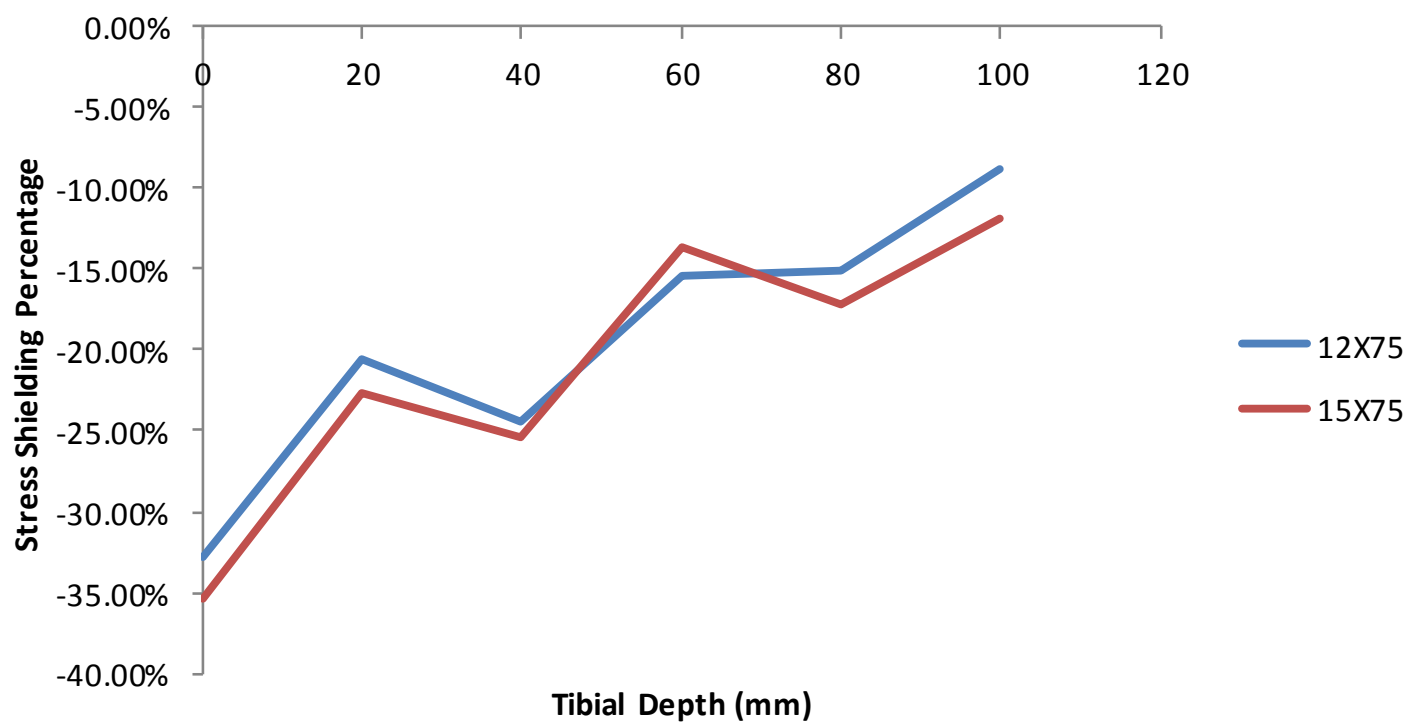




\section{Stress Shielding as a Function of Tibial Depth in the Medial Region}

for Stem Type Geometry with a Length of $50 \mathrm{~mm}$

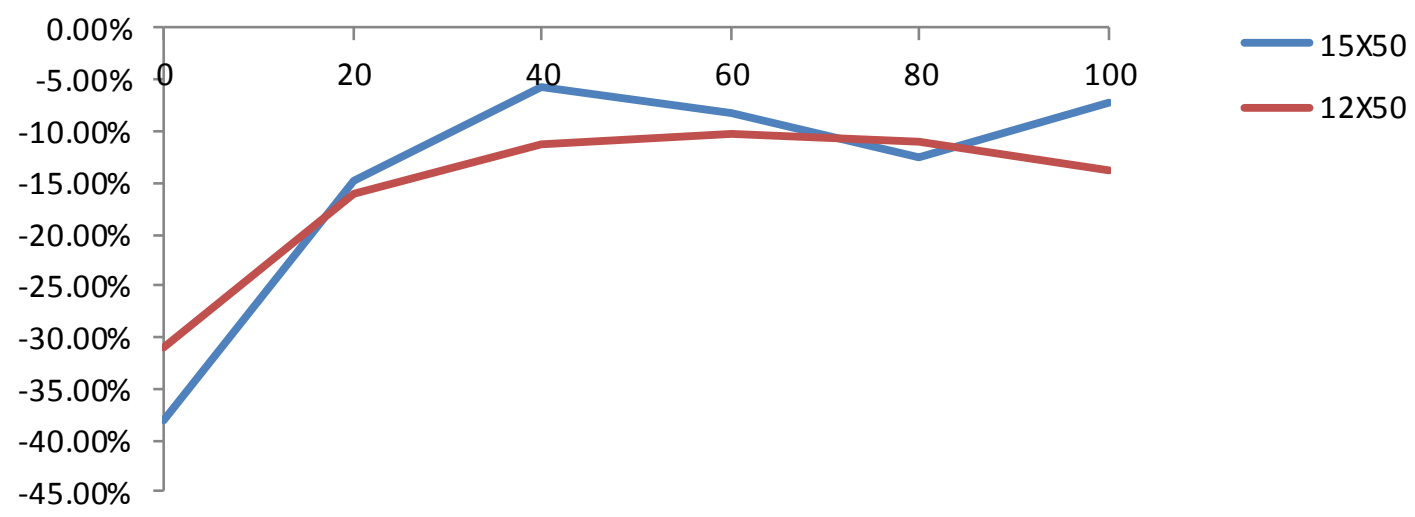

Stress Shielding as a Function of Tibial Depth in the Posterior

Region for Stem Type Geometry with a Length of $50 \mathrm{~mm}$

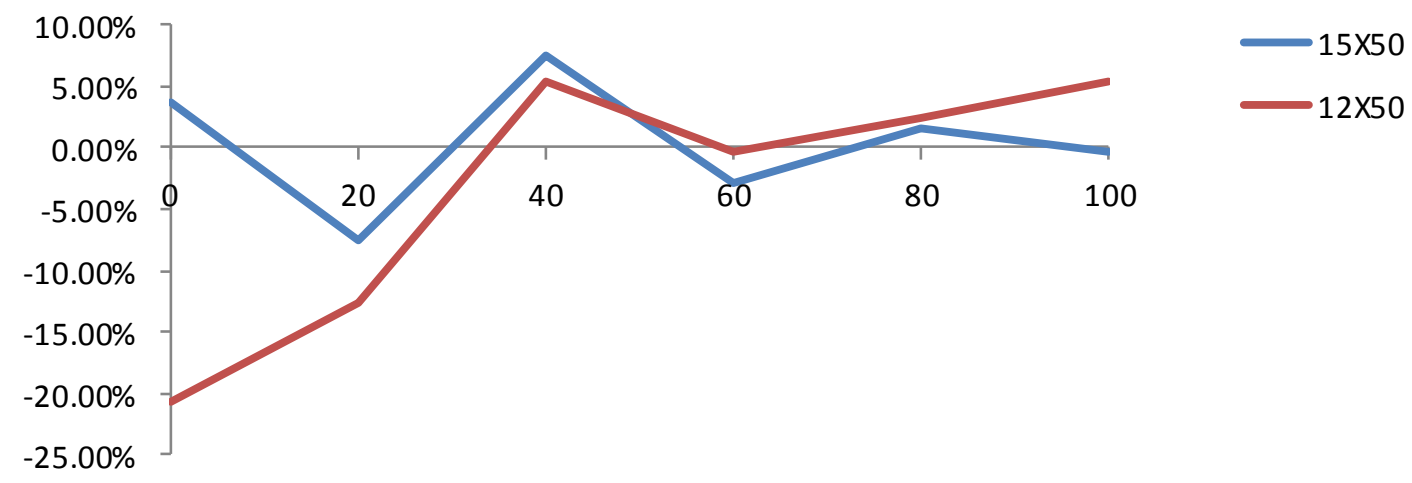


Stress Shielding as a Function of Tibial Depth in the Medial Region for Stem Type Geometry with a Length of $25 \mathrm{~mm}$

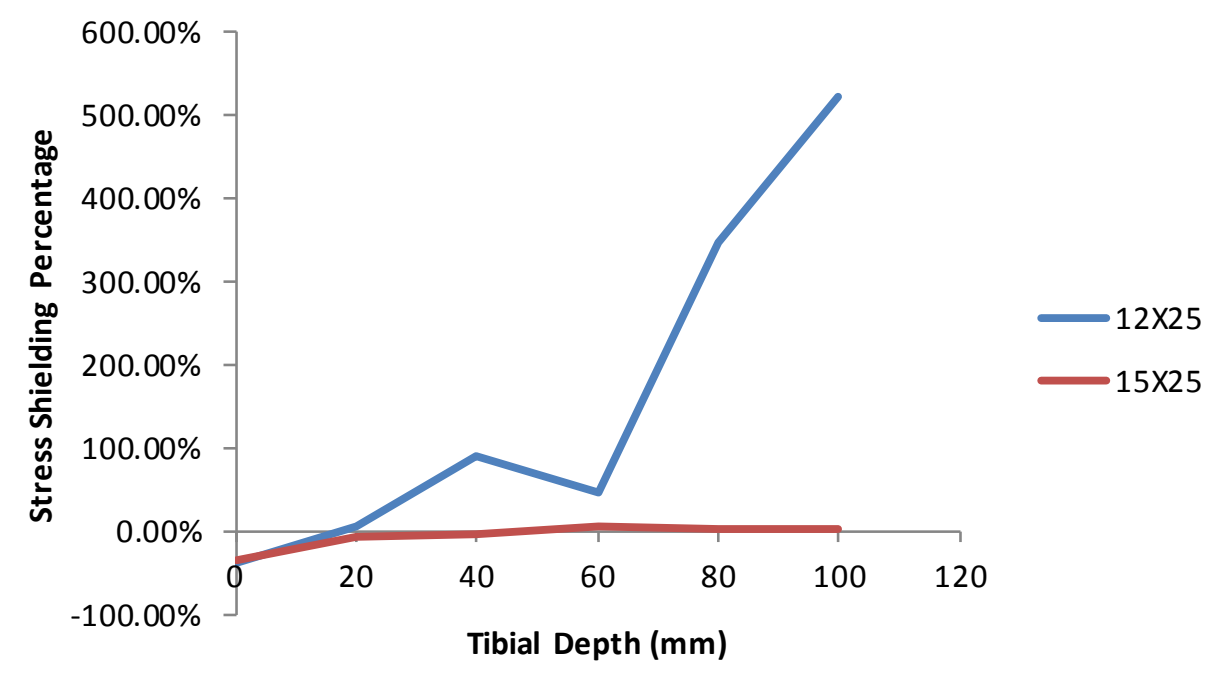

Stress Shielding as a Function of Tibial Depth in the Posterior Region for Stem Type Geometry with a Length of $25 \mathrm{~mm}$

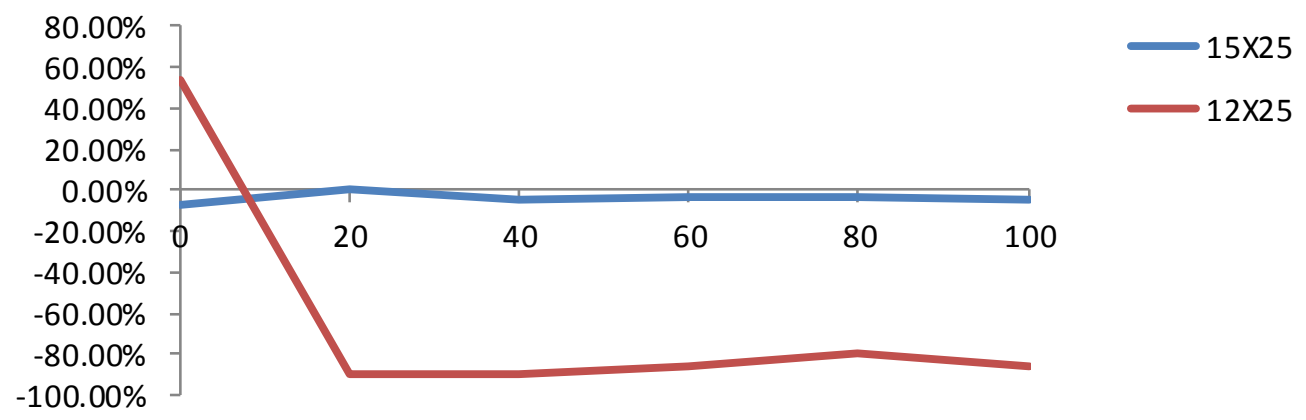


Stress Shielding Percentage as a Function of Tibial Depth for the Medial Region for Peg Type Geometry with $12 \mathrm{~mm}$ Long Pegs

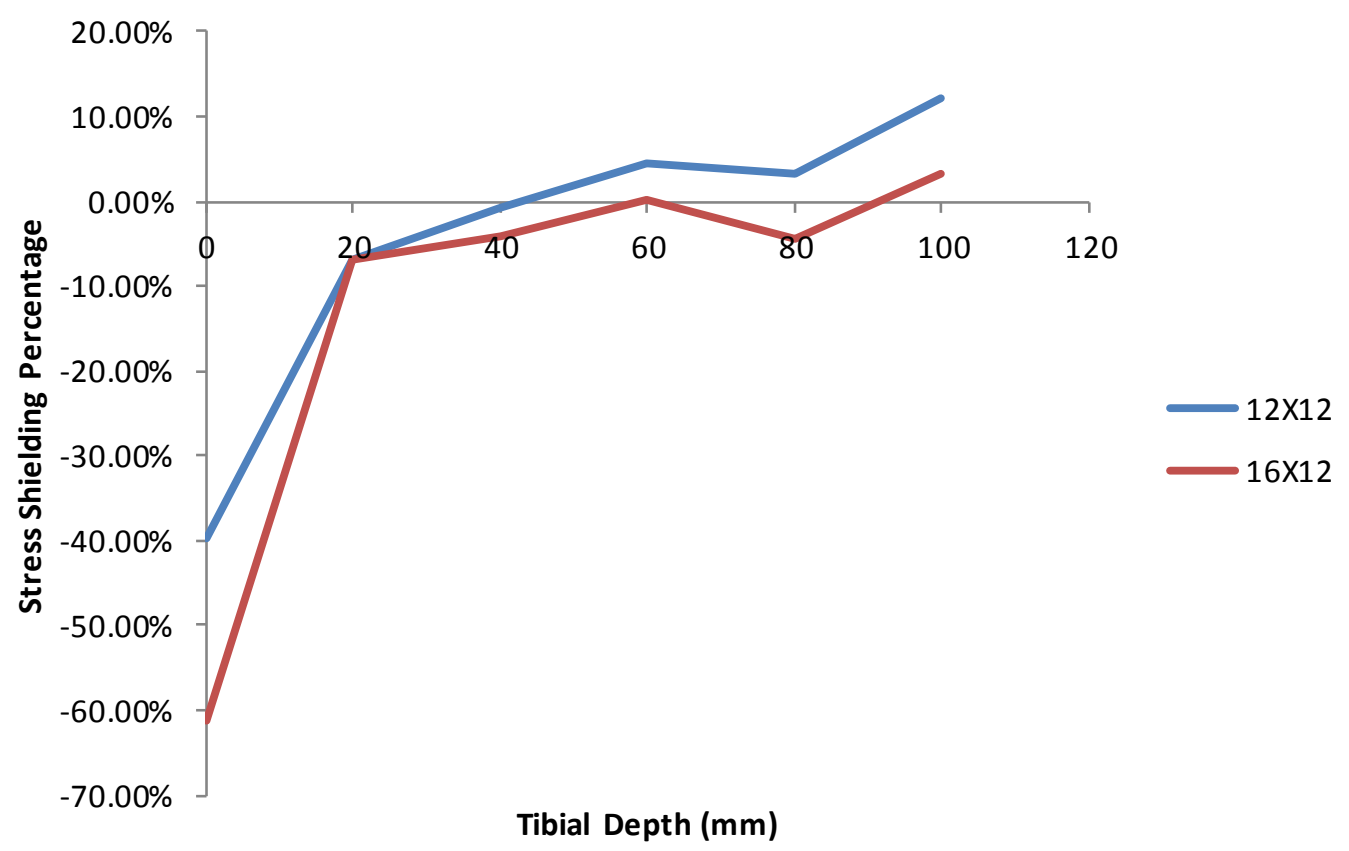

Stress Shielding Percentage as a Function of Tibial Depth for the Posterior Region for Peg Type Geometry with 12 mm Long Pegs

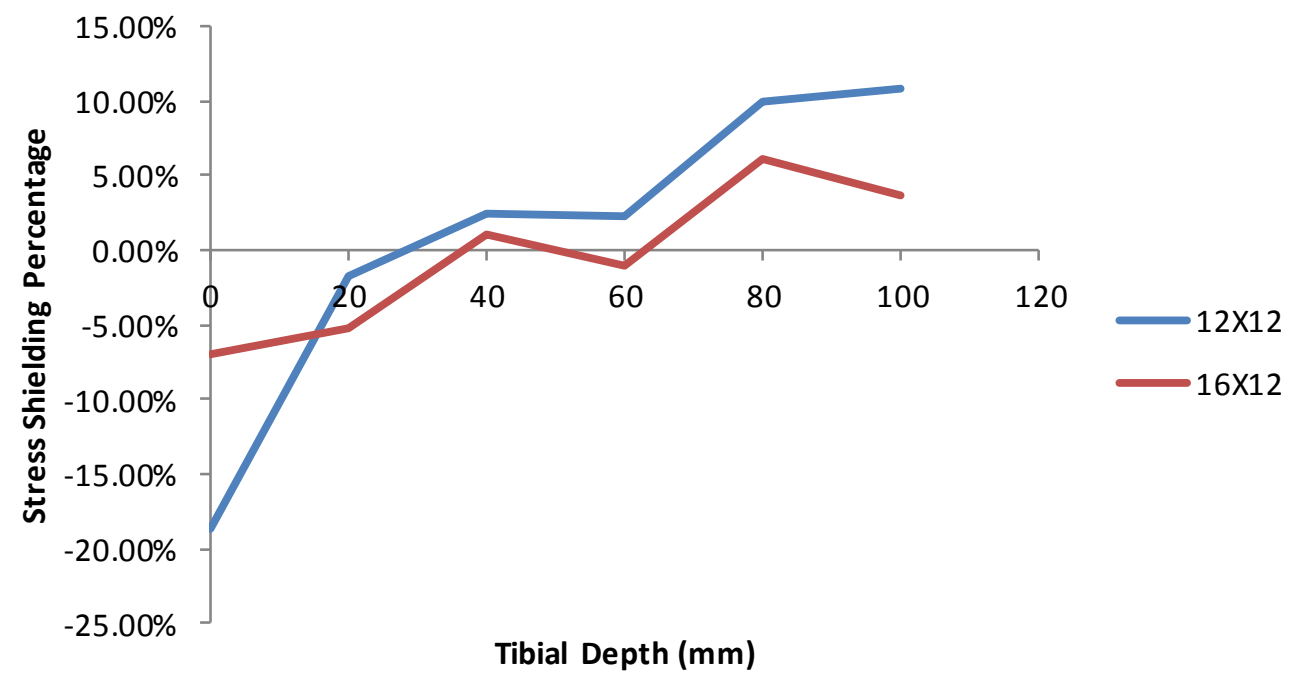


Stress Shielding Percentage as a Function of Tibial Depth for the Medial Region for Peg Type Geometry with $18 \mathrm{~mm}$ Long Pegs

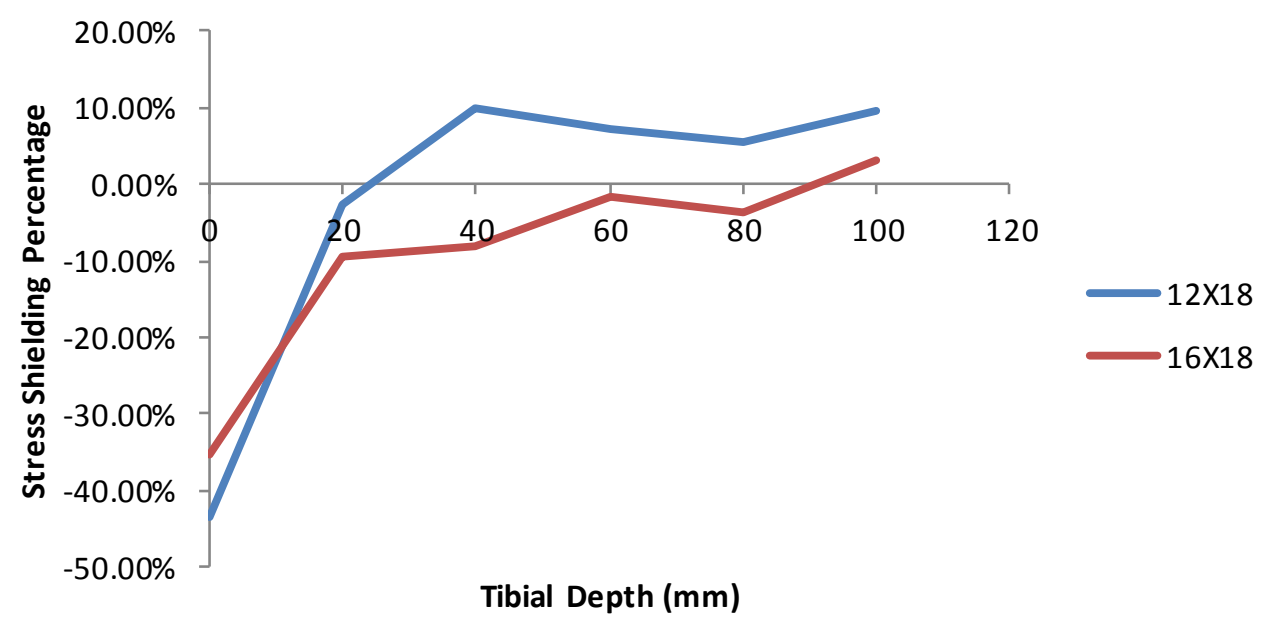

Stress Shielding Percentage as a Function of Tibial Depth for the Posterior Region for Peg Type Geometry with 18 mm Long Pegs

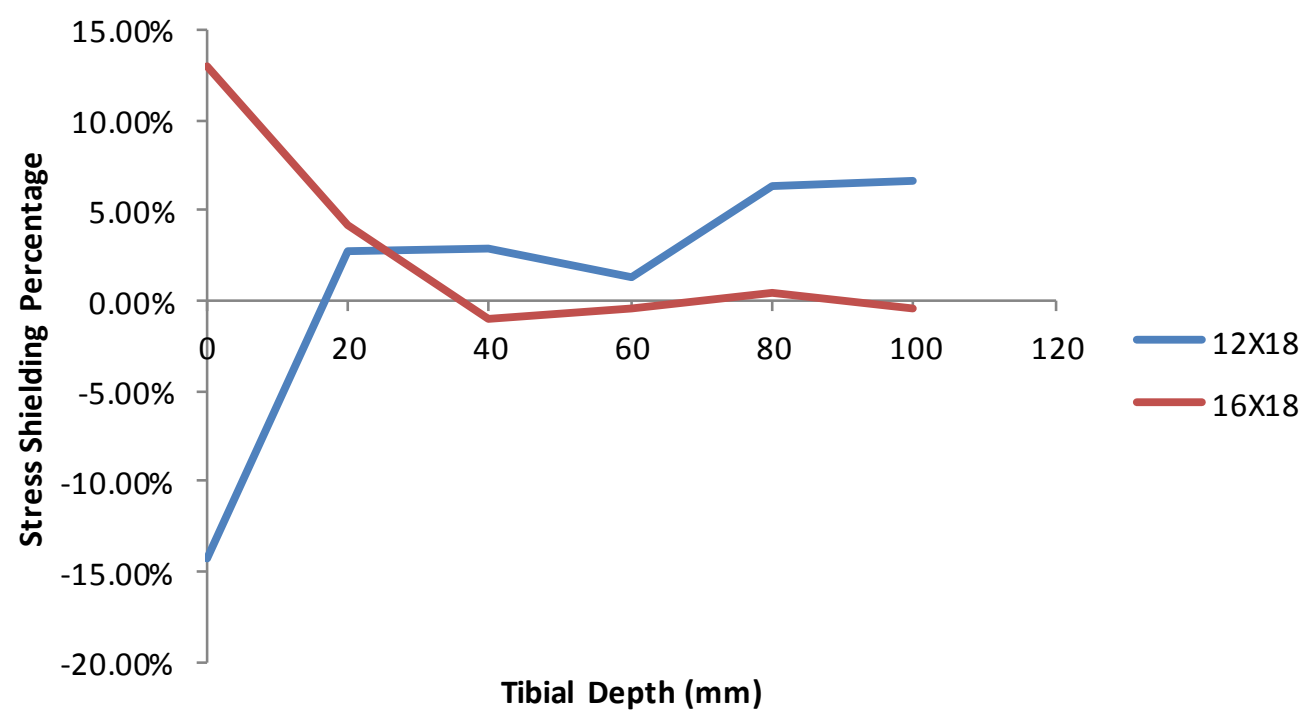


Stress Shielding Percentage as a Function of Tibial Depth for the Medial Region for Peg Type Geometry with 24 mm Long Pegs

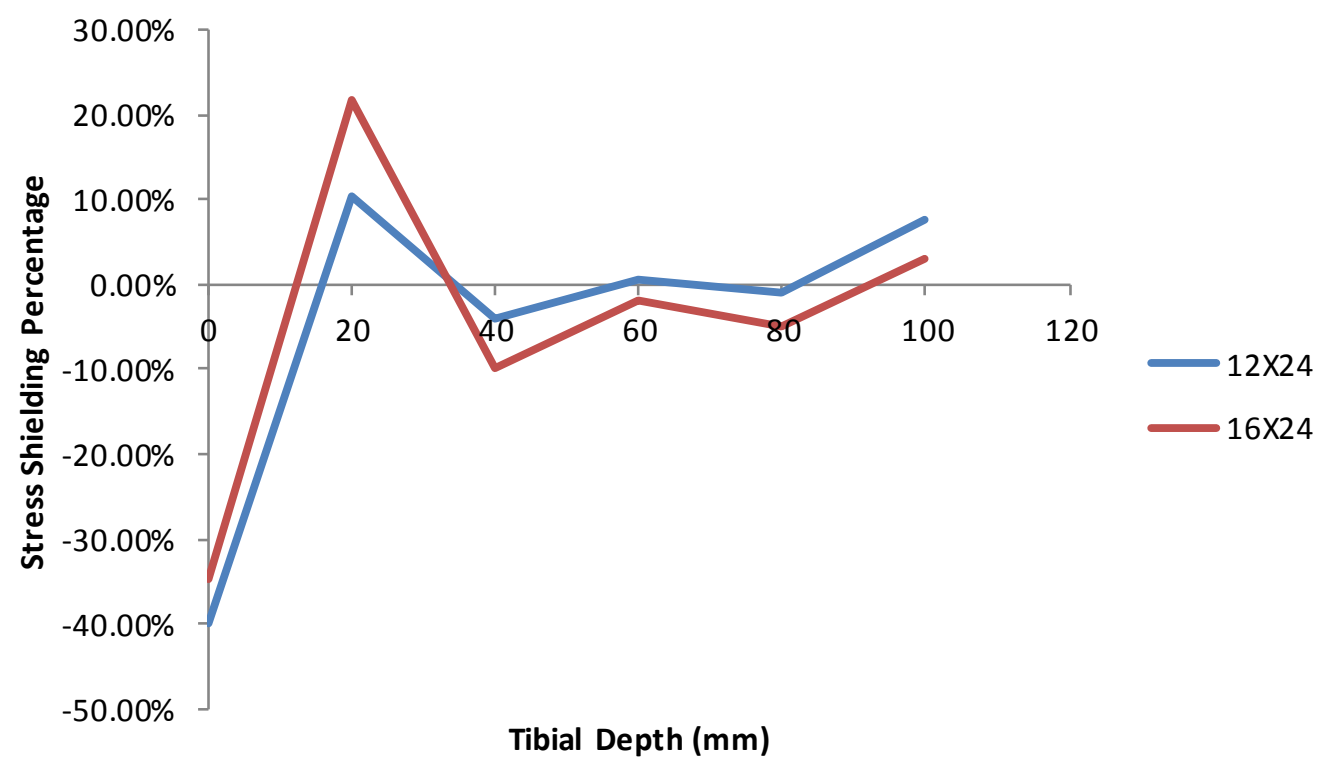

Stress Shielding Percentage as a Function of Tibial Depth for the Posterior Region Peg Type Geometry with 24 mm Long Pegs

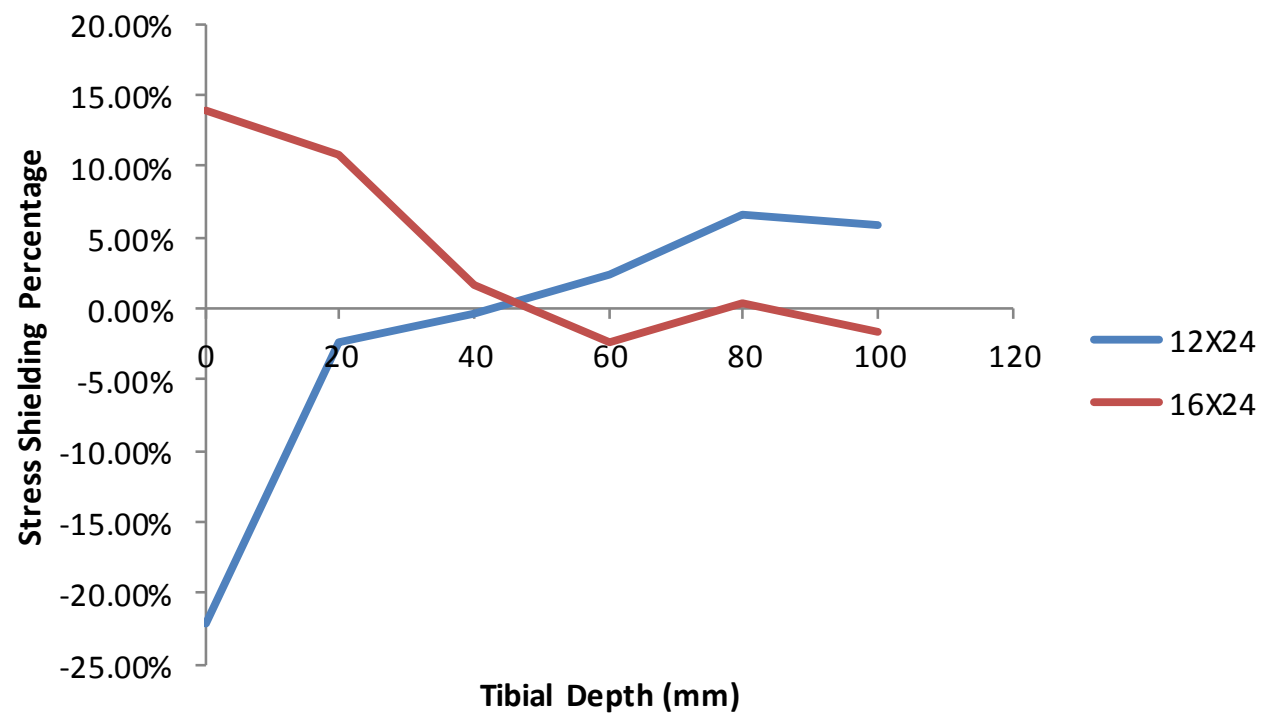

